\title{
Manual para el Diseño de Investigación Operativa en Planificación Familiar
}

\author{
Andrew A. Fisher \\ Population Council \\ John E. Laing \\ John E. Stoeckel \\ Population Council \\ John Townsend \\ Population Council
}

Follow this and additional works at: https://knowledgecommons.popcouncil.org/departments_sbsr-rh

Part of the Demography, Population, and Ecology Commons, Family, Life Course, and Society

Commons, Health Services Research Commons, International Public Health Commons, and the Medicine and Health Commons

How does access to this work benefit you? Let us know!

\section{Recommended Citation}

Fisher, Andrew A., John Lang, John E. Stoeckel, and John Townsend. 1991. "Manual para el Diseño de Investigación Operativa en Planificación Familiar." New York: Population Council. 



\section{Manual para el Diseño de Investigación Operativa en Planificación Familiar}

Segunda Edición

Andrew A. Fisher John E. Laing John E. Stoeckel John W. Townsend

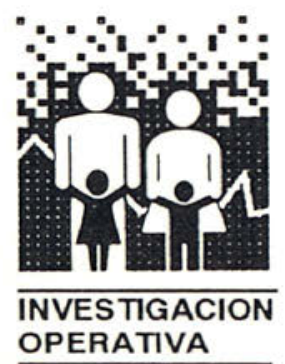

The Population Council 
Oficina Regional para

América Latina y el Caribe

Alejandro Dumas 50

11560 México, D. F.
One Dag Hammarskjold Plaza

New York, New York 10017

U.S.A.

Biblioteca del Congreso

Catalogado en Datos de Publicación

Manual para el Diseño de Investigación Operativa en Planificación Familiar / Andrew A. Fisher ... [et al.] Segunda Edición Revisada del Manual para el Diseño de Investigaciones Operacionales en Planificación Familiar / Andrew Fisher, John Laing, John Stoeckel.

Incluye referencias bibliográficas.

ISBN 0-87834-061-0

1. Planificación Familiar-Investigación-Manuales, etc.

2. Investigación operativa-Manuales, etc. I. Fisher, Andrew, 1941-. II. Fisher, Andrew, 1941-Handbook for family planning operations research design.

HQ763.5.H36 1991

9363.9'6'072073-dc20

91-6284

CIP

Cualquier parte de este Manual puede ser copiada o adaptada para satisfacer las necesidades locales, sin permiso de los autores ni del Population Council, siempre y cuando las partes copiadas se distribuyan gratuitamente o al costo (sin fines de lucro). Cualquier reproducción comercial requiere autorización previa del Population Council. Los autores agradecerán una copia de cualquier material en el que se haya usado el texto del Manual.

Andrew A. Fisher, Sc.D. Senior Associate y Director del Proyecto de Investigación Operativa y Cooperación Técnica de Africa (Africa OR/TA Project)

The Population Council, Nairobi, Kenia.

John E. Laing, Ph.D. Consultor, Austin,Texas. Anteriormente fue Senior Associate del Population Council en el Sur y Este de Asia.

John E. Stoeckel, Ph.D. Senior Associate, The Population Council, Bangkok, Tailandia.

John W. Townsend, Ph.D. Senior Associate y Representante Regional para América Latina y el Caribe, The Population Council, México, D. F., México.

Primera Edición en Inglés 1983

Primera Edición en Español 1985

Segunda Edición en Español 1991

Diseño gráfico: Fare Diseño Industrial y Gráfico S.A. de C.V.

Impreso en México 


\section{Contenido}

Prefacio a la segunda edición IX

Agradecimientos $\mathbf{X}$

\section{Introducción}

A ¿Qué es investigación operativa? 1

B El enfoque y los objetivos de la investigación operativa 1

C Tipos de estudios de investigación operativa 2

1 Estudios de exploración/diagnóstico

2 Estudios de intervenciones de campo

3 Estudios de evaluación

D Los métodos y diseños de los estudios de investigación operativa Temas ilustrativos para estudios de investigación operativa 3

\section{Identificación, definición y justificación de un problema de investigación}

A Identificación de un problema susceptible de investigación 5

1 Ejemplo de problema no susceptible de ser investigado

2 Ejemplo de problema susceptible de ser investigado

3 Ejemplo de problema susceptible de ser investigado

4 Ejemplo de problema susceptible de ser investigado

B Definición de un problema de investigación 8

1 Incidencia y prevalencia

2 Areas geográficas a fectadas

3 Características de grupos de la población

4 Causas probables del problema

5 Soluciones posibles

6 Preguntas sin respuesta

1 Ejemplo de identificación y definición de un problema de investigación: Asia.

2 Comentarios sobre el ejemplo

3 Ejemplo de identificación y definición de un problema de investigación: Africa.

4 Comentarios sobre el ejemplo

QUE HACER: Identificación y definición del problema 


\title{
C Justificación de la investigación 14
}

1 Ejemplo de justificación de un proyecto de investigación: Asia

2 Comentarios sobre el ejemplo

3 Ejemplo de justificación de un proyecto de investigación: Africa

4 Comentarios sobre el ejemplo

QUE HACER: Justificación de un proyecto de investigación $\quad 16$

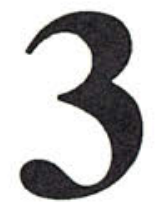

\section{Selección de estrategias para solucionar el problema}
A Usar el esquema de calidad de atención 17
B Ejemplos de estrategias para prueba $\mathbf{1 7}$
C Guías para la selección de una estrategia adecuada 18
1 Ejemplo de una estrategia para solucionar un problema: América Latina
2 Comentarios sobre el ejemplo

QUE HACER: Selección de una estrategia 20

\section{Objetivos e hipótesis}

\author{
A Objetivos últimos 22 \\ 1 Ejemplos de objetivos últimos \\ B Objetivos inmediatos 23 \\ 1 Ejemplos de objetivos inmediatos \\ 2 Comentarios sobre los ejemplos
}

\section{Hipótesis 24 \\ 1 Ejemplos de hipótesis \\ 2 Comentarios sobre los ejemplos}

QUE HACER: Redacción de objetivos últimos, objetivos inmediatos e hipótesis $\mathbf{2 7}$ 


\title{
Descripción de la intervención
}

A ¿Quién será responsable de llevar a cabo la intervención?

B ¿En dónde se llevarán a cabo las actividades? 29

C ¿Con qué actividades se iniciará la intervención?

1 Ejemplo de descripción de una intervención: Africa

2 Lugares de la intervención

3 Actividades del estudio

a Puestos fijos de servicio

b Servicios móviles

4 Reclutamiento y capacitación del personal de campo

QUE HACER: Descripción de la intervención 32

\section{Definiciones operacionales}

A Definiciones operacionales de las variables 33

1 Ejemplos de definiciones operacionales de las variables

B Definiciones operacionales de los términos 35

1 Ejemplos de definiciones operacionales de los términos

QUE HACER: Redacción de las definiciones operacionales

\section{Diseño del estudio}

\author{
A Confiabilidad y validez $\mathbf{3 8}$ \\ B Fuentes de error 38 \\ 1 Efectos coyunturales \\ 2 Efectos de selección \\ 3 Efectos de la observación repetitiva \\ 4 Efectos de los instrumentos de evaluación \\ 5 Efectos de maduración \\ 6 Efectos de desaparición o pérdidas en la muestra
}


C Tipos de diseños de estudio 41

1 Diseños no experimentales

a Diseño post-evaluatorio

b Diseño pre y post-evaluatorio

c Comparación estática entre grupos

2 Diseños experimentales 43

a Pre-evaluatorio y post-evaluatorio con un grupo de control

b Post-evaluatorio con grupo de control

3 Diseños cuasi-experimentales $\mathbf{4 4}$

a Series de tiempo

b Grupo de control no equivalente

c Muestras independientes para la pre-evaluación y post-evaluación

D Selección de un diseño de investigación 48

1 Aspectos éticos

2 Aspectos prácticos y administrativos

3 Aspectos técnicos

E Guías para seleccionar un "buen" diseño de investigación 49

F El principio de las tres múltiples 49

QUE HACER: Diseño de un estudio $\mathbf{5 0}$

\section{Muestreo}

A Selección de área y población $\mathbf{5 2}$

B Métodos de muestreo $\mathbf{5 2}$

1 Muestreo probabilístico $\mathbf{5 3}$

a Muestreo aleatorio simple

b Muestreo sistemático

c Muestreo estratificado

d Muestreo de conglomerados

e Muestreo multi-etápico

f Selección con probabilidades proporcionales al tamaño (PPT)

2 Muestreo no probabilístico $\mathbf{5 5}$

C Tamaño de la muestra 56

QUE HACER: Muestreo $\mathbf{6 0}$

\section{Recolección de datos}


1 Entrevistas estructuradas

2 Estadísticas de servicio

3 Entrevista indirecta

4 Fuentes secundarias de datos

B Datos cualitativos 65

1 La entrevista no estructurada

2 Discusiones con grupos focales

3 Observación directa

4 Análisis de contenido

QUE HACER: Recolección de datos

67

C Control de calidad de los datos $\mathbf{6 8}$

QUE HACER: Control de calidad de los datos

68

D Confidencialidad de la información 69

QUE HACER: Confidencialidad de la información

69

\section{Tabulación y análisis de datos}

A Tabulación, codificación y verificación de datos 70

QUE HACER: Codificación y verificación 71

B Plan para el análisis de datos $\mathbf{7 2}$

1 Características de los datos $\mathbf{7 2}$

a Tendencia central

b Varianza de los datos

c Diferencias entre datos

d Relaciones entre datos

2 Procedimientos de análisis $\mathbf{7 3}$

a Transformación de variables

b Análisis univariado

c Análisis de series de tiempo

d Comparaciones

e Análisis bivariado

f Análisis multivariado

g Análisis de costo-efectividad

h Análisis de uso-efectividad

i Análisis de fecundidad

C Prototipos de tablas $\mathbf{8 3}$

QUE HACER: Plan de análisis de los datos 


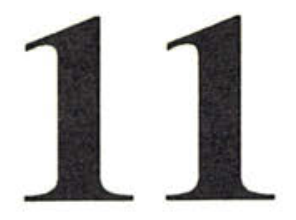

Difusión de los resultados de la investigación
A Estrategias de difusión $\quad \mathbf{8 5}$
B Elaboración de informes $\mathbf{8 5}$

QUE HACER: Informe de los resultados de la investigación

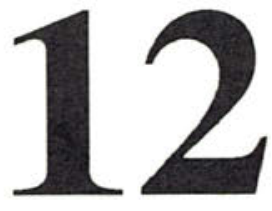

\section{Utilización de los resultados de la investigación}

QUE HACER: Utilización de los resultados

88

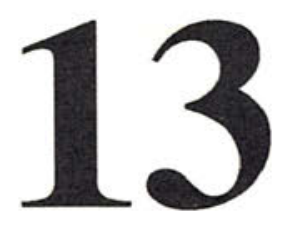

\section{Limitaciones del estudio}
A Limitaciones del diseño y del análisis $\mathbf{8 9}$
B Aspectos particulares de la situación $\mathbf{8 9}$
QUE HACER: Limitaciones del estudio
89

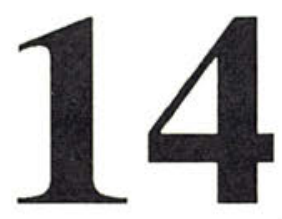

\section{Recursos e infraestructura}
A Recursos $\mathbf{9 0}$
B Presupuesto $\mathbf{9 0}$

QUE HACER: Recursos e infraestructura

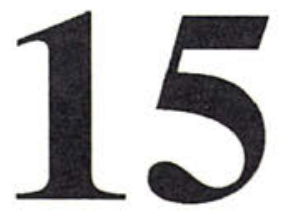

Apéndices 92

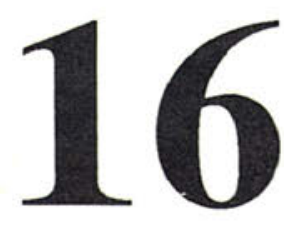

Portada y Abstracto 


\section{Prefacio a la Segunda Edición}

$\mathbf{E}$

ste Manual fue publicado por primera vez en 1983 por el Population Council con

base en las experiencias de los autores en investigaciones operativas en Asia. Originalmente escrito en inglés, posteriormente el Manual fue traducido al francés, español, tailandés, indonesio, árabe y chino, por lo que ha sido ampliamente difundido y utilizado en Asia, América Latina y Africa.

En esta segunda edición se ha mantenido el mismo formato básico del Manual, pero se han revisado y aumentado algunas secciones. Se han añadido ejemplos de América Latina y Africa, donde se ha considerado apropiado. En la Introducción se hace una revisión completa y actualizada del desarrollo de la investigación operativa en salud y planificación familiar. Se han agregado nuevos capítulos, como por ejemplo, sobre la selección de la intervención a ser probada en el estudio de investigación operativa y sobre la descripción de los principales elementos de la intervención estudiada. Se ha ampliado el capítulo sobre difusión y se ha agregado uno nuevo sobre la utilización de los resultados.

El Manual supone cierta familiaridad del lector con los términos y conceptos del diseño de la investigación y las estadísticas, así como cierta experiencia en la ejecución de estudios de campo. El Manual tiene varios objetivos. El primero y más importante, está orientado a ayudar a los investigadores en salud y planificación familiar a diseñar y elaborar una propuesta detallada de investigación operativa. Asimismo, el Manual ha sido utilizado como guía en talleres de capacitación para desarrollar propuestas de investigación bien escritas y detalladas. El Manual tiene también el objetivo de ayudar a los administradores y gerentes de programas a entender mejor el proceso de la investigación operativa y cómo usar sus resultados para mejorar los servicios. Por último, aunque éste no es un Manual sobre métodos de investigación, se revisan los conceptos básicos y los métodos esenciales para llevar a cabo estudios de investigación de campo. 


\section{Agradecimientos}

$\mathbf{L}$

primera versión del Manual fue escrita originalmente como material de capacitación relacionado con el proyecto de Investigación Operativa en Planificación Familiar en Asia, bajo contrato con la Oficina de Población de la Agencia para el Desarrollo Internacional (USAID) Núm. DPE-0632-00-1029-00. Esta segunda edición ha sido revisada bajo los siguientes contratos con la Oficina de Población de USAID: Estrategias para Mejorar los Servicios de Planificación Familiar, Proyecto de Investigación Operativa y Cooperación Técnica en Africa (Núm. DPE-3030-Z-00-8065-00); y Proyecto de Investigación Operativa y Cooperación Técnica en Planificación Familiar en América Latina y el Caribe, INOPAL II, (Núm. DPE-3030-Z-00-9010-00).

Los autores agradecen especialmente los comentarios constructivos de los participantes a los talleres de capacitación y a otros usuarios del Manual en Asia, Africa y América Latina. Agradecen también las aportaciones, apoyo y motivación recibidos de sus colegas en la USAID, agencias colaboradoras, la Universidad de Columbia, la Universidad de Michigan, la Universidad de Johns Hopkins, la Universidad de Tulane y la Universidad de Hawaii. Hasta donde ha sido posible, se han tratado de incorporar estas aportaciones, sin alterar el formato original. Por último, agradecen la revisión crítica y las útiles sugerencias de sus colaboradores y amigos en el Population Council: Ian Askew, Beverly Ben Salem, John Bongaarts, George Brown, María Elena Casanova, Hervé Ludovic de Lys, Mamadou Diallo, James R. Foreit, Joanne Gleason, Dale Huntington, Anrudh Jain, Michael Keonig, Federico León, Antonieta Martín, Peggy McEvoy, Robert Miller, Cecilia Ndeti, Lewis Ndhlovu, José García Núñez, Sandra Rosenhouse, Pauline Russell-Brown, Diouratie Sanogo, Valeda Slade, Placide Tapsoba, Luis Varela, y Ricardo Vernon.

La traducción, edición y producción de la Segunda Edición en español estuvo a cargo de John W. Townsend y Antonieta Martín. 


\section{Introducción}

\section{A ¿Qué es la investigación operativa?}

Los programas nacionales de salud y planificación familiar en Asia, Africa y América Latina, tienen como meta modificar las tasas de natalidad, mortalidad y morbilidad. Estos programas tienen altos costos financieros, emplean una gran cantidad de personas, cubren extensas áreas geográficas y efectúan una amplia gama de actividades. Dichas actividades son complejas y requieren una esmerada planeación y coordinación en todos los niveles, así como una capacitación y supervisión cuidadosa del personal, sin descuidar la evaluación continua del desarrollo y el impacto del programa. La investigación operativa (IO) es una herramienta primordial para apoyar las actividades de planeación, coordinación, capacitación y evaluación.

La investigación operativa es un proceso para identificar y resolver los problemas de los programas. Tal como se aplica actualmente en programas de salud, planificación familiar y en otros programas de desarrollo, la investigación operativa puede definirse como un proceso continuo con cinco pasos básicos:

1) Identificación y diagnóstico del problema;

2) Selección de la estrategia;

3) Experimentación y evaluación de la estrategia;

4) Difusión de la información; y

5) Utilización de la información.

El proceso de la investigación operativa está diseñado para incrementar la eficiencia, eficacia y calidad en la prestación de servicios, así como la disponibilidad, acceso y aceptación de estos servicios desde el punto de vista de los usuarios.

\section{B El enfoque y los objetivos de la investigación operativa}

La investigación operativa está enfocada en la observación de las "operaciones" diarias de los programas de salud y planificación familiar. Estas operaciones son responsabilidad de los gerentes y administradores y se refieren, por ejemplo, a la capacitación, la logística, las actividades de información y educación, la operación de las clínicas y de los sistemas de servicios rurales. La investigación operativa no se ocupa de problemas que afectan la demanda, sino la oferta de servicios. Características de la investigación operativa son su enfoque en los problemas diarios de la oferta y prestación de servicios y la búsqueda de 
soluciones, o como diría el investigador, se ocupa de las variables que puede manipular el administrador o gerente.

La investigación operativa en salud y planificación familiar ofrece respuestas a los problemas de los programas de servicio. Uno de sus objetivos más importantes es dar a los gerentes, administradores y formuladores de políticas la información que requieren para mejorar los servicios presentes y planear para el futuro. La investigación operativa busca soluciones prácticas y ofrece alternativas viables para las operaciones no satisfactorias. Diagnostica y evalúa los problemas de los programas y compara modelos de prestación de servicios en términos de impacto, costo-efectividad, calidad y aceptación por el cliente.

\section{Tipos de estudios de investigación operativa}

Los estudios de investigación operativa pueden ser clasificados bajo tres rubros:

1 Estudios de exploración/diagnóstico. Estos estudios tienen como objetivo determinar los parámetros de un problema que afecta la prestación de servicios. Examinan los factores que afectan la eficacia, eficiencia y calidad de los servicios que ofrece el programa. Tienen un diseño retrospectivo o de corte transversal y se emplean cuando se percibe la existencia de un problema cuya naturaleza se desconoce. Una característica esencial de estos estudios es la búsqueda de variables manipulables programáticamente.

2 Estudios de intervenciones de campo. En estos estudios se experimentan nuevas soluciones a un problema. Muchas veces se conocen los factores que ocasionan el problema, pero se desconocen las formas más eficientes y costo-efectivas para solucionarlo. Los estudios de campo prueban nuevas formas de prestación de servicios. Estos estudios son siempre prospectivos y longitudinales y generalmente emplean diseños de investigación experimental o cuasi-experimental.

3 Estudios de evaluación. Es frecuente encontrar que las actividades de planificación familiar y salud se lleven a cabo durante años, sin ser evaluadas. En tales casos, los estudios de evaluación son una forma muy útil de la investigación operativa para estudiar retrospectivamente o a través de un corte transversal los efectos de un programa.

Las tres categorías de estudios arriba mencionadas no se excluyen mutuamente. Es frecuente que una investigación operativa comience con una fase de exploración/ diagnóstico para identificar las variables clave; que continúe en la segunda fase con una intervención de campo y prosiga con una fase evaluativa para determinar el impacto de dicha intervención. 


\section{Los métodos y diseños de los estudios de investigación operativa}

Los métodos de la investigación operativa van desde los cualitativos hasta los cuantitativos y los diseños van desde los no-experimentales hasta los experimentales. No existe un tipo específico de método o diseño exclusivo de la investigación operativa. No es tampoco la aplicación de métodos particulares o del uso de un diseño lo que la distingue de otras formas de investigación. Son, más bien, su enfoque y objetivos los que la distinguen. En términos generales, el objetivo de la investigación operativa es mejorar la prestación de servicios. Aunque emplee diseños experimentales o no-experimentales, incluya análisis cuantitativos de procesos demográficos o discusiones sobre temas cualitativos en salud, el objetivo central de la investigación operativa es lograr una mejor comprensión de las "operaciones" del programa para poder mejorarlas.

\section{Temas ilustrativos para estudios de investigación operativa}

Se han llevado a cabo cientos de estudios de investigación operativa en salud y planificación familiar en Asia, Africa y América Latina. A modo de ejemplo, se listan a continuación nueve temas generales que se han empleado en la investigación operativa.

1 Programas de capacitación. Cantidad de trabajadores de salud y planificación familiar han recibido capacitación en el mundo. Es frecuente ver que los estudios de investigación operativa examinen el contenido y métodos de la capacitación, o que se compare un tipo de capacitación con otro, en términos de conocimientos adquiridos y desempeño del trabajador.

2 Información, educación y comunicación (IEC). Informar a la gente es una de las actividades más importantes de la mayoría de los programas de salud y planificación familiar. Los estudios de investigación operativa están frecuentemente diseñados para comparar los distintos enfoques de la comunicación en términos de la comprensión del mensaje, su retención, costo-efectividad, y éxito para llegar a las audiencias blanco.

3 Sistemas de información gerenciales. Todos los programas de salud y planificación familiar recogen información de sus clientes y los servicios prestados. Sin embargo, algunas veces, la información es inexacta o simplemente no se usa para ningún propósito administrativo. La investigación operativa puede diseñarse para experimentar con sistemas nuevos de recolección de datos y para probar nuevos procedimientos de uso de la información recolectada para mejorar los servicios.

4 Impacto del programa. Es frecuente ver que la investigación operativa haga estudios prospectivos y de campo, sobre el impacto de distintas formas de prestar servicios, como por ejemplo, la distribución comunitaria de anticonceptivos (DCA), o el uso de parteras empíricas. El impacto puede medirse de varias maneras, por ejemplo, examinando la prevalencia de anticonceptivos, las tasas de continuidad, la satisfacción del cliente con los servicios, o una mayor disponibilidad y acceso a los servicios. 
5 Administración y gerencia. La evaluación cualitativa de la administración y gerencia de un programa son, algunas veces, tema para los estudios de diagnóstico.

6 Calidad de atención. Cada vez con mayor frecuencia, la investigación operativa se orienta a evaluar la calidad y aceptación de los servicios que se ofrecen a los clientes. Estos estudios analizan el estado de los servicios de salud y planificación familiar.

7 Canales comerciales de distribución. Muchos programas de planificación familiar usan canales comerciales, como las farmacias, para distribuir anticonceptivos que no requieren prescripción médica. Se puede diseñar una investigación operativa para comparar sistemas de servicios comerciales con los no comerciales.

8 SIDA (VIH) y planificación familiar. En muchos países los administradores de los programas están preocupados por el posible impacto que el SIDA o virus de inmunodeficiencia adquirida (VIH) y otras enfermedades sexualmente transmitidas (ETS) puedan tener sobre las actividades de planificación familiar. En Africa y América Latina se han llevado a cabo estudios de investigación operativa para probar el efecto de incorporar información y educación sobre el SIDA (VIH) y otras (ETS) en los programas de planificación familiar.

9 Participación del hombre en la planificación familiar. En algunos programas nacionales de planificación familiar se ha dado atención casi exclusivamente a las mujeres y los servicios sólo están disponibles en los centros de salud materno-infantil. Muchas investigaciones operativas se han dedicado a probar mecanismos para lograr la participación del hombre en la planificación familiar y para que los programas le ofrezcan los servicios, ya sea en el lugar de trabajo o en otros lugares.

Existen, obviamente, muchos otros temas que pueden explorarse en la investigación operativa. Pero cualquiera que sea el tema seleccionado, es importante recordar que la meta principal de la investigación operativa no es solamente recolectar información y descubrir la razón de un problema. La meta es usar la información recolectada para solucionar el problema. El diseño y la conducción de un estudio de investigación operativa es sólo una parte del proceso. La difusión de los resultados del estudio y su utilización para mejorar la prestación del servicio, constituyen la otra parte esencial del proceso de la investigación operativa. 


\title{
Identificación, definición y justificación de un problema de investigación
}

\section{A Identificación de un problema}

\begin{abstract}
A través del desarrollo de programas de salud y planificación familiar surgen distintos problemas cuya identificación para fines de investigación no siempre resulta fácil. Una condición indispensable para efectuar la investigación operativa es la identificación y definición del problema objeto de estudio. En la medida en que el problema sea claro para el investigador, el contenido de la propuesta de investigación también lo será; el investigador podrá llegar así a una formulación precisa de los objetivos e hipótesis de investigación, variables principales de estudio, y la metodología a seguir para medir la incidencia de las variables.
\end{abstract}

Un proyecto de investigación surge cuando se reúnen tres elementos:

1 Una discrepancia entre lo que es y lo que debe ser.

2 Una pregunta sobre las causas de esta discrepancia.

3 Por lo menos dos respuestas plausibles a esta pregunta.

Este último punto es particularmente importante. De no existir más de una respuesta plausible a la pregunta, la investigación no procede. Considérese el siguiente ejemplo:

\section{Ejemplo de problema no susceptible de ser investigado}

\author{
Descripción del problema: \\ Los resultados derivados de una encuesta en el Distrito A demostraron que mil \\ mujeres estaban tomando regularmente píldoras anticonceptivas. Sin embargo, el \\ informe estadístico de servicios del mes anterior revelaba que ninguna de estas \\ mujeres estaba empleando anticonceptivos.
}

Discrepancia:

Según la encuesta, estas mil mujeres debían estar tomando anticonceptivos, pero las estadísticas demostraron que no era así.

\section{Pregunta:}

¿Qué factor o factores originaron la discontinuidad en el uso de la píldora entre las mil mujeres? 


\title{
Respuesta:
}

Una inundación ocasionó que la dotación de anticonceptivos no llegara al

Distrito A, habiéndose terminado la dotación anterior.

El ejemplo anterior demuestra que no es necesario llevar a cabo una investigación para conocer las causas de la discontinuidad en el uso de la píldora, ya que, si los datos son correctos, ya se sabe la respuesta a la pregunta. Sin embargo, sería útil realizar un estudio sobre las fallas logísticas y de suministro, así como sobre la incapacidad de distribuir anticonceptivos al Distrito A durante la época de lluvias.

\section{Ejemplo de problema susceptible de ser investigado}

\author{
Descripción del Problema: \\ El Distrito A siempre se inunda durante la época de lluvias. Conscientes del \\ problema, los responsables del programa nacional de planificación familiar \\ establecieron un sistema logístico de suministro para este distrito. Al inicio de las \\ lluvias, a cada usuario se le asignó una dotación anticipada de cuatro meses. \\ Durante esta temporada, se encuentran disponibles lanchas para transportar nuevos \\ suministros a los trabajadores de planificación familiar en los centros de \\ distribución de más fácil acceso. A pesar de estas nuevas medidas, las estadísticas \\ de este año demuestran que se agotaron las reservas de anticonceptivos en el \\ Distrito A.
}

Discrepancia:

Si bien, el nuevo sistema logístico debiera asegurar la continuidad en el suministro de anticonceptivos, este año no sucedió así.

Pregunta:

¿Cuáles son las causas por las que no funcionó adecuadamente el nuevo sistema?

\section{Respuestas posibles:}

1 No se pidió la nueva dotación de pastillas antes de las lluvias.

2 Las lanchas de las que se dependería para estas entregas estaban averiadas.

3 No se les informó a los trabajadores de campo sobre el nuevo sistema, por lo que no entregaron a los usuarios la dotación de pastillas convenida de cuatro meses, antes del inicio de las lluvias.

En este ejemplo se presentan varias respuestas plausibles que pueden ser correctas. Por lo tanto, este problema puede ser sujeto a una investigación operativa.

En algunos casos, resulta relativamente fácil identificar y definir el problema, elaborar hipótesis sobre las causas posibles y seleccionar aquéllas que se apegan a la realidad. En el ejemplo anterior las causas que originaron las fallas del sistema logístico de suministros pueden detectarse fácilmente sin necesidad de llevar a cabo una investigación costosa. Sin embargo, otros casos son mucho más complejos y la identificación del problema es más complicada. Veamos el siguiente ejemplo:

\section{Ejemplo de problema susceptible de ser investigado operativamente}

Descripción del Problema:

Una encuesta de planificación familiar realizada en varias aldeas reveló enormes 
diferencias en sus tasas de uso de anticonceptivos. Aún cuando todas las aldeas tienen el mismo nivel de servicios de salud y planificación familiar, algunas de ellas tienen un índice de prevalencia de hasta el $80 \%$, mientras que otras alcanzan apenas el $6 \%$.

\title{
Discrepancia:
}

Todas las aldeas deberían tener aproximadamente la misma tasa de prevalencia de uso de anticonceptivos pero, de hecho, ésta varía considerablemente.

\section{Pregunta al problema:}

¿Cuáles son los factores determinantes de las diferencias regionales en la tasa de prevalencia de uso de anticonceptivos?

\section{Respuestas Posibles:}

1 Las aldeas difieren en sus características socioeconómicas: algunas son netamente agrícolas, otras viven de la pesca. Algunas gozan de fácil acceso a la ciudad, mientras que en otras el acceso a la ciudad es sumamente difícil, prácticamente imposible. Algunas cuentan con escuelas, dispensarios, electricidad y servicio de agua; otras no tienen esas facilidades. Estas diferencias socioeconómicas influyen en la práctica anticonceptiva.

2 El apoyo institucional de planificación familiar a las aldeas, difiere de una a otra. En algunas aldeas, los políticos locales brindan más apoyo al programa nacional de planificación familiar que en otras. En algunas aldeas existen grupos de madres que apoyan la planificación familiar, en otras no. Estas diferencias también influyen en la tasa de prevalencia.

3 La eficiencia del personal de salud y planificación familiar varía según la aldea. Algunos trabajadores están muy motivados y trabajan activamente en las áreas que tienen asignadas, con otros no sucede lo mismo. Estas diferencias en el rendimiento del personal también afectan el nivel de la práctica anticonceptiva.

\section{Ejemplo de problema susceptible de ser investigado}

\author{
Descripción del Problema: \\ Durante sus visitas periódicas a los clientes, los supervisores de un programa \\ comunitario de planificación familiar, observan que muchas usuarias de \\ anticonceptivos orales no están bien informadas sobre el uso correcto de la píldora. \\ Por ejemplo, $58 \%$ de las mujeres consultadas habían tomado la \\ píldora de manera incorrecta en el mes anterior. Algunas habían esperado \\ demasiado y otras no lo suficiente después de su ciclo menstrual; otras no sabían \\ qué hacer en caso de haber olvidado tomar su píldora.
}

\section{Discrepancia:}

El programa se precia de dar servicios de alta calidad. Casi todas las promotoras de salud que dan información y suministros a las usuarias, reciben tres días de capacitación cuando ingresan al programa. También son supervisadas cuando se les resurten los métodos. Todas las usuarias deberían saber usar correctamente el método que escogieron, pero es claro que no saben.

\section{Pregunta:}

¿Cómo puede la gerencia garantizar un nivel adecuado de calidad en el uso de su programa comunitario rural?

\section{Respuestas Posibles:}

1 El programa no tiene procedimientos adecuados de selección de candidatas 
para los puestos de promotoras rurales voluntarias. Estos procedimientos deben ser revisados y quizá modificados.

2 El programa tradicional de capacitación es inadecuado por lo que se refiere a su contenido y a la forma de comunicarlo a las clientes. El programa de capacitación debe ser revisado.

3 El sistema de supervisión le dedica a todas las promotoras el mismo tiempo, sin tomar en cuenta las necesidades de la comunidad o las habilidades de la promotora. El sistema de supervisión debe ser revisado.

4 La gerencia del programa no está muy interesada respecto a la calidad del servicio en la comunidad, puesto que acepta cualquier nivel de competencia en las promotoras. Los elementos de calidad de atención deberían ser incorporados al programa.

5 La cantidad de servicios que se pide que haga la promotora son muchos y complejos para la mayoría del personal voluntario. Debe cambiarse la cantidad de servicios por promotora.

En este ejemplo el problema es claro. Los supervisores han observado que muchas usuarias de anticonceptivos orales han recibido poca información sobre el uso de la píldora. Las usuarias de píldora deberían saber tomar correctamente la píldora, pero la mayoría no lo sabe. La discrepancia entre lo que debería ser y lo que es, indica que existe un problema y cinco respuestas posibles. No se sabe cuál de estas cinco posibles respuestas son correctas.

Una manera importante en que la investigación operativa cumple con el paso de la identificación del problema es invitando a participar en el proceso, además de los investigadores, a los administradores y a otras personas como los cabecillas en los pueblos, los maestros y otros líderes similares. Cuando todas estas personas intervienen, se combinan la experiencia y punto de vista de los administradores y líderes locales con los conocimientos técnicos y metodológicos de los investigadores.

Formar un equipo con los investigadores y administradores del programa representa una experiencia de aprendizaje para ambos, que puede tener resultados favorables en el largo plazo y que van mucho más allá del mero diseño e implementación de un simple proyecto de investigación operativa. En este caso, los investigadores, por ejemplo, entienden mejor las preocupaciones diarias de los administradores y los problemas que enfrentan las organizaciones en la prestación de servicios. Esta comprensión ayuda a que el estudio afine su enfoque en aquellos aspectos de los problemas del programa que pueden solucionarse. Por otra parte, los administradores aprecian y sienten la necesidad de identificar y definir los problemas con base en los datos precisos. Entienden que la investigación es una herramienta importante para tomar decisiones y un proceso continuo en el que pueden contribuir. Su participación desde el inicio del proceso de la investigación operativa, hace más probable que se interesen posteriormente en revisar y utilizar los resultados de los estudios.

\section{B Definición del problema}

Para elaborar una propuesta de investigación, el paso más importante es la definición del problema. Este deberá ser definido en términos de su frecuencia, intensidad, distribución y otras medidas, para las cuales hay datos disponibles. El objetivo es precisar todo lo que se conoce actualmente del problema y el porqué de su existencia. Si bien es tentador adivinar la causa del problema, las conjeturas empíricas resultan frecuentemente erróneas y no pueden proporcionar las bases sólidas que requiere el proyecto de investigación. La mejor 
manera de definir un problema es mediante la revisión de toda la literatura relevante al respecto, el análisis de las estadísticas de servicio más recientes, la búsqueda de opiniones de expertos en el campo y la investigación de teorías económicas, sociales y de salud.

Una revisión cuidadosa de las fuentes de datos existentes sobre el problema y un diagnóstico epidemiológico permitirán al investigador determinar lo siguiente:

\section{Incidencia y prevalencia}

Se debería hacer un diagnóstico epidemiológico si los problemas están relacionados con la salud y la planificación familiar. En otras palabras ¿cuál es el alcance del problema, su frecuencia y distribución? Este diagnóstico epidemiológico contribuirá a establecer el marco del problema.

\section{Areas geográficas afectadas}

Es importante conocer cuáles son las áreas geográficas más afectadas por el problema. Preguntarse si el problema ocurre generalmente en áreas rurales; si afecta también a las ciudades; si se limita a las áreas montañosas, costeras o islas.

\section{Características de grupos de la población}

¿Existen grupos especiales de la población afectados por el problema, como madres, niños y adolescentes, recién casados o mujeres de más de 35 años?

\section{Causas probables del problema}

Del análisis de los datos disponibles se desprenderán varias causas probables. Preguntarse cuál es la experiencia actual acerca de las causas del problema: si existe consenso general sobre estas causas o, por el contrario, si los puntos de vista son divergentes y antagónicos.

\section{Soluciones posibles}

Verificar si se han hecho intentos previos para solucionar el problema. ¿Qué tipo de soluciones se han propuesto? ¿Qué tan exitosas resultaron y cuáles dieron buenos resultados y cuáles no?

\section{Preguntas sin respuesta}

A partir de la revisión de la información sobre el problema, ¿cuáles han sido las preguntas que han quedado sin respuesta? ¿Qué aspectos del problema necesitan investigarse más a fondo?

Un paso importante del proceso de investigación es la revisión de lo que hasta el momento se conoce acerca del problema. Un análisis formal de la información actualizada permitirá evaluar la importancia social, económica, política y de salud, del problema. Asimismo, este análisis facilitará la identificación de los conceptos teóricos y las variables esenciales que otros investigadores ya han considerado relevantes en el pasado y se hallarán hipótesis que deberán ser probadas en la investigación. De esta manera, el investigador evitará emprender investigaciones que ya han sido realizadas en múltiples ocasiones con resultados idénticos.

\section{Ejemplo de identificación y definición de un problema de investigación: Asia}

1 A pesar del progreso en la reducción de las tasas de fecundidad que se hizo en la década pasada en varios países del sudeste asiático, todavía existen limitaciones en los programas que pueden impedir un avance en la declinación de la fertilidad. En Indonesia, la tasa de prevalencia relativamente alta de $42 \%$ en Bali y Java, debe compararse con la tasa más bien baja de $17 \%$ en la Isla Exterior I y con el $6 \%$ de la Isla Exterior II. En las Filipinas, sólo el 25\% de la práctica anticonceptiva incluye el uso de métodos modernos. En Malasia, las esterilizaciones constituyen menos 
del $6 \%$ y el dispositivo intrauterino menos del $3 \%$ de todas las usuarias nuevas. En Tailandia, el programa de vasectomía es muy débil, a pesar de las tasas importantes de aceptación que se obtuvieron cuando los equipos del sector privado llevaron los servicios directamente a las aldeas.

2 En Asia, casi todos los ạdministradores de programas, están conscientes de la necesidad de intensificar los esfuerzos, si se quieren mantener las tendencias establecidas en la década de los setenta. En Indonesia, no sólo a las Islas Periféricas sino también al área urbana, se le debe prestar una atención especial, principalmente a Yakarta. Esta ciudad posee un sistema de prestación de servicios de salud y planificación familiar que, en principio, debiera cubrir todas las áreas de . la ciudad; actualmente la prevalencia entre mujeres casadas es sólo del $21 \%$, que representa aproximadamente la mitad de la prevalencia global de Java y Bali. Otras grandes áreas urbanas del país se encuentran atrasadas con relación a las áreas rurales.

3 Aún cuando se desconocen los factores que determinan las diferencias entre áreas rurales y urbanas en cuanto a las tasas de prevalencia en Indonesia, se cree que las zonas urbanas no tienen la estructura tradicional de organización y dirección comunitaria que apoya al programa de planificación familiar en las zonas rurales. Estas diferencias pueden originarse, entre otras razones, por el hecho de que los habitantes, especialmente los recién inmigrados, desconocen en donde proveerse de anticonceptivos. Muchos de estos inmigrantes tienen bajos niveles de instrucción, poco o nulo acceso a fuentes de información y desconocen la ubicación de centros de salud y de planificación familiar. También es difícil que el personal urbano de planificación familiar pueda atender a domicilio y de manera continua a los nuevos inmigrantes, sobre todo por la frecuencia con la que suelen cambiar su lugar de residencia. En ocasiones, estos cambios llevan a la pareja a abandonar, o al menos interrumpir, la práctica anticonceptiva.

4 En el pasado, se han hecho varios intentos por aumentar el uso de anticonceptivos en el medio urbano, tratando de hacerlos más accesibles al usuario. En Yakarta, unidades móviles han sido utilizadas para llevar los servicios a las áreas periféricas de la ciudad. Otra estrategia ha sido distribuir preservativos y pastillas a pequeños comercios para su venta. Si bien estas medidas han sido útiles, tienen, por otro lado, grandes deficiencias. Las unidades móviles destinadas a la distribución son caras y cubren sólo un sector limitado de la población. Los pequeños comercios son cómodos para los ya usuarios, pero no constituyen un medio eficaz para captar la atención de nuevos usuarios, ni pueden ofrecer ciertos servicios necesarios de salud materno-infantil, como vacunas y consultas pre y post-natales.

5 En las zonas urbanas se requiere de un sistema capaz de abarcar el mayor número de usuarios activos y aceptantes potenciales ofreciéndoles una amplia gama de servicios de salud y planificación familiar. Esta es una empresa difícil, aún no resuelta por el programa nacional de planificación familiar.

6 Un sistema propuesto, pero aún no experimentado, consiste en formar una nueva categoría de personal de salud y planificación familiar en el medio urbano que establezca contacto en el lugar de trabajo con los aceptantes actuales y potenciales. Con la ayuda de patrones y sindicatos, los agentes de salud y planificación familiar podrían crear centros de servicio en el interior de las fábricas, oficinas de gobierno, hoteles, obras en construcción, mercados y otros sitios de trabajo. Es probable que este sistema fuera menos costoso que la utilización de unidades móviles; además de que permitiría abarcar a una población más numerosa y ofrecer una gama de servicios más amplia que aquélla proporcionada por pequeños comercios. 


\section{Comentarios sobre el ejemplo}

En el primer párrafo del ejemplo anterior se identifica el problema en forma general. Si bien varios países del Sureste de Asia han logrado disminuir sustancialmente sus tasas de fecundidad, las limitaciones del programa obstaculizan su progreso. En seguida se presentan varios ejemplos de dichas limitaciones, lo que nos ayudan a identificar las áreas geográficas afectadas por el problema.

En el segundo párrafo, las limitaciones mencionadas se reducen a un sólo país, Indonesia. Asimismo, la atención se concentra en un sólo aspecto: la diferencia en las tasas de prevalencia de uso de anticonceptivos entre las áreas urbanas y las rurales. Se hace notar la siguiente discrepancia: Yakarta tiene un sistema de prestación de servicios de salud y planificación familiar diseñado para cubrir la ciudad entera. Teóricamente este sistema debería igualar las tasas de prevalencia de la ciudad con las del medio rural. Sin embargo, en Yakarta la tasa de prevalencia es 50\% menor que en Java y Bali. Al final del segundo párrafo, sabemos cuál es el problema específico: diferencias entre áreas urbanas y rurales en el uso de anticonceptivos. Sabemos dónde se localiza el problema en Indonesia, o sea, áreas urbanas y en especial Yakarta.

Conocemos la magnitud del problema, $21 \%$ de prevalencia en Yakarta comparado con $42 \%$ para todo Java y Bali. También sabemos que la población que interesa es la del medio urbano.

En el tercer párrafo, se mencionan las posibles causas de estas dificultades pero no se sabe cuál de ellas corresponde mejor a la realidad.

En el cuarto párrafo, se indican soluciones al problema de la tasa tan baja de prevalencia en zonas urbanas: unidades móviles y pequeños comercios. Si bien estas medidas son útiles, ambas son rechazadas por inoperantes e inadecuadas.

El quinto párrafo, sugiere qué debe hacerse para resolver el problema, y el sexto propone una estrategia alternativa que aún no ha sido probada o experimentada.

\section{Ejemplo de identificación y definición de un problema de investigación: Africa}

1 En Oagadugu, Burkina Faso, hace varios años, fue iniciado un programa de visitas domiciliarias, efectuadas por voluntarios, para dar educación a las parejas sobre planificación familiar y referirlas a los lugares de servicio. Se esperaba que el programa sirviera como modelo de los nuevos esfuerzos del gobierno sobre planificación familiar, especialmente en zonas urbanas. Se pensó que si se empleaban usuarios satisfechos de anticonceptivos como voluntarios para visitar los hogares en su comunidad y hablar sobre planificación familiar, sería una manera más efectiva de llegar a las parejas, que si se usaran medios masivos o "sage-femmes" (parteras) de tiempo completo y remuneradas.

2 A pesar de que algunos voluntarios han sido muy activos y han reclutado nuevos clientes de planificación familiar, el programa no ha tenido tanto éxito como se había anticipado. Un estudio diagnóstico del programa de voluntarios indicó varios problemas:

a Aunque es verdad que el empleo de voluntarios para visitar los hogares es obviamente menos costoso que el empleo de "sage-femmes" remuneradas, eso no significa que sea más efectivo. Los voluntarios pueden o no, estar motivados para visitar los hogares regularmente. Es típico que la motivación inicial y el entusiasmo, pronto se desvanezcan y después de un periodo de algunos meses, los voluntarios visitan pocos o ningún hogar. 
b El área que se asigna a cada voluntario, generalmente un Sector, es demasiado grande para que una sola persona lo cubra adecuadamente. Los voluntarios tienden a adoptar sus propios métodos para hacer las visitas domiciliarias y no cuentan con un plan coordinado para hacerlas.

C Hay muy poca o ninguna supervisión para los voluntarios en el campo. Esta puede ser una de las razones por las que el entusiasmo de muchos voluntarios decae.

d No obstante que los voluntarios recibieron un curso inicial de orientación en planificación familiar, no se han hecho esfuerzos para darles capacitación sobre la marcha, que serviría para reforzar e incrementar sus habilidades.

e Los informes de las parejas que fueron contactadas por los voluntarios indican que la información que se les proporcionó durante las visitas domiciliarias tiende a ser superficial. Aparentemente, muchos voluntarios no pueden dar la información específica que los usuarios potenciales desean saber sobre métodos anticonceptivos.

f No hay seguimiento. Una vez que se ha visitado un hogar, difícilmente se repite la visita.

3 Estos problemas han sido ampliamente discutidos por las autoridades competentes de salud y planificación familiar. Se desconoce cuál o qué combinación de problemas están afectando al programa de visitas domiciliarias voluntarias. Sin embargo, con base en el estudio diagnóstico, varias posibles soluciones a los problemas parecen factibles:

a Sería posible eliminar completamente a los trabajadores voluntarios y reemplazarlos por "sage-femmes" remuneradas que trabajaran tiempo completo. Es indudable que las "sage-femmes" dedicarían más tiempo a las visitas domiciliarias y estarían en posibilidad de dar información más detallada a los clientes potenciales. Por otro lado, el empleo de "sage-femmes" pagadas resultaría costosísimo, probablemente insostenible.

b Una segunda alternativa, sería recapacitar a los voluntarios. Aunque esta solución sería ciertamente menos costosa que contratar "sage-femmes" de tiempo completo, no resolvería todos los problemas. El Sector asignado a los voluntarios sería de todos modos muy grande para ser cubierto de manera efectiva. También sería necesario instituir un programa de supervisión en el campo. El seguimiento a los clientes quedaría probablemente como problema y aunque la recapacitación de los voluntarios podría mejorar sus conocimientos sobre planificación familiar, es muy poco probable que adquirieran los conocimientos detallados que tienen las "sage-femmes".

C Una tercera alternativa sería eliminar por completo el programa de visitas domiciliarias y apoyarse en las campañas en medios masivos y en las reuniones comunitarias de los Sectores como formas de educar a la gente sobre planificación familiar. Aunque el uso de esta alternativa ayudaría a informar a la gente, probablemente no tendría éxito para cambiar sus prácticas. La literatura sobre comunicación persuasiva, sugiere enfáticamente que el cambio de comportamiento es generalmente el resultado de la comunicación interpersonal, no de los medios masivos. Por lo tanto, esta alternativa probablemente no tendría como resultado un gran número de usuarios nuevos de planificación familiar.

d Una cuarta alternativa sería combinar algunos de los mejores aspectos de los tres enfoques anteriores. Por ejemplo, se podría diseñar un programa de la siguiente manera: 
1 Asignando a los usuarios voluntarios satisfechos un área más pequeña que fuera más manejable y que pudieran cubrir fácilmente;

2 Organizándolos para que trabajaran durante la semana coordinadamente con las "sage-femmes" y en horarios cortos;

3 Dando apoyo, supervisión y recapacitación periódica a los voluntarios;

4 Organizando reuniones Sectoriales sobre planificación familiar. Los voluntarios podrían ayudar a localizar a los amigos, parientes y vecinos más interesados en los servicios. Las "sage-femmes" podrían supervisar a los voluntarios y dar información más detallada y específica sobre planificación familiar y salud materno-infantil a los clientes potenciales.

\section{Comentarios sobre el ejemplo}

El primer párrafo está enfocado en un sólo país, Burkina Faso, y en el programa de una ciudad, Oagadugu, que por medio de promotores voluntarios trataba de educar y ofrecer servicios más accesibles y al alcance de las parejas. Originalmente, se pensó que este programa sería más efectivo que los medios masivos o las "sage-femmes" remuneradas.

En el segundo párrafo se destaca un problema, la discrepancia entre lo que se esperaba (un programa de voluntarios funcional) y lo que realmente es (un programa con problemas). Un estudio diagnóstico encontró seis problemas en el programa de visitas domiciliarias.

En el tercer párrafo se indica que los problemas del programa de visitas domiciliarias han sido discutidos ampliamente, pero que no se sabe qué problema o combinación de problemas son los más importantes. A continuación se presentan varias posibles soluciones para mejorar el programa. Las primeras tres se rechazan por inadecuadas por varias razones. La cuarta solución es una combinación de elementos de las otras tres y se acepta como la que tiene más posibilidades de éxito, por lo que se presenta como la solución que debe ser probada en un estudio de intervención de investigación operativa.

\section{QUE HACER: Identificación y definición del problema}

1 Para identificar y definir el problema, deben seguirse los siguientes pasos:

a Hacer una breve descripción del problema.

b Ampliar la descripción del problema con la literatura disponible y, a través de ésta, estudiar más a fondo el problema.

c Enfocar la atención hacia los aspectos más importantes del problema a investigarse.

2 Realizar una prueba preliminar para identificar el problema, siguiendo el siguiente plan:

\section{Problema:}

Redactar un breve párrafo describiendo el problema.

\section{Discrepancia:}

Mencionar la discrepancia entre lo que es y lo que debe ser.

\section{Pregunta:}

Redactar la pregunta principal.

Posibles Respuestas:

Sugerir dos o más respuestas plausibles. 
3 Enriquecer la descripción con elementos relativos al tema basados en la literatura existente, estadísticas de servicios disponibles, opiniones de especialistas y toda clase de información pertinente. Buscar conceptos teóricos y variables operacionales que se hubieran podido pasar por alto. Hacer una lista de estos aspectos y variables conforme vayan apareciendo. De ser posible, responder a las preguntas siguientes:

a ¿Cuál es la incidencia y prevalencia del problema?

b ¿Cuáles son las zonas geográficas afectadas?

c ¿Qué sectores de la población son afectados por el problema?

d ¿Cuáles son los resultados de otras investigaciones?

e ¿Qué se ha hecho anteriormente para solucionar el problema?

f ¿Qué tan exitosos fueron los esfuerzos anteriores?

g ¿Qué aspectos importantes del problema quedaron sin solución?

4 Redactar nuevamente la identificación y descripción del problema, integrando todos los elementos reunidos a partir de la información disponible, siguiendo el esquema: descripción de la situación; discrepancia; pregunta; respuestas posibles. Hay que delimitar bien el problema; concentrarse en los aspectos más importantes que deben investigarse, y lograr esto con claridad y precisión.

5 El documento preparado deberá ser leído por una o más personas para confirmar su claridad y precisión. Si el problema no está claro, si la discrepancia entre lo que es y lo que debe ser no es evidente para el lector, será necesario empezar de nuevo.

\section{Justificación de la investigación}

Una vez que se ha identificado y definido el problema, es necesario justificar por qué es importante resolverlo. La investigación requiere de recursos económicos y humanos suficientes, por lo que es necesario replantearse preguntas sobre la importancia del estudio y la necesidad de llevarlo a cabo.

\section{Ejemplo de justificación de un proyecto de investigación: Asia}

En Indonesia, la diferencia en las tasas de prevalencia de uso de anticonceptivos entre áreas rurales y urbanas se debe esencialmente a la elevada tasa de crecimiento demográfico en el medio urbano, al igual que a la falta de un sistema adecuado y eficiente de prestación de servicios. De igual manera, en el Asia Meridional y del Sudeste, el crecimiento demográfico en el medio urbano es notoriamente mayor que en el medio rural, debido esencialmente a la alta fecundidad y a la continua inmigración del campo. Las tasas de crecimiento en área urbana son del $4 \%$ al $8 \%$ comparadas con $2 \%$ al $3 \%$ en el área rural. Los inmigrantes que se desplazan hacia las ciudades en busca de trabajo y de mejores condiciones de vida, se enfrentan en el medio urbano a situaciones socio-económicas y de salud más adversas que las del campo. En la mayoría de las grandes ciudades aún no se han diseñado sistemas efectivos para prestar servicios básicos de salud. 
El Programa Nacional de Planificación Familiar (PNPF) y los planificadores de políticas están conscientes de las diferencias existentes en las tasas de prevalencia anticonceptiva entre Yakarta y las zonas rurales. Este problema indica lo inadecuado e ineficiente que es el sistema de salud y planificación familiar en las áreas urbanas. Deben buscarse y experimentarse nuevas estrategias que se adapten más al estilo de vida de los habitantes de las ciudades y sus áreas metropolitanas. Los nuevos inmigrantes, así como la población de los sectores marginados, deben constituir el foco prioritario de atención, ya que para ellos los servicios actuales de salud y planificación familiar no están disponibles ni accesibles. Mientras esta situación exista, las diferencias observadas en las tasas de uso anticonceptivo en las zonas rurales y urbanas persistirán.

\section{Comentarios sobre el ejemplo}

Los argumentos básicos para justificar el proyecto de investigación se presentan en distintas formas. Se señala en primer lugar, que no solamente Indonesia sino también gran parte del Asia Meridional y del Sudeste se caracterizan por tener diferencias en sus tasas de prevalencia en áreas urbanas y rurales. Lo que significa, en otras palabras, que esta situación está muy extendida. Segundo, el problema se presenta hoy día y se agrava a medida que continúa el crecimiento demográfico de las ciudades. Tercero, el problema es reconocido como un asunto de gran preocupación por los directores del Programa Nacional de Planificación Familiar. Cuarto, se muestra que el problema guarda estrecha relación con lo inadecuado e ineficiente que es el actual sistema de servicios de salud y planificación familiar en el medio urbano. Finalmente se afirma que, de no establecerse nuevas estrategias de prestación de servicios de salud y planificación familiar, las tasas de prevalencia en el área urbana seguirán siendo más bajas que las de áreas rurales.

\section{Ejemplo de justificación de un proyecto de investigación: Africa}

No obstante el rápido crecimiento urbano en casi todos los países de Africa, los programas de planificación familiar han puesto más atención a las zonas rurales que a las urbanas. Además, los programas que se han iniciado en las ciudades no siempre han tenido éxito. Los habitantes de las ciudades tienden a tener mayor educación y recursos económicos, pero esto no significa que la población urbana tenga mayores conocimientos o acceso a los centros de salud y planificación familiar.

En Butkina Faso la población urbana pobre aumenta continuamente, por lo que se requiere urgentemente una solución por medio de nuevas estrategias. No es realista pensar que unos cuantos hospitales y clínicas en Oagadugu provean servicios de calidad en planificación familiar, cuando generalmente están sobrecargados de pacientes y tienen un enfoque hacia la medicina curativa. No es tampoco realista pensar que la población urbana tenga más deseos que la rural de gastar tiempo, dinero y esfuerzo para viajar a las clínicas, donde no es seguro que haya los servicios que buscan. La educación y los servicios tienen que ir a donde está la población. Así como los programas de distribución comunitaria han probado ser efectivos y sostenibles en el área rural, así deberían desarrollarse programas basados en la distribución en los barrios de las zonas urbanas.

\section{Comentarios sobre el ejemplo}

La justificación de este problema menciona que los programas de planificación familiar en muchos países de Africa no toman en cuenta a los centros urbanos. En otras palabras, el problema de servicios inadecuados de planificación familiar para población urbana, que es un grupo específico e importante de la población, es un problema general y no limitado a un sólo país. El problema es también actual en Burkina Faso, donde la gente de escasos recursos en las ciudades aumenta constantemente. Finalmente, en la justificación del estudio está implícito el problema de la equidad. La misma atención que se ha puesto al desarrollo 
de los programas de distribución comunitaria en las zonas rurales, debe ponerse al desarrollo de programas de distribución en los barrios de las ciudades.

\section{QUE HACER: Justificación de un proyecto de investigación}

1 Para justificar el proyecto de investigación es importante responder a las siguientes preguntas:

a ¿Es de actualidad el problema? ¿Se agravará conforme pase el tiempo?

b ¿Está muy extendido? ¿Afecta a muchas regiones y personas?

c ¿Afecta más específicamente a ciertos grupos de la población, tales como madres e hijos?

d ¿Se encuentra relacionado el problema con las actividades del programa actual?

e ¿Está vinculado el problema con factores económicos, sociales y de salud, tales como desempleo, desigualdad de ingresos, status de la mujer, educación y salud materno-infantil?

f ¿A quiénes interesa más el problema: a dirigentes del país, a médicos, o a otros profesionistas?

2 A través de las respuestas a estas preguntas, se desarrolla la justificación del proyecto de investigación. 


\section{Selección de estrategias para solucionar el problema}

\section{A Usar el esquema de calidad de atención}

Una vez que se ha identificado, definido y justificado el problema susceptible de ser estudiado por la investigación operativa, se pueden sugerir una serie de estrategias para solucionarlo. Estas estrategias generalmente prueban alguna pequeña modificación a los servicios o al sistema gerencial, que no significa que se hagan cambios mayores como el rediseño de un nuevo sistema de prestación de servicios.

Se ha visto que muchos problemas de los programas y sus posibles soluciones, se refieren a temas de calidad de atención. En el diseño de una estrategia apropiada para resolver un problema específico, es siempre útil referirse a los seis elementos de calidad de atención que se mencionan a continuación, ya que cada uno de ellos puede implicar una estrategia de solución:

1 Ampliar la gama de métodos anticonceptivos que se encuentran disponibles en las clínicas, hospitales, puestos de venta comercial o de distribución comunitaria.

2 Dar información, clara y específica a los clientes sobre los diferentes métodos disponibles, sus ventajas y desventajas.

3 Mejorar la competencia técnica de los proveedores del servicio.

4 Incrementar la cantidad y calidad de las relaciones personales entre cliente y proveedor.

5 Promover la continuidad en el uso de anticonceptivos.

6 Ofrecer una constelación adecuada de servicios a los clientes.

\section{B Ejemplos de estrategias para prueba}

Es claro que las estrategias específicas para solucionar un problema operativo en planificación familiar con base en los elementos de calidad de atención son muy vastas. Por ejemplo, entre los cientos de estudios de investigación operativa que se han llevado a cabo en Asia, Africa y América Latina, se han desarrollado estrategias para probar lo siguiente:

Incrementar la disponibilidad y acceso de los servicios de planificación familiar usando puestos de venta comercial, distribución en el lugar de trabajo, clínicas satélite, depósitos de anticonceptivos en las aldeas, clínicas móviles, ayuda para la transportación de clientes y horas de servicio flexibles. 
Mejorar la información, educación y comunicación usando los canales de comunicación masiva y personal, tales como educación para adultos, reuniones de grupos en las aldeas, consejería a los clientes, compañeros consejeros y usuarios satisfechos.

Introducir o promover el uso de métodos anticonceptivos específicos, usando distintos tipos de personal, por ejemplo, enfermeras para inserción de DIUs o NORPLANT ${ }^{\otimes}$; estableciendo clínicas para hombres para promover la vasectomía; llevando a cabo reuniones educativas en clubes de madres para promover la lactancia materna y la lanificación familiar por métodos naturales.

Mejorar el desempeño de los trabajadores a través de mejores procesos y criterios de selección, capacitación basada en la competencia del trabajador, descripciones realistas de funciones, mejor o más selectiva supervisión, y un ambiente de trabajo agradable.

Reforzar el desempeño del programa mediante la capacitación de la gerencia, para mejorar el flujo de información para la toma de decisiones y la planeación del programa, a través del uso de microcomputadoras, estadísticas de servicios completas y exactas, sistemas para expeditar el flujo de los recursos financieros, sistemas logísticos más efectivos y eficientes, y un mejor mantenimiento de las instalaciones, vehículos y otro equipo.

Servir las necesidades de nuevas poblaciones blanco tales como hombres, adolescentes, mujeres en el lugar de trabajo, grupos de escasos recursos económicos en áreas urbanas, y grupos étnicos o religiosos, mediante la elaboración de materiales de información, educación y comunicación (IEC) y servicios especiales para estos grupos.

Incrementar la recuperación de los costos para el sostenimiento del programa involucrando al sector privado, cobrando por los productos o servicios, estableciendo un programa de mercadeo social, cobrando contribuciones a los patrones o al gobierno local, estableciendo programas de aseguramiento de la comunidad, o por medio de inversiones conjuntas del sector público y privado.

Integrar servicios de planificación familiar con otros programas de salud como vacunación, promoción de la lactancia materna y otras actividades de atención primaria de la salud.

\section{Guías para la selección de una estrategia}

Antes de seleccionar una estrategia gerencial o de servicio para probar en un estudio de investigación operativa, revise otra vez los detalles del problema que le preocupa. La naturaleza del problema determinará la estrategia para solucionarlo. En otras palabras, si se selecciona correctamente la estrategia se soluciona el problema. Esto puede parecer obvio, pero en ocasiones es sorprendente la cantidad de veces que se usa el mercadeo social o la IEC (más afiches, videos, folletos y panfletos) como panaceas para solucionar casi todos los problemas de un programa sin pensar en si son o no las estrategias indicadas.

Además de la revisión cuidadosa del problema, existen otras guías que se pueden seguir para ayudar a seleccionar y desarrollar la estrategia adecuada para ensayar en un estudio de investigación operativa. 
1 Revise las estrategias que otros han usado para solucionar problemas similares. Una forma de hacerlo es revisando los resultados de la investigación operativa en planificación familiar en la gran cantidad de estudios que se han llevado a cabo en todo el mundo. Averigüe qué estrategias funcionan mejor para solucionar cada problema.

2 Reúnase con las personas que se ven más afectadas por el problema o que están más preocupadas por él. Las personas afectadas por el problema gerencial o de servicio tienen sus opiniones, a veces muy particulares, sobre las posibles estrategias para solucionar el problema. Siempre es importante recoger sus ideas, ya que estas personas pueden sugerir las mejores estrategias de solución.

3 Seleccione las estrategias que pueden ser implementadas sin una carga excesiva para la institución. Si los requerimientos de recursos para la solución del problema son tan altos que interfieren con los servicios actuales, entonces no debe probarse esa estrategia.

4 Seleccione las estrategias que pueden sostenerse a través del tiempo. No importa qué tan efectiva sea una solución en el corto plazo, o sea, durante la intervención del estudio de investigación operativa, si la organización no la puede mantener a largo plazo (o después que ha terminado la investigación operativa) no es factible que tenga mucho efecto para solucionar el problema. Busque estrategias que tengan muchas probabilidades de ser sostenibles financieramente.

5 Busque estrategias simples en su implementación. Cuando se trate de escoger estrategias que posiblemente tengan el mismo impacto, seleccione la estrategia más simple en términos de requerimientos de instalaciones y equipo, personal y capacitación, tiempo y dinero, logística y administración y otras consideraciones prácticas similares.

6 Escoja estrategias cuya solución esté bajo el control del gerente del programa. La solución propuesta o lo que es lo mismo, "las variables independientes", deben estar bajo el control del gerente del programa de planificación familiar.

7 Evite seleccionar estrategias que incluyan una prueba de campo que sea más costosa que los beneficios esperados. Es obvio que una estrategia de investigación operativa no debe probarse si los beneficios que se esperan de ella son pocos en comparación con el esfuerzo que requiere su implementación.

8 Evite las estrategias que no sean consistentes con las metas, objetivos y planes de desarrollo de la institución. Una estrategia que no va de acuerdo con los objetivos y planes de la institución pueden encontrar oposición y no recibir los recursos y atención que requieren para una implementación exitosa.

\section{Ejemplo de una estrategia para solucionar un problema: América Latina}

$\mathrm{El}$ alto porcentaje de usuarias de anticonceptivos orales que no toman correctamente la píldora, es un problema que se relaciona directamente, por lo menos, con dos elementos de la calidad de atención:

1 La información a los clientes.

2 Las relaciones personales entre el cliente y el proveedor.

El hecho de que el 58\% de las clientes de anticonceptivos orales tomen la píldora incorrectamente, parece indicar que no están recibiendo la información necesaria. Puede ser que no estén recibiendo la información correcta por parte de sus 
proveedores o que exista una relación interpersonal negativa entre el cliente y el proveedor, lo que ocasiona que la comunicación de la información sea poco efectiva.

En una situación como ésta puede haber varias estrategias para solucionar el problema.

Primero, podrían diseñarse materiales de IEC como folletos, afiches o videos enseñando el uso correcto de los anticonceptivos orales, tratando de llegar a los clientes nuevos y actuales con estos materiales. Una segunda estrategia sería revisar el programa de capacitación de los promotores rurales de salud. En particular, podrían volverse a capacitar a los promotores, enfatizando el desarrollo de habilidades de comunicación efectiva, con objeto de dar a los clientes información completa sobre todos los aspectos del uso de anticonceptivos orales. Esta segunda estrategia será la que se desarrolle, pruebe y evalúe antes de considerar otras alternativas.

Las razones principales para seleccionar la estrategia de recapacitación son las siguientes:

a Algunos estudios previos de investigación operativa en América Latina sugieren que la comunicación personal entre clientes y proveedores, cuando tiene lugar en una atmósfera de comprensión, respeto y honestidad y que permite el diálogo, tiende a ser un medio más eficaz para transmitir la información a los clientes, que el uso de medios masivos que son impersonales.

b El programa de planificación familiar cuenta actualmente con un plan de capacitación y recapacitación de los promotores rurales de salud. Será mucho más fácil revisar el contenido de este plan, que desarrollar, probar y producir nuevos materiales de IEC.

C La recapacitación es una estrategia más sostenible, porque tanto los costos iniciales como los de largo plazo son menores que los del diseño de nuevos materiales de IEC.

\section{Comentarios sobre el ejemplo}

En el ejemplo anterior, el problema sobre el uso incorrecto de la píldora está relacionado con los elementos de calidad de atención. Estos elementos ofrecen dos posibilidades para solucionar el problema. Una sería dar información a los clientes usando medios masivos de comunicación (folletos, afiches, videos) y la otra se apoyaría en el uso de canales de comunicación interpersonal entre el cliente y el proveedor, después de haber vuelto a capacitar a los promotores rurales de salud. Se ha seleccionado la segunda estrategia para ser desarrollada, probada en el campo y evaluada. Existen tres razones para seleccionar esta estrategia: 1) estudios previos de investigación operativa indican que es más efectiva, 2) es más sencillo volver a capacitar a los promotores que desarrollar nuevos materiales de IEC y, 3) la estrategia de recapacitación es menos costosa y por lo tanto es más sostenible en el largo plazo.

\section{QUE HACER: Selección de una estrategia}

Después de que un problema importante para el programa ha sido identificado, definido y justificado, debe seleccionarse una estrategia apropiada para solucionarlo. Primero, haga una revisión de la naturaleza del problema que le preocupa. ¿Se relaciona con la calidad de atención? Y si es así, ¿existen una o más estrategias para solucionarlo en el marco de los seis elementos de calidad de atención? 
Revise las guías para seleccionar la estrategia y después en su propuesta de investigación deberá:

1 Identificar las estrategias para solucionar el problema.

2 Indicar claramente cuál o cuáles estrategias ha seleccionado como la(s) más apropiada(s) para solucionar el problema.

3 Justificar la selección de una o más estrategias de solución, indicando:

a El éxito que se ha obtenido anteriormente en la aplicación de esta estrategia para solucionar problemas similares.

b La facilidad de poner en marcha esta estrategia en comparación con otras que posiblemente produzcan el mismo impacto.

C La posibilidad de sostener la aplicación de la estrategia después de que el estudio de investigación operativa haya terminado. 


\section{Objetivos e hipótesis}

De la identificación, descripción y justificación del proyecto de investigación, aspectos antes descritos, debe derivarse la formulación de los objetivos y las hipótesis. Esta sección se enfoca directamente al propósito central del estudio. Se presentan objetivos específicos que describen las contribuciones deseadas y los resultados del estudio, así como las variables que serán medidas. Se formulan también las hipótesis aptas a experimentación que describen las relaciones entre las variables.

\section{A Objetivos últimos}

La mayoría de los proyectos de investigación formulan, dentro de sus objetivos últimos, las implicaciones o contribuciones que esperan lograr del estudio. El objetivo último de muchos proyectos de salud y planificación familiar es el de contribuir, de alguna manera, al descenso de la mortalidad, morbilidad y fecundidad. Este es, por supuesto, un objetivo poco realista, ya que sería imposible que un solo estudio pudiera lograr ese objetivo. Un objetivo más realista podría ser: proporcionar a los administradores de programas y planificadores de políticas información útil para mejorar el sistema de prestación de servicios o reorientar el programa.

La formulación de los objetivos últimos sirve, por un lado, para situar al estudio dentro del contexto económico, social y de salud y, por el otro, para precisar los resultados que se esperan del estudio con lo que se reafirma, al mismo tiempo, la necesidad de llevarlo a cabo. El investigador debe formular los objetivos de manera realista.

\section{Ejemplos de objetivos últimos}

1 Estudio de las variaciones regionales en la práctica anticonceptiva en México. El objetivo último de este estudio consiste en colaborar con la dirección del programa en la elaboración de un nuevo enfoque educativo para motivar a las parejas de zonas rurales que tienen bajas tasas de prevalencia anticonceptiva.

2 Estudio para probar un modelo de provisión de servicios de planificación familiar a población urbana en Burkina Faso. "El objetivo último de este estudio es desarrollar un modelo costo-efectivo y sostenible de servicios de calidad en salud y planificación familiar para población urbana."

3 Estudio experimental para integrar servicios de educación en planificación familiar con servicios primarios de salud en dos zonas rurales de Camerún. "El objetivo último de este estudio es desarrollar un sistema rural, integrado y costo-efectivo de servicios de planificación familiar cuyo impacto pueda ser medido en la disminución de la morbilidad y mortalidad materna e infantil."

4 Encuesta sobre conocimiento, actitudes y prácticas (CAP) respecto a la planificación familiar de las personas con influencia política en Brasil. El objetivo último de este estudio es incrementar la participación de las personas influyentes de la comunidad en las actividades del programa de salud y planificación familiar. 


\section{B Objetivos inmediatos}

A diferencia de los objetivos últimos, que indican lo que se espera lograr, los objetivos a corto plazo constituyen lo que efectivamente pasará en relación con el problema objeto de estudio. El investigador presentará dentro de los objetivos a corto plazo las actividades que, de hecho, se desarrollarán y las variables específicas a estudiar.

En la mayoría de los casos, y particularmente en las evaluaciones, los objetivos a corto plazo deben definirse en términos de lo que se va a realizar. Los objetivos deben especificar: ¿quién lo hará?, ¿cuánto?, ¿para quién?, ¿cuándo?, ¿dónde?, y ¿con qué propósito?

\section{Ejemplos de objetivos inmediatos}

1 Estudio experimental de investigación operativa en Gambia para proveer servicios de planificación familiar en el lugar de trabajo. "En un estudio de intervención de 18 meses, la Asociación de Planificación Familiar de Gambia, trabajando en 15-20 fábricas, hoteles y otros negocios en el área de Banjul, implementará un estudio de investigación operativa para probar dos modelos de prestación de servicios en el lugar de trabajo. Se compararán las dos modalidades entre sí y con un tercer modelo (de control), por lo que respecta a costo, conocimiento y uso de anticonceptivos, satisfacción con los servicios y otras medidas."

2 Estudio de las diferencias en las tasas de prevalencia de anticonceptivos en áreas urbanas y rurales de Indonesia. "En la primera fase del estudio, la asociación indonesia BKKBN llevará a cabo un estudio exploratorio en Yakarta y en dos localidades rurales en Kecamatan, para determinar los factores de carácter institucional y programático, que inciden en la varianza de la práctica anticonceptiva en las mujeres casadas entre 15-44 años de edad."

"En la segunda fase del estudio que será conducida en 1993, la BKKBN evaluará un nuevo modelo de prestación de servicios de salud y planificación familiar, por lo que respecta a a) el aumento de la práctica anticonceptiva en las mujeres unidas de 15-44 años, y b) una mayor utilización de las instalaciones para atención primaria de salud por las personas de estratos socio-económicos bajos."

3 Evaluación de diversas metodologías de capacitación. "La División de Capacitación del Proyecto de Planificación Familiar y Salud Materno-Infantil de Nepal, llevará a cabo una evaluación para determinar causas de las diferencias en el desempeño de los trabajadores de campo, entre los que reciben capacitación en el salón de clase y los que la reciben en el campo."

4 Encuesta sobre conocimientos, actitudes y prácticas de planificación familiar entre personas importantes en la comunidad en Sri Lanka. "En 1992, el Ministerio de Planeación llevará a cabo una encuesta en 100 poblaciones seleccionadas al azar para determinar el conocimiento, actitudes y prácticas de planificación familiar de personas importantes en la comunidad."

\section{Comentarios sobre los ejemplos}

Debe notarse que en cada uno de los objetivos, el investigador está comprometido a llevar a cabo una actividad específica: hacer, evaluar, encuestar, o determinar. El contexto de la 
investigación es también específico. Se precisa quiénes son los responsables del estudio, así como el periodo y lugar en que se llevará a cabo. Finalmente, como condición esencial se especifican las variables más importantes que serán objeto de estudio, incluyendo los factores económicos, sociales, culturales y otros inherentes al programa; la práctica anticonceptiva; la utilización de servicios de atención primaria en salud; el desempeño de labores de los trabajadores de campo; capacitación y otros. Más adelante, las variables deberán ser detalladas cuidadosamente en términos operacionales, pero mientras tanto, éstas contribuyen a dar un enfoque más preciso a la propuesta de investigación.

\section{Hipótesis}

Una hipótesis de investigación establece la existencia de una determinada relación entre dos o más variables, la cual debe probarse empíricamente. Mientras que los objetivos últimos citan las posibles repercusiones de las conclusiones del estudio, los objetivos a corto plazo (formulados en términos de comportamiento) definen las actividades a realizar, así como las variables a medir. Por otro lado, las hipótesis de investigación especifican la relación que se espera exista entre dos o más variables.

Estas hipótesis sirven fundamentalmente para orientar el proceso de investigación y describir las variables dependientes y las independientes que serán utilizadas, así como los datos necesarios y el tipo de análisis adoptado para medir las relaciones entre ellas.

Una hipótesis determinada puede sugerir que el efecto de la variable A está asociado con el de la $\mathbf{B}$, o que el efecto de la variable A es causado por la variable B. Algunas veces una hipótesis puede establecer que, bajo ciertas condiciones, $\mathbf{X}, \mathbf{Y}$, y $\mathbf{Z}$, la variable A está asociada con, o bien resulta ser la causa de la variable B. Una hipótesis bien redactada indica al investigador las variables específicas.

Cuando se establece la hipótesis es muy importante distinguir entre variables independientes y dependientes. Una variable independiente causa, determina o influye en las variables dependientes. La relación básica entre estos dos tipos de variables se presenta como lo muestra la Figura 4.1.

Este modelo muestra una relación directa entre ambas variables. En otras palabras, la variable dependiente varía en función de los cambios de la variable independiente. La variable dependiente depende de la variable independiente. Es, sin embargo, bastante difícil encontrar un tipo de relación tan directo en las investigaciones de planificación familiar.

En la gran mayoría de los casos, la relación entre ambas variables se da de una manera indirecta, a través de variables denominadas "variables intermedias". El efecto de la variable independiente sobre la dependiente es, en este caso, ampliado o amortiguado por el efecto de las variables intermedias, llamadas en ocasiones "variables de control". Los investigadores en materia de planificación familiar recurren con frecuencia a un esquema que comprende las variables intermedias. (Ver la Figura 4.2.)

Por ejemplo: en un esfuerzo por incrementar la aceptación de anticonceptivos (variable dependiente) un proyecto de planificación familiar intenta iniciar un programa de información, educación y comunicación (variable independiente). En forma aislada, el Programa de IEC no puede aumentar la práctica anticonceptiva, sino que deberá actuar y operar a través de un número de variables intermedias, las cuales, al mismo tiempo, producirán cambios o influirán en la práctica anticonceptiva. Pueden existir muchas otras variables, pero las más susceptibles de verse afectadas por el programa de IEC serían las que se refieren al conocimiento sobre planificafión familiar, la actitud hacia el uso de 
anticonceptivos y la opinión sobre el tamaño ideal de la familia. La Figura 4.3 presenta un esquema de investigación para evaluar los efectos del programa de IEC.

FIGURA 4.1

Una relación directa entre variables independientes y dependientes.
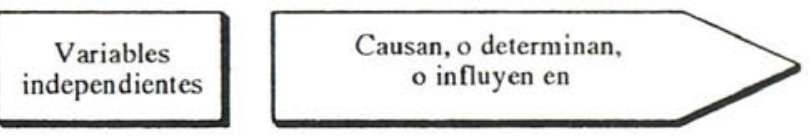

Variables dependientes

FIGURA 4.2

Variables intermedias.

Variables intermedias

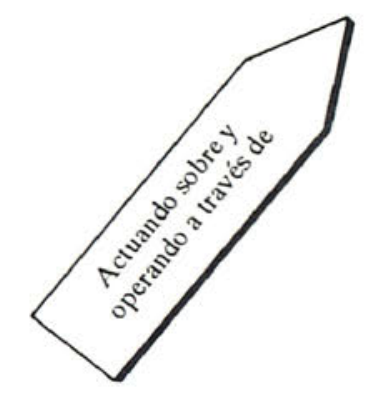

Variables independientes

FIGURA 4.3

El efecto de las variables intermedias en un programa de IEC.

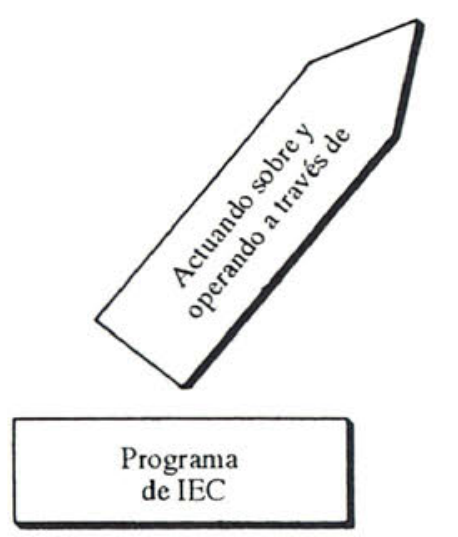


En la investigación operativa de los programas de planificación familiar las hipótesis de mayor importancia son aquellas que generalmente consideran las actividades del programa de IEC como variable independiente. El objetivo de la investigación es determinar hasta qué punto la variable independiente afecta la variable dependiente. Comúnmente la variable dependiente es la que cobra mayor interés en la propuesta de investigación. Las variables intermedias son también importantes pues ellas tienden ya sea a incrementar o a disminuir la relación entre las acciones del programa (variable independiente) y los efectos finales (variable dependiente).

En la mayoría de las investigaciones se estudian muchas variables independientes, muchas variables intermedias, pero pocas variables dependientes. Las hipótesis de investigación siempre deberán considerar las relaciones entre las variables. Se trata, en primer lugar, de poner en relieve el problema central del estudio (variables dependientes); en seguida, se considera el o los factores (variables independientes) que puedan causar, determinar o afectar el problema (variables independientes). Finalmente, se deberá reflexionar si hay una relación entre las variables dependientes e independientes, y si resulta ser directa o indirecta a través de las variables intermedias.

\section{Ejemplos de hipótesis}

1 La tasa de prevalencia de uso de anticonceptivos deberá ser más elevada en las aldeas con características de modernización, comparadas con las que no las tienen.

2 Las aldeas en donde el personal de planificación familiar inspira confianza a la gente deberán tener tasas más elevadas de prevalencia anticonceptiva que aquéllas en donde no se confía en el personal.

3 El personal de salud y planificación familiar que ha tenido una capacitación de cinco semanas en trabajo de campo deberá ser más eficiente que un personal similar que ha recibido un curso de capacitación teórica de cuatro semanas.

4 El mejor desempeño del personal de trabajo de campo favorece una mayor aceptación de métodos anticonceptivos entre las parejas.

5 Un programa de información y educación por radio, televisión e impresos, aumentará el conocimiento de la población en planificación familiar.

6 Las personas con niveles más altos de conocimientos de planificación familiar tienen más probabilidades de usar métodos anticonceptivos que las que no tienen conocimientos.

\section{Comentarios sobre los ejemplos}

Nótese que en cada hipótesis se sugiere una relación con dos o más variables. En la primera hipótesis se espera que haya una relación entre las características de modernización de las aldeas (variable independiente) y la práctica anticonceptiva (variable dependiente). En la segunda hipótesis, la credibilidad hacia el personal de salud (variable independiente) está relacionada con la práctica anticonceptiva (variable dependiente). La tercera y cuarta hipótesis son similares. En la tercera hipótesis se establece la relación entre un curso de capacitación de cinco semanas en el campo (variable independiente) y la productividad del personal (variable intermedia pero a la vez variable dependiente). En la cuarta hipótesis la productividad del personal de campo actúa como variable independiente y la aceptación de uso de métodos anticonceptivos pasa a ser la variable dependiente. El modelo para estas dos hipótesis sería como el que se muestra en la Figura 4.4. De igual manera, juntando a las hipótesis cinco y seis, el conocimiento sobre planificación familiar es la variable 
dependiente en la hipótesis cinco, pero se convierte en la variable independiente en la hipótesis seis.

FIGURA 4.4

Un modelo para dos hipótesis

Productividad del personal de trabajo de campo

sobre el efecto de la capacitación

del personal de campo en

las tasas de aceptación

de anticonceptivos.

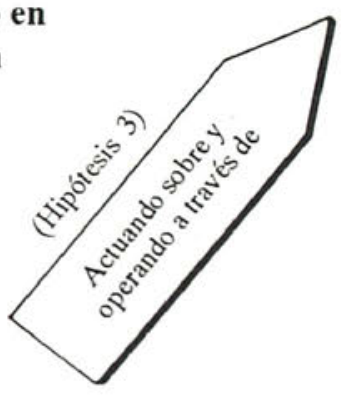

Prograna de capacitación del personal de campo

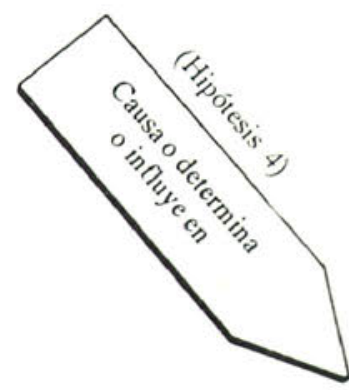

Tasas de aceptación de uso de anticonceptivos

En síntesis, para cada proyecto de investigación se deben formular 1) los objetivos últimos, 2) los objetivos inmediatos y 3) las hipótesis de investigación (a excepción de los estudios puramente exploratorios o descriptivos). Cada uno de estos rubros tiene una función.

1 Los objetivos últimos indican las repercusiones posibles y esperadas del estudio.

2 Los objetivos inmediatos indican lo que se realizará en el estudio.

3 Las hipótesis establecen una relación esperada entre dos o más variables.

\section{QUE HACER: Redacción de objetivos últimoss, objetivos inmediatos e hipótesis}

1 Hacer una lista de las variables principales a estudiar, distinguiendo entre variables dependientes e independientes. Las variables intermedias pueden clasificarse, según el caso, bajo ambos rubros. Las variables dependientes deben estar relacionadas directamente con el problema objeto de estudio.

2 Revisar la lista de las variables dependientes y redactar una descripción de los objetivos finales relacionados con el estudio. Hacerse la pregunta: ¿Cómo puede ayudar a los directores y responsables del programa, el conocimiento de los factores que influyen, causan o determinan los cambios en las variables dependientes? ¿En qué medida pueden ayudar los resultados del estudio a mejorar el sistema de prestación de servicios, o a perfeccionar los programas de capacitación y a elaborar mejor material educativo? En otras palabras, ¿cuáles serán las repercusiones esperadas del estudio? 
3 Redactar los objetivos a corto plazo del estudio. Detallar las acciones específicas que deben realizarse al igual que las variables que se desean medir, para que con esto se pueda responder a las siguientes preguntas:

a ¿Quién estará a cargo de las acciones?

b ¿Qué acciones de cada actividad y cuántas se realizarán?

C ¿A quiénes van dirigidas las acciones?

d ¿Cuándo se realizarán?

e ¿Dónde se llevarán a cabo estas acciones?

f ¿Con qué fines?

4 Finalmente, describir las hipótesis que el estudio se propone verificar. Revisar la lista de variables independientes y dependientes. ¿Cómo se relacionan estas variables? ¿Hay condiciones especiales que deban existir para que se relacionen? La redacción de las hipótesis deberá hacerse en forma positiva, no negativa. Habrá una hipótesis para cada una de las relaciones que se desee probar en el estudio. 


\section{Descripción de la intervención}

Si en el estudio se incluye una intervención, por ejemplo, probar un nuevo procedimiento de capacitación o comparar dos modalidades de prestación de servicios, deberá describirse ampliamente en la propuesta el tipo de intervención que se propone. Esencialmente se trata de elaborar sobre las preguntas que se propusieron y respondieron cuando se describieron los objetivos inmediatos, o sea: ¿quién lo hará?, ¿cuánto y qué?, ¿para quién?, ¿cuándo?, ¿dónde?, y ¿con qué propósito?

Específicamente, es importante responder en detalle a las siguientes preguntas:

\section{A ¿Quién será responsable de llevar a cabo la intervención?}

No es suficiente con indicar qué organización(es) será(n) responsable(s) de la implementación, sino el tipo de personal que va a participar (enfermeras, doctores, parteras, promotores, otros) y el papel que desempeñará cada uno.

\section{B ¿En dónde se llevarán a cabo las actividades?}

Debe especificarse claramente en dónde estará localizada la intervención. ¿Se implementará la intervención en toda una provincia, en un distrito, en diez aldeas, en treinta fábricas, o en cuatro clínicas? Hay que estar seguros de mencionar la localización de los lugares donde se efectuará el estudio.

\section{¿Con qué actividades se iniciará la intervención?}

Debe indicarse la secuencia de los eventos que se van a realizar. Por ejemplo, una intervención puede iniciarse con la capacitación de los trabajadores de campo. Deberá entonces describirse la naturaleza y duración de la capacitación. A continuación se piensa tener una serie de reuniones en la aldea, por lo tanto, se deberán indicar la frecuencia y propósito de estas reuniones. Finalmente, los trabajadores de campo visitarán, por lo menos, cinco hogares cada día durante un periodo de un año. Entonces, deberán describirse el propósito de las visitas y las actividades que se espera lleven a cabo los trabajadores durante las visitas. Cuando se describan las actividades, es también importante indicar el nivel o intensidad de cada una. Por ejemplo, si lo que se prueba es una campaña de IEC, deberá describirse detalladamente la naturaleza de la campaña. Se debe indicar el tipo de medios que se usarán (televisión, radio, periódico, folletos, afiches, reuniones con grupos, comedias, canciones); mencionar la intensidad de la campaña en los medios (100 afiches, 1000 folletos, tres cuñas radiales por día durante seis meses, un programa de televisión 
semanal durante tres meses); especificar quién producirá los afiches, folletos, guiones de radio y televisión, comedias y canciones, qué tipo de capacitación será necesario impartir y qué equipo especial se requerirá. En resumen, hay que dar los detalles y especificar las actividades.

\section{Ejemplo de descripción de una intervención: Africa}

Estudio experimental de investigación operativa en Gambia para proveer servicios de planificación familiar en el lugar de trabajo.

\section{Lugares de la intervención}

El estudio sobre planificación familiar en el lugar de trabajo será implementado por la Asociación de Planificación Familiar de Gambia (siglas en inglés GFPA). Todos los lugares de trabajo estarán localizados dentro o alrededor de Banjul. Los posibles lugares del estudio serán aquéllos con 100 empleados por lo menos, de los cuales 20 o más sean mujeres. Se estima que unos 25 lugares de trabajo tendrán estas características y que aproximadamente 15 o 20 de ellos aceptarán participar en el proyecto. Con base en esto, se calcula que los 15 lugares de trabajo tendrán aproximadamente 1500 empleados (15 lugares con 100 empleados), de los cuales 300 (1500 x .20) serán mujeres. De hecho se espera que el número total de empleados y de mujeres empleadas sea mucho mayor.

No obstante que en Gambia no existen grandes complejos industriales, hay varias empresas que tienen más de 100 trabajadores, como por ejemplo las cervecerías, hoteles, puertos marítimos y granjas comerciales. En algunos de estos negocios la mayoría de los empleados son mujeres. Por ejemplo, una planta limpiadora y empacadora de camarón emplea a más de 200 mujeres. La GFPA ya se ha puesto en contacto con varias de estas empresas para averiguar el interés que tendrían en participar en este estudio y todas ellas han expresado su interés.

Para asegurar su participación activa e informada en el proyecto, la GFPA organizará visitas y seminarios para los gerentes y representantes de trabajadores de las empresas antes que comience la intervención. El propósito de estos seminarios será exponer el diseño del proyecto y sus objetivos y convencer a los gerentes de las ventajas en el corto y largo plazo de participar en esta actividad. Los seminarios serán organizados en colaboración con el Ministerio del Trabajo y el Departamento Médico y de Salud.

\section{Actividades del estudio}

Las empresas que deseen participar en el proyecto serán estratificadas con base en el número de mujeres empleadas. Para este fin se harán dos estratos: 1) empresas con 20-49 empleadas y 2) empresas con 50 o más empleadas. Dentro de cada estrato se asignará a las empresas al azar a uno de tres grupos: servicios fijos, servicios móviles y un grupo de control. A continuación se describen las actividades de los dos grupos experimentales:

\section{A Puestos fijos de servicio}

Con la aprobación de la gerencia, se seleccionará un distribuidor de métodos de planificación familiar por cada 40 trabajadores en los lugares de servicios fijos. Los distribuidores recibirán, durante diez días, capacitación en planificación familiar y enfermedades sexualmente transmisibles (ETS). Antes de iniciar la fase de intervención se habrán completado cinco días de capacitación. Los siguientes cinco días de capacitación serán distribuidos a lo largo del periodo de intervención, un día a la vez. 
El trabajo principal del distribuidor consistirá en dar a sus compañeros de trabajo información sobre planificación familiar y ETS, vender condones y espermicidas, ganando una comisión por las ventas, y referir a las clínicas de GFPA a los compañeros que deseen métodos como DIU y esterilización. Cada distribuidor recibirá tres camisetas de colores brillantes, con el logo de GFPA, lo que ayudará a sus compañeros a identificarlos. Asimismo, los promotores recibirán un maletín para guardar los anticonceptivos y las formas para llevar los registros de usuarios.

Los lugares de servicios fijos serán visitados mensualmente por un educador de GFPA que es una partera capacitada. Una de las funciones principales de la educadora/partera de GFPA es vender los condones y espermicidas al distribuidor para su reventa a los clientes. El distribuidor podrá quedarse con la mitad del producto de las ventas. Actualmente una tira de cuatro condones cuesta aproximadamente 12 centavos. Por lo tanto, por cada tira de cuatro condones que venda, el distribuidor gana 6 centavos y GFPA recupera 6 centavos.

La educadora/partera de GFPA examina a las mujeres que desean píldoras y cuando es indicado, les da un ciclo inicial y las reabastece en visitas posteriores. Aunque las píldoras son gratuitas para las clientes, la educadora/partera cobrará un pequeño honorario a las usuarias de píldoras. Este mismo procedimiento se sigue en las clínicas de GFPA.

Además de reabastecer a las distribuidoras y dar píldoras a las nuevas usuarias y a las continuadoras, la educadora/partera también organiza reuniones con grupos de trabajadoras para hablar sobre ETS, métodos de planificación familiar, efectos colaterales y fuentes de abastecimiento. Se solicita a los gerentes de las empresas que den 15 minutos del tiempo de trabajo, cada dos semanas, para las sesiones educativas. Asimismo, se pide a las trabajadoras que den de su tiempo de descanso los mismos 15 minutos para las sesiones.

\section{B Servicios móviles}

Las empresas asignadas al grupo de servicios móviles recibirán visitas de la educadora/partera de GFPA cada dos semanas. La educadora organizará reuniones con grupos de trabajadoras para hablar sobre métodos de planificación familiar, efectos colaterales y fuentes de abastecimiento de anticonceptivos. Se solicitará a los gerentes de las empresas que den 15 minutos del tiempo de trabajo cada dos semanas para las sesiones educativas. También se pide a las trabajadoras que den de su tiempo de descanso los mismos 15 minutos para las sesiones. En las sesiones se dará también información sobre ETS y SIDA.

Además de lo anterior, la educadora/partera venderá condones y espermicidas a las clientes. El valor total de la venta será reintegrado a GFPA. Al igual que en lugares de servicios fijos, se distribuirán las píldoras gratuitamente, pero se cobrará un pequeño honorario por los servicios. Por lo que respecta a otros métodos como el DIU y la esterilización, la educadora/partera hará una cita en la clínica de GFPA más cercana para que asista la trabajadora.

\section{Reclutamiento y capacitación del personal de campo}

La GFPA cuenta actualmente con una planta de educadoras/parteras que tienen a su cargo los programas de información, educación y comunicación de la Asociación. De esta planta de parteras/educadoras, serán seleccionadas cuatro para trabajar en el proyecto de investigación operativa. Ellas serán responsables de llevar a cabo las actividades de campo, programar las visitas de educación a las empresas, vigilar las actividades de distribución de anticonceptivos, recoger las estadísticas de servicios indicando ventas, usuarias nuevas y continuadoras, y dar educación y capacitación en el lugar de trabajo a las distribuidoras. 
Dos educadoras/parteras serán responsables de las actividades en los lugares de servicios fijos y otras dos serán responsables de los lugares de servicios móviles.

Aunque las educadoras/parteras ya han recibido capacitación en las áreas șustantivas de planificación familiar, se organizará un programa corto de orientación para este estudio de investigación operativa. Esta orientación dará la oportunidad de hablar sobre el diseño del proyecto y de revisar los requerimientos y responsabilidades del personal de GFPA y de los distribuidores en el lugar de trabajo.

Un miembro del personal de GFPA servirá de asistente de investigación. El asistente de investigación entrevistará a los trabajadores y recolectará las estadísticas de servicios y otros datos importantes de los lugares de trabajo. La oficina de GFPA dará capacitación al asistente de investigación.

El reclutamiento de los distribuidores en el lugar de trabajo será coordinado por el Investigador Principal del proyecto con apoyo de dos educadoras/parteras. Se motivará a las empleadas de los lugares de trabajo para que seleccionen al distribuidor de su establecimiento. Se les darán los criterios de selección para ayudarles a identificar a los distribuidores más capaces. Los distribuidores seleccionados deberán mostrar interés en participar en el proyecto, tener actitudes positivas hacia el uso de anticonceptivos y tener el respeto de sus compañeros y de la gerencia.

Se pedirá a los distribuidores que participen en una sesión de capacitación de cinco días y en una serie subsecuente de cinco sesiones de capacitación de un día cada una, que serán conducidas por el personal de GFPA. Estas sesiones de capacitación serán programadas en días y horarios convenientes para los participantes y los capacitadores.

\section{QUE HACER: Descripción de la intervención}

1 Describa tan detalladamente como sea posible la intervención del proyecto.

2 Describa las actividades en el orden en que van a ocurrir.

3 Asegúrese de que la descripción de la intervención responde a las tres preguntas básicas:

a ¿Quién será responsable de la implementación?

b ¿Dónde tendrá lugar la intervención?

C ¿Qué actividades se van a iniciar, a qué nivel de intensidad? 


\section{Definiciones operacionales}

Después de haber formulado los objetivos e hipótesis y de haber descrito ampliamente la intervención del estudio, el siguiente paso en el proceso de la investigación es definir operacionalmente las variables y los términos que se emplearán en el estudio. Las definiciones operacionales sirven para dos propósitos esenciales: 1) establecer las reglas y procedimientos que el investigador usará para medir las variables; y 2) proporcionar los significados precisos de los términos que podrían interpretarse de distintas maneras. Toda propuesta de investigación debe incluir las definiciones operacionales de las variables y términos principales.

\section{A Definiciones operacionales de las variables}

Tomemos como ejemplo el conocimiento de planificación familiar como la variable independiente. Primeramente será necesario establecer la metodología que se adoptará para medir las variables, así como el sentido que se dará a la palabra "conocimiento" en materia de planificación familiar. Esta variable será definida mediante hechos observados que servirán como indicadores del fenómeno "conocimiento" relativo a la planificación familiar. En efecto, el término "conocimiento" no constituye, en sí mismo, un hecho observable ya que no se puede ver, oler, tocar, gustar, ni escuchar. Por lo tanto, el investigador recurrirá a una serie de preguntas cuyas respuestas servirán como hechos observables, es decir, como indicadores del "conocimiento". La encuesta podrá comprender estas preguntas:

"¿Ha oído hablar de la píldora anticonceptiva?" "¿Puede decirme con qué frecuencia se debe tomar para evitar un embarazo?" "¿Ha oído hablar del DIU?" "¿Puede decirme dónde se obtiene el DIU?" Cada una de estas preguntas constituye un indicador de un aspecto relativo al conocimiento en materia de anticoncepción. Todas las preguntas y respuestas representan hechos observables, susceptibles de ser medidos.

El estudio puede comprender 20 preguntas relativas al conocimiento. Por cada respuesta positiva, el encuestador podrá registrar un puntaje de 1 (uno) y por cada respuesta negativa un puntaje de 0 (cero). El puntaje final para cada encuesta en materia de conocimiento puede obtenerse sumando las respuestas positivas de las 20 preguntas. El puntaje puede variar de 0 a 20 . Las personas que hayan sacado 20 serán las que más conocimiento poseen en planificación familiar. En esta forma la variable "conocimiento en planificación familiar" puede definirse operacionalmente. En la propuesta de investigación, la variable puede definirse como sigue:

Conocimiento de planificación familiar $=$ número de respuestas positivas a las 20 preguntas sobre metodología anticonceptiva. 
Obviamente el ejemplo no constituye la única definición posible de la variable. Podríamos establecer distintas categorías de conocimiento, distinguiendo entre niveles alto, medio, bajo o nulo. Cada uno de estos niveles corresponde a una categoría de la variable y cada uno de estos niveles requieren de una regla a través de la cual se puede clasificar a toda persona encuestada dentro de alguna categoría.

Nivel elevado de conocimiento $=15$ o más respuestas correctas de las 20 preguntas.

Nivel medio de conocimiento $=$ mínimo de 8 y máximo de 14 respuestás correctas de las 20 preguntas.

Nivel bajo de conocimiento $=$ mínimo de una y máximo de siete respuestas correctas de las 20 preguntas.

Nivel nulo de conocimiento $=$ ninguna respuesta correcta de las 20 preguntas.

Debe señalarse que estas categorías son mutuamente exclusivas (no hay traslape). De esta manera las normas operativas adoptadas no permiten clasificar a un mismo individuo en dos diferentes categorías. Por otro lado, no existen más de cuatro categorías, ya que en estas cuatro se incluyen todos los niveles posibles de conocimiento.

En ocasiones es preferible no ser tan preciso en la definición previa de las categorías; es decir, optar por delimitar cada categoría una vez que se hayan recopilado y analizado los datos relativos a la variable. Como regla general, se podrían clasificar las respuestas de manera que resultaran categorías similares en número. De esta manera en el ejemplo precedente, cada una de las cuatro categorías debiera constar del $25 \%$ del total de las respuestas. En caso de que sea necesario conocer la distribución de las respuestas de la variable, antes de definir el procedimiento para establecer las categorías, los títulos de éstas podrán especificarse en la sección de "Definiciones operativas" de la propuesta de investigación, mencionando que cada categoría debe constar de un número similar de respuestas.

Cada variable debe tener al menos dos categorías de respuestas, de lo contrario sería una constante. Al definir operativamente una variable, es conveniente dividir ésta en varias categorías y no en sólo unas cuantas. En el ejemplo anterior, la variable "conocimiento en materia de planificación familiar" oscila entre 0 y 20 puntos, resultando en un total de 21 distintas categorías que se reagrupan en el segundo ejemplo en un número más pequeño de categorías, cuatro niveles distintos de conocimiento: alto, medio, bajo y nulo. Sería posible disminuir aún más el número de categorías, pasando de cuatro a dos solamente:

Conocimiento en materia de planificación familiar

Desconocimiento en materia de planificación familiar =
= al menos una respuesta correcta de las 20 preguntas.

\section{0 preguntas.}

Si se comienza con varias categorías, siempre será factible agruparlas después en un número más pequeño, pero lo contrario es imposible. En efecto, si se comete el error de partir de un número relativamente pequeño de categorías será imposible posteriormente realizar una agrupación mayor. En general el agrupamiento de las respuestas y el paso de un número elevado de categorías a un número más pequeño, se hace una vez que la recopilación de datos ha sido concluida y que se puede proceder con la distribución de frecuencias de la variable. 


\title{
1 Ejemplos de definiciones operacionales de las variables
}

\author{
Aceptación de la planificación familar \\ $=$ iniciar el uso de cualquier método \\ anticonceptivo moderno.
}
Desempeño de labores del personal de campo $=$ número de tareas realizadas por el personal de campo de las 20 previamente establecidas.
Mejoramiento en el desempeño del personal $=$ cualquier trabajador que reclute más aceptantes de planificación familiar, o haga más reuniones en las aldeas, o distribuya más paquetes de sales de rehidratación oral que lo que había logrado seis meses antes.
Actitud respecto a la planificación familiar $=$ número de respuestas positivas a 10 preguntas, que indican aprobación al uso de métodos anticonceptivos.

\section{B Definiciones operacionales de los términos}

Recuerde que una hipótesis de investigación expresa la relación probable que existe entre dos o más variables. En la misma forma en que tuvimos que definir operacionalmente las variables, tendremos que dar definiciones operacionales de la terminología que describe las relaciones entre las variables. Como ejemplo se pueden señalar los términos siguientes que se mencionan en la formulación de hipótesis:

\begin{tabular}{|l|l|}
\hline $\begin{array}{l}\text { más que } \\
\text { menos que } \\
\text { mayor que } \\
\text { menor que }\end{array}$ & $\begin{array}{l}\text { superior a } \\
\text { más numeroso que } \\
\text { más grande que } \\
\text { más pequeño que }\end{array}$ \\
\hline
\end{tabular}

También se pueden encontrar palabras como:

\begin{tabular}{|l|l|}
\hline $\begin{array}{l}\text { más seguro } \\
\text { aceptable } \\
\text { mejor }\end{array}$ & $\begin{array}{l}\text { significativo } \\
\text { extendido } \\
\text { incrementado }\end{array}$ \\
\hline
\end{tabular}

Cada uno de estos términos puede tener distinto significado y, por lo tanto, es necesario definirlos operativamente. El problema con los términos "más que" o "incrementado" es 
que ambos expresan una comparación sin indicar los parámetros de comparación. Se requiere saber "cuánto más" e "incrementado por cuánto".

Véase el siguiente ejemplo de hipótesis de investigación:

Un programa de capacitación práctica en el campo, de cinco semanas, resultará en el incremento de conocimientos en salud y planificación familiar del personal participante.

En esta hipótesis, el programa de capacitación constituye la variable independiente que ya ha sido en parte definida, por una duración de cinco semanas y por el hecho de tratarse de una capacitación práctica en el campo. El conocimiento en materia de planificación familiar constituye la variable dependiente que ya ha sido definida como el número de respuestas positivas a las 20 preguntas. Queda por definir el término "incremento de conocimientos" de lo contrario no es posible saber a partir de qué nivel será verificada o no la hipótesis. En otras palabras, se requiere de una escala de referencias que vaya demostrando los niveles de incremento. El término "incremento" puede ser definido en la siguiente forma:

Incremento $=$

El puntaje medio de conocimiento en planificación familiar obtenido por los participantes después de la capacitación, que es mayor y significativamente distinto del obtenido por un grupo de control que no recibió esta capacitación.

Debe señalarse que en esta definición operacional, no sólo se explica el significado de "incremento" sino que también se dice cómo se va a medir. El puntaje medio de conocimiento sobre planificación familiar obtenido por los participantes después del periodo de capacitación (grupo experimental) se compara con el puntaje medio obtenido por el grupo de control. Para ser totalmente claros, conviene definir lo que se entiende por "estadísticamente significativo":

Estadísticamente significativo $=$
Una probabilidad igual o mayor a .95 de que el puntaje medio de los capacitados sea mayor que el puntaje medio del grupo de control.

En resumen, las definiciones operacionales establecen las reglas y procedimientos que el investigador planea usar para medir y dar sentido a las variables y la terminología. Estas definiciones se harán mediante indicadores de hechos observables; se debe tener capacidad para hacer una pregunta, escuchar una respuesta, observar un comportamiento, registrar una acción, medir un hecho o característica. Las categorías deben ser mutuamente exclusivas y que incluyan todas las posibles eventualidades. En las definiciones operacionales, el investigador presentará por último una escala de referencias que le permitirá aceptar o rechazar la hipótesis propuesta.

\section{Ejemplos de definiciones operacionales de los términos}

Usuarios de métodos de planificación familiar $=$
Toda mujer casada entre 15 y 44 años de edad y todo hombre casado de más de 15 años que haya declarado haber utilizado, al menos una vez, un método anticonceptivo moderno, en el curso del mes pasado. 
Método anticonceptivo

moderno $=$

Mejoramiento del desempeño de labores del personal $=$

Aldea moderna $=$
Cualquiera de los siguientes métodos anticonceptivos: píldoras, DIU, esterilización femenina o masculina, espermicidas, condones y diafragmas.

Cualquier personal de campo de planificación familiar que reclute a más nuevos usuarios; lleve a cabo más reuniones, o distribuya mayor número de sobres de sales rehidratantes que lo que logró en los seis meses anteriores.

Toda aldea que cuente con tres o más de los elementos siguientes: electricidad, dispensario público, una calle pavimentada de más de $1 \mathrm{~km}$, escuela primaria, banco, oficina de correos, sistema de riego para el $50 \%$ o más de las tierras cultivadas.

\section{QUE HACER: Redacción de las definiciones operacionales}

1 Redactar una definición operacional para cada una de las variables dependientes e independientes.

2 Redactar una definición operacional para cada uno de los términos utilizados para describir la relación entre las variables.

3 Hacerse las siguientes preguntas sobre cada definición:

a ¿Han sido claramente formuladas las reglas y métodos para medir las variables?

b ¿Se han especificado bien las categorías de las variables tanto mutuamente exclusivas como inclusivas? 


\section{Diseño del estudio}

\section{A Confiabilidad y validez}

El diseño del estudio es el plan de acción del investigador para alcanzar los objetivos del mismo. Al seleccionar un diseño en particular, se busca aumentar al máximo la confiabilidad y validez de los datos y con esto reducir al mínimo los posibles errores en los resultados del estudio.

La confiabilidad se refiere a la consistencia, coherencia o estabilidad de los datos. El investigador necesita asegurarse de que, al medir una variable, los resultados sean confiables. Una medida confiable sería aquella en la que, si el estudio se repitiera por segunda vez, los resultados fueran los mismos que los obtenidos la primera vez. Si los resultados llegaran a ser diferentes, entonces la medición no sería confiable.

La validez se refiere a que los datos no solamente sean confiables, sino también verdaderos y exactos; es decir, un dato es válido hasta el punto en que representa lo que se supone debe representar. Si una medición es válida, también es confiable; pero en cambio no significa que si es confiable, sea siempre válida. Por ejemplo, considérese la siguiente pregunta: "¿qué edad tiene usted?" y la respuesta es "tengo 49 años". Para verificar la confiabilidad de la medición el investigador hace una segunda pregunta: "¿en qué mes y año nació usted" obteniendo la siguiente respuesta " en septiembre de 1941". Si la encuesta se está llevando a cabo en febrero de 1991, el encuestador verifica que la persona interrogada tiene realmente 49 años.

En este ejemplo se obtuvo un mismo resultado en las dos preguntas para medir la edad. Los resultados son consistentes y estables; es decir, son confiables. Supóngase ahora que el encuestador, por casualidad, llega a ver el acta de nacimiento de la persona interrogada y se percata de que su fecha de nacimiento es septiembre de 1938. El encuestador concluye que, aunque las primeras dos preguntas dieron resultados confiables, ello no condujo a resultados válidos o verdaderos.

\section{B Fuentes de error}

El investigador desea obtener información precisa y evitar las posibles fuentes de error que puedan invalidar los resultados del estudio. Por lo tanto, uno de los aspectos que deben tomarse en cuenta en el diseño del estudio, es el grado de control sobre aquellos factores que puedan originar fuentes de error. Si bien existe un buen número de éstas, a continuación se describen las fuentes de error más comunes.

\section{Efectos coyunturales}

Algunas veces, durante el desarrollo de un proyecto, ciertos acontecimientos tienden a disminuir o ampliar el efecto que se espera de éste. Estos acontecimientos, llamados coyunturales, suceden natural e inesperadamente, repercutiendo sobre los resultados del estudio. 
Supóngase, por ejemplo, que un grupo de trabajadores de campo toma un curso de capacitación a fin de mejorar el desempeño de sus labores y que, al cabo de seis meses, los resultados de una evaluación indican que no hubo progreso alguno en su capacitación. Se podría concluir que el programa de capacitación fracasó. Pero al analizar los hechos más a fondo se observa que, después del curso, dichos trabajadores decidieron ir a una huelga de tres semanas para obtener aumentos salariales. Esta huelga no estaba prevista en el proyecto y repercute en el resultado de la evaluación, constituyendo un factor coyuntural o fuente de error. Entonces, la pregunta que surge es ¿fue el programa de capacitación ineficaz?

Si de alguna manera pudiera controlarse el efecto de la huelga, ¿podría evaluarse el impacto del curso de capacitación sobre el desempeño de labores de los trabajadores? En otras palabras, ¿cuál es el efecto verdadero del programa de capacitación? La respuesta a esta pregunta dependerá de la forma en que la investigación haya sido diseñada.

Considérese otro ejemplo. Se desea evaluar el impacto de una campaña de motivación sobre los conocimientos y actitudes de la población en materia de planificación familiar. Una forma de realizarlo, consistiría en llevar a cabo una encuesta antes y después de la campaña con el fin de comparar los resultados. Esta comparación podría mostrar un aumento en los conocimientos sobre planificación familiar y actitudes más favorables hacia el control natal. Es muy probable que el investigador concluya que la campaña fue un éxito y que sus objetivos fueron satisfechos. Pero, supongamos que durante el transcurso de su campaña, el presidente del país hizo una declaración a nivel nacional por radio y televisión sobre el rápido crecimiento de la población y la utilidad de la planificación familiar.

La cuestión que se plantea aquí es determinar si el aumento de conocimientos y cambio de actitud sobre la planificación familiar se debieron a la campaña de motivación o a la declaración presidencial, o a ambos factores. La declaración presidencial constituye en este contexto un factor coyuntural. En este ejemplo, el efecto de la campaña de motivación sobre los conocimientos y actitudes de la población difícilmente podrá medirse; es decir, a menos que el diseño del estudio lo permita, el efecto de la campaña motivacional no podrá separarse del efecto coyuntural (declaración presidencial).

\section{Efectos de selección}

En ocasiones sucede que las características de las personas que forman el grupo de control son diferentes de aquéllas que constituyen el grupo experimental, lo cual constituye un problema para la validez de los resultados. Por ejemplo, supóngase que un programa especial de incentivos en planificación familiar se ofrece a gente del distrito A (grupo experimental), pero no se ofrece a la gente del distrito $\mathrm{B}$ (grupo de control). Al cabo de un año, el programa de incentivos es evaluado en ambos distritos en términos de tasas de prevalencia de uso de métodos de planificación familiar. Esta evaluación muestra un aumento significativo en la tasa de prevalencia del distrito A en relación con el distrito B, por lo cual el investigador podría concluir que el programa ha sido exitoso. Sin embargo, un análisis más profundo revela que las características de ambos distritos son muy diferentes. Los habitantes del distrito A son en general más jóvenes, más instruídos, más urbanizados, y tienen un nivel económico más alto que los del distrito B; por lo tanto, las personas pertenecientes al grupo experimental son más susceptibles de adoptar la planificación familiar con o sin un programa especial de motivación. Aquí se plantea una vez más la cuestión de validez del programa: ¿cuál fue el verdadero efecto del programa de incentivos en planificación familiar? Si ambos grupos hubieran sido similares, podríamos responder a esta pregunta; pero debido a las diferencias iniciales, el efecto del programa de incentivos no puede medirse separadamente de las diferencias originadas por el efecto de selección.

\section{Efectos de repetición u observación repetitiva}

Cuando una evaluación o prueba se aplica antes y después de un curso o programa, generalmente la primera evaluación tiende a tener un efecto sobre la segunda. Las 
respuestas que se obtienen en la evaluación final (al concluir el estudio) son generalmente más acertadas cuando el individuo interrogado fue sometido previamente a una evaluación similar, ya que el individuo puede recordar las preguntas y errores cometidos en la primera. De ahí que los resultados de la evaluación final pueden reflejar los efectos de la pre-evaluación y no los del programa en sí (por ejemplo, en el caso de un curso de capacitación).

Esta situación se produce en las encuestas sobre conocimientos, actitudes y prácticas anticonceptivas (CAP), cuando éstas se efectúan a las mismas personas año atrás año. Al cabo de cierto tiempo, las personas interrogadas logran responder adecuadamente a preguntas como: "¿Podría usted mencionar tres métodos anticonceptivos modernos?" La respuesta puede reflejar la experiencia previa de otras encuestas CAP y no un incremento en conocimientos de planificación familiar como resultado de un programa educativo. De esta manera, el efecto de repetición entra en juego cuando se aplica varias veces el mismo examen a la misma gente, pudiendo invalidar los resultados del estudio.

\section{Efectos de los instrumentos de evaluación}

Otro tipo de efecto que puede presentarse y que es independiente del proyecto o programa, se origina por las modificaciones que sufre el instrumento de evaluación (por ejemplo un cuestionario) entre la etapa de pre-evaluación y la de evaluación final.

Si durante la pre-evaluación y con objeto de medir el grado de conocimientos en la materia, se hace la pregunta "¿Ha oído hablar de la planificación familiar?" y en la evaluación final la pregunta se cambia a "¿Podría citar tres métodos anticonceptivos modernos?", es probable que se llegue a resultados distintos y esta diferencia puede deberse a la modificación de la pregunta. El mismo tipo de efecto puede producirse cuando los encuestadores adquieren más experiencia. Un encuestador experimentado puede obtener datos más completos que uno sin experiencia. La mayor calidad de los datos obtenidos en esta forma puede ser el resultado de la capacidad de los encuestadores para hacer preguntas u observar hechos y no al programa que se pretende evaluar. De este modo, los cambios en la manera de recopilar información o en los instrumentos usados para ello, pueden repercutir en la validez de la información.

\section{Efectos de maduración}

A través del tiempo, las personas (y las cosas) cambian. En programas de capacitación de larga duración, no es raro que las personas a las que se esté capacitando se cansen, pierdan el interés, se desesperen o inclusive se decepcionen. Asimismo, particularmente en aquellos estudios longitudinales que duran varios años, la gente se hace más conocedora, más prudente, más resistente y, desde luego, más vieja, es decir, la gente madura con el tiempo. Este proceso de maduración puede provocar efectos independientes de los que se pretenden alcanzar con un nuevo programa. En esta forma, si a un grupo de personas fatigadas, con hambre o con falta de interés se les aplica una evaluación final, es de esperarse que los resultados, en promedio, sean más bajos que los que se hubieran obtenido si las personas hubieran estado en mejor forma. Al comparar estos resultados con los de la pre-evaluación, se podría constatar que la diferencia es muy pequeña y concluir que el curso de capacitación no tuvo éxito. Pero, ¿es éste realmente el caso? o es que los resultados se deben al efecto de la maduración, que es otro problema para la validez.

\section{Efectos de desaparición o pérdidas en la muestra}

En estudios de cohortes, también denominados estudios de panel, estos efectos suceden cuando se hace seguimiento de un mismo grupo de individuos a través del tiempo, ya que algunos de ellos desaparecen durante el periodo de observación. En la segunda encuesta a 
veces es imposible localizar a todos los individuos que fueron interrogados en la primera. Esto constituye una pérdida de la muestra para llevar a cabo el seguimiento y los efectos son más obvios cuando los individuos que desaparecieron poseen características distintas de las de aquellos que pueden ser localizados en la segunda encuesta. De ahí que, en algunas ocasiones, las diferencias observadas entre los resultados de ambas encuestas obedecen en parte al efecto de la pérdida de la muestra y no al efecto del programa en sí.

$\mathrm{Al}$ diseñar el estudio, es importante examinar cuidadosamente las fuentes posibles de error: efectos de selección, de repetición, de instrumentos de evaluación, de maduración y de desaparición. A menos que estén bajo el control del investigador, cada uno de estos efectos es una posible explicación de por qué un programa tuvo o no un determinado efecto. En otras palabras, siempre es necesario distinguir entre los efectos propios de un programa y los que son resultado de otros fenómenos colaterales (fuentes de error).

\section{Tipos de diseños de estudio}

Aquí se mencionan los diseños más comúnmente empleados en estudios sobre planificación familiar. Estos diseños pueden clasificarse en no-experimentales, cuasi-experimentales y experimentales. Para describir estos diseños, se recurre a la notación desarrollada por Campbell y Stanley (ver bibliografía) y explicada en la Figura 7.1.

FIGURA 7.1

Notación para diseños de estudio.

Grupo Experimental

$\mathbf{A A}$
Grupo de Control Tiempo
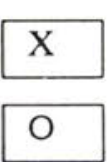

O y X en un renglón

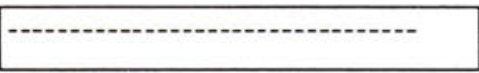

= Asignación aleatoria de casos (sujetos, interrogados, pacientes, otros) al grupo experimental y al grupo de control.

$=$ El transcurrir del tiempo. El extremo izquierdo de un diseño representa el principio de un proyecto o estudio y el extremo derecho su final.

= Un programa o experimento de intervención.

= Una medida de observación. Para distinguir una observación de otra, por ejemplo, $\mathrm{O}_{1}, \mathrm{O}_{2}, \mathrm{O}_{3}, \mathrm{O}_{4}$.

= Un renglón o línea conteniendo un solo grupo de sujetos.

= La separación de dos grupos que no se asignaron aleatoriamente.

Ejemplo de un diseño de estudio

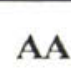

Grupo Experimental

Tiempo

AA

Grupo de Control

$\mathrm{O}_{1} \times \mathrm{O}_{2}$

$\mathrm{O}_{3}$

$\mathrm{O}_{4}$ 
En este diseño los individuos de una misma población se asignan aleatoriamente (AA) a dos grupos: uno de control y otro experimental. Cada grupo es objeto de una medición o evaluación inicial (pre-evaluación $\mathrm{O}_{1} \mathrm{y} \mathrm{O}_{3}$ ). Al grupo experimental se le aplica un "programa de intervención" y el grupo de control no recibe ninguna "intervención". Al final del programa cada grupo es objeto de una nueva medición $\left(\mathrm{O}_{2}\right.$ y $\left.\mathrm{O}_{4}\right)$. Dado que el programa de intervención $(X)$ fue aplicado al grupo experimental, se espera que $\mathrm{O}_{2}$ sea mayor que $\mathrm{O}_{4}$. Asimismo, debido a que los individuos fueron asignados aleatoriamente, tanto al grupo experimental como al grupo de control, se espera que $\mathrm{O}_{1}$ sea igual a $\mathrm{O}_{3}$ en lo que se refiere a ciertas variables clave como edad, sexo, paridad y educación.

El diseño de investigación antes descrito constituye un experimento "modelo", ya que permite controlar al máximo diferentes fuentes de error. Este diseño sirve como punto de referencia para describir otros que a continuación se presentan.

\title{
1 Diseños no-experimentales
}

Existen varios diseños no-experimentales empleados comúnmente por investigadores en planificación familiar. Estos diseños se adaptan particularmente a estudios de tipo descriptivo, o bien cuando el estudio consta de pocos casos; no son recomendables para evaluar el impacto de un programa de intervención, pero pueden ser útiles para diagnosticar las causas posibles de un problema.

\section{a Diseño post-evaluatorio}

\author{
Grupo Experimental $\frac{\text { Tiempo }}{\mathrm{X} \mathrm{O} \quad \mathrm{O}_{1}}$
}

Con este diseño se realiza una medición o evaluación $\mathrm{O}_{1}$ después de la aplicación de un programa de intervención $(\mathrm{X})$. Dado que no hay grupo de control, no existe la posibilidad de comparar la medición $\mathrm{O}_{1}$ con otra, por lo que lo único que puede proporcionar la medición $\mathrm{O}_{1}$ es información descriptiva. Los efectos coyunturales, de selección, de maduración y desaparición del campo de observación, constituyen posibles fuentes de error que no son controlables y que hay que tener en cuenta. Este enfoque es útil en investigaciones que tienen como objetivo conocer, por ejemplo, las características demográficas de las usuarias del DIU o de las que se someten a esterilización. La adopción de uno de estos métodos de planificación familiar se representa con (X) y las características demográficas observadas se representan con $\left(\mathrm{O}_{1}\right)$. Si bien existen numerosos problemas asociados con este tipo de diseño, especialmente cuando se pretende hacer un análisis comparativo, este diseño puede proporcionar información útil sobre el programa, si se recurre a técnicas de análisis multivariado (ver Capítulo 10 Sección B.2.f).

\section{b Diseño pre y post-evaluatorio}

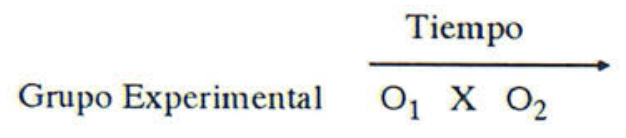


Aquí tampoco se tiene un grupo de control, pero al menos existe una medición inicial $\mathrm{O}_{1}$ que permite examinar cambios a través del tiempo. Es importante tomar en cuenta que las posibles fuentes de error, tales como efectos coyunturales, de repetición, de duración, de modificaciones al proyecto y de instrumentos de recopilación, pueden estar presentes en este diseño.

\title{
C Comparación estática entre grupos
}

\author{
Grupo Experimental \\ Grupo de Control
}

$\frac{\text { Tiempo }}{\stackrel{\mathrm{X} \quad \mathrm{O}_{1}}{\mathrm{O}}}$

Contrariamente a los dos diseños precedentes, éste utiliza un grupo de control o de comparación. Se efectúa una observación $\left(\mathrm{O}_{1}\right)$ sobre el grupo experimental después de la aplicación de un programa de intervención $(\mathrm{X})$. Esta observación es comparada con la correspondiente a la del grupo de control $\left(\mathrm{O}_{2}\right)$, el cual no recibió programa de intervención. Nótese que, ambos grupos están separados por una línea discontinua (-----), lo cual indica que no se usó un proceso aleatorio para formar los dos grupos.

Este diseño puede ser utilizado para medir, por ejemplo, la evolución que se manifestó entre los pacientes de una clínica tras la introducción de un programa especial (grupo

experimental), mediante la comparación con la situación de otra clínica que no fue sometida a ningún programa (grupos de control). Las principales fuentes de error las constituyen, en este caso, los factores relativos a la selección y a la desaparición de individuos. Las características tales como la edad, paridad e instrucción pueden diferir grandemente de un grupo a otro. Además, es posible que muchos de los pacientes del grupo experimental que recibieron el programa de intervención (X) se pierdan y no se les pueda hacer la observación $\mathrm{O}_{1}$. Por lo tanto, las diferencias entre $\mathrm{O}_{1}$ y $\mathrm{O}_{2}$ pueden deberse a efectos de selección y desaparición, y no al programa de intervención (X).

\section{Diseños experimentales}

\section{a Pre-evaluatorio y post-evaluatorio con un grupo de control}

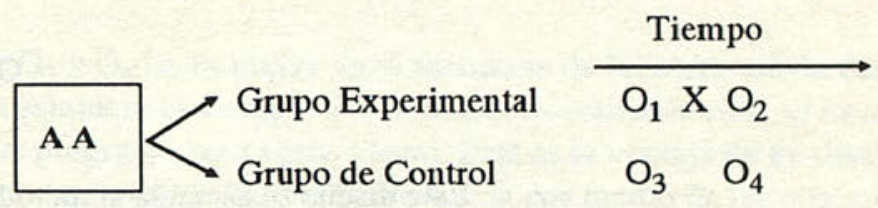

Este procedimiento, típicamente experimental, ya ha sido discutido anteriormente. Se caracteriza principalmente por una asignación aleatoria (AA) de los individuos del grupo de control y del experimental. Esto permite suponer que ambos grupos tengan las mismas características que tenían antes del programa de intervención; es decir, si la aleatoriedad se lleva a cabo adecuadamente, se sabe que existe una probabilidad de diferencia entre los dos grupos. Por lo tanto, dado que, antes de la intervención los dos grupos son prácticamente iguales, cualquier diferencia que exista entre las observaciones $\mathrm{O}_{2}$ y $\mathrm{O}_{4}$ será atribuible a los 
efectos del programa (X). Este diseño permite controlar eficazmente los efectos de las fuentes posibles de error. Sin embargo, esta concepción teórica es a veces difícil de realizar en la práctica, ya que con frecuencia es imposible distribuir a los individuos en forma aleatoria entre los dos grupos. Por razones éticas o programáticas, a veces es imposible negar la intervención de un programa a un grupo y ofrecérsela a otro. Pero existen, sin embargo, algunas situaciones donde la asignación de casos aleatorios es posible; por ejemplo, cuando la demanda de un servicio es mayor que la oferta. Esta situación ocurre algunas veces cuando se introduce un nuevo método anticonceptivo como el NORPLANT ${ }^{\circledR}$. La disponibilidad del anticonceptivo puede ser muy limitada, pero la demanda potencial muy alta. Una situación similar ocurre cuando eí número de personas que requiere capacitación excede al número de plazas disponibles en un curso de capacitación particular. En estas instancias, los "casos" experimentales pueden seleccionarse de manera aleatoria, escogiendo de entre los clientes potenciales de NORPLANT ${ }^{\circledR}$ o de las personas que requieren capacitación. Las personas no seleccionadas se convierten en el grupo de control.

\section{b Post-evaluatorio con grupo de control}

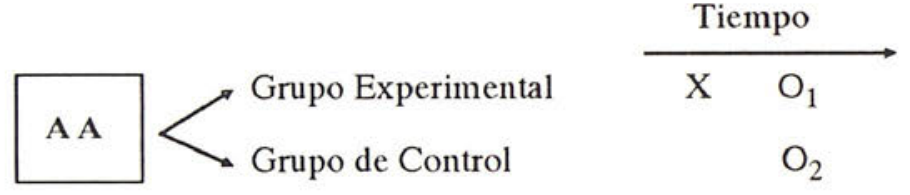

Este diseño constituye una variante del anterior, difiere de aquél por la ausencia de una pre-evaluación. Debido a la asignación aleatoria de los individuos entre los dos grupos, se supone que las situaciones al inicio son idénticas. Después de la introducción del programa, la comparación de la situación del grupo experimental con la del grupo de control, permite medir los efectos posibles del programa. Sin embargo, la carencia de una pre-evaluación no permite estimar el grado de modificación dentro del grupo experimental.

\section{Diseños cuasi-experimentales}

Frecuentemente, en la práctica, resulta muy costoso y bastante difícil, a veces imposible, cumplir con el criterio aleatorio de un diseño experimental. Es, por lo tanto, deseable evitar las posibles fuentes de error asociadas a los métodos no-experimentales. Una alternativa consiste en utilizar diseños cuasi-experimentales, que sin tener las restricciones que conlleva una selección aleatoria, permiten controlar muchas de las fuentes de error.

\section{a Series de tiempo}

\section{Grupo Experimental}

Tiempo

$\mathrm{O}_{1} \mathrm{O}_{2} \mathrm{O}_{3} \times \mathrm{O}_{4} \mathrm{O}_{4} \mathrm{O}_{5} \mathrm{O}_{6}$

Este diseño se asemeja al método no-experimental que utiliza una pre-evaluación y una post-evaluación con la ventaja de que hace observaciones repetidas antes y después del programa (X). Por ejemplo, si no se presenta ninguna variación entre $\mathrm{O}_{1}, \mathrm{O}_{2}$ y $\mathrm{O}_{3}$ pero se produce una variación brusca entre $\mathrm{O}_{3}$ y $_{4}$ manteniéndose presente en $\mathrm{O}_{5}$ y $\mathrm{O}_{6}$, se puede concluir, con un alto grado de confianza, que esta súbita variación obedece a los efectos del programa $(\mathrm{X})$. Estas variaciones se representan gráficamente en la Figura 7.2.

Supongamos que en este ejemplo el programa de intervención (X) lo constituye una campaña de educación a gran escala destinada a incrementar el nivel de conocimiento de la 
población en materia de planificación familiar. Las observaciones $\mathrm{O}_{1}, \mathrm{O}_{2}$ y $\mathrm{O}_{3}$ revelan que, antes de la introducción del programa, solamente el $30 \%$ de la población adulta de una región determinada conocía y comprendía el significado de planificación familiar. Las observaciones $\mathrm{O}_{4}, \mathrm{O}_{5}$ y $\mathrm{O}_{6}$ efectuadas después del programa, revelan que este nivel subió al $50 \%$. La causa más probable de este cambio es la campaña educativa, sin embargo la existencia de un acontecimiento coyuntural entre $\mathrm{O}_{3}$ y $\mathrm{O}_{4}$, podría también ser el motivo del cambio.

Aun cuando puedan estar presentes los efectos coyunturales o relativos al instrumento de medición, las series de tiempo permiten evitar al investigador errores o falsas conclusiones. Nótese en la Figura 7.3 que existe un incremento porcentual constante y continuo en el tiempo.

FIGURA 7.2

Incremento repentino en una variable después de la intervención de un programa.

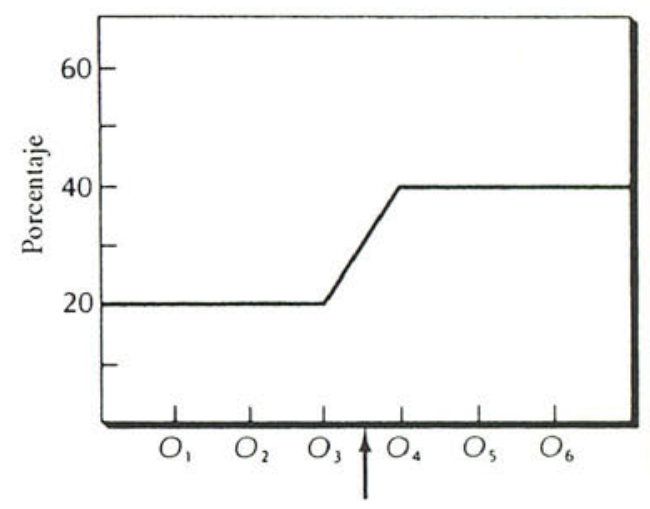

Intervención del programa $(X)$

FIGURA 7.3

Incremento constante en una variable antes y después de la intervención de un programa.

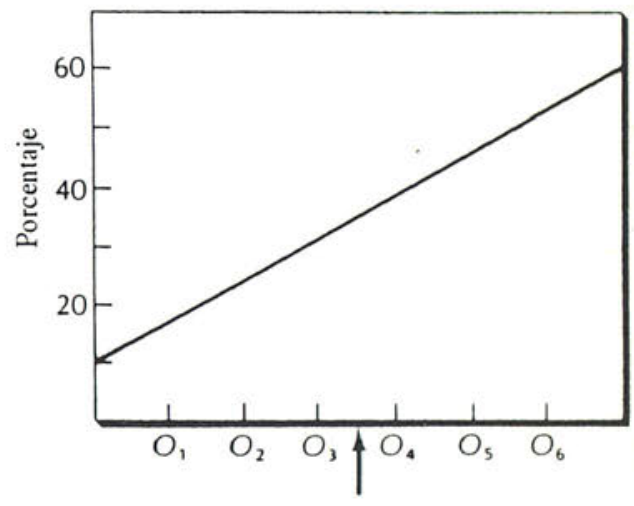

Intervención del programa (X)

El crecimiento entre $\mathrm{O}_{3}$ y $\mathrm{O}_{4}$ no es mayor en el momento de la intervención del programa (X) de lo que es en cualquiera otra etapa. Obviamente, en esta situación, el investigador no puede concluir que el programa tuvo algún efecto. Esta es la ventaja de un diseño de series de tiempo, el cual permite conocer cuál es la tendencia por medio de las observaciones. Si el investigador hubiera recurrido al método de pre-cvaluación y post-evaluación, en lugar de las series de tiempo y hubiera comparado únicamente $\mathrm{O}_{3}$ contra $\mathrm{O}_{4}$, habría concluido que la introducción del programa había tenido un efecto positivo, lo cual es inexacto.

Examínese la Figura 7.4, en la cual aparece un comportamiento regular y sistemático en las altas y bajas de los porcentajes. La introducción del programa no parece haber cambiado esta tendencia, pero, nuevamente, se podría haber concluido que el programa había tenido 
algún impacto de haberse comparado $\mathrm{O}_{3} \mathrm{y}_{4}$ recurriendo a un procedimiento que empleara una pre-evaluación y una post-evaluación.

El método de series de tiempo conviene cuando se tiene acceso a un sistema periódico y regular de recopilación de datos, tal como estadísticas mensuales de servicio. Los datos, así como el momento de introducción del programa, pueden marcarse en una gráfica. Si antes o después de la introducción del programa la curva muestra un cambio brusco muy diferente a la tendencia registrada antes o después del programa, se puede deducir, con bastante seguridad, que el cambio fue producido por el programa.

Considérese la Figura 7.5 y supóngase, en este ejemplo, que cada mes el $40 \%$ de los nuevos usuarios de métodos anticonceptivos opta por la esterilización. La cifra está apoyada por las observaciones $\mathrm{O}_{1}, \mathrm{O}_{2}$ y $\mathrm{O}_{3}$. Posteriormente, se emprende una vasta campaña de información y educación. La observación $\mathrm{O}_{4}$ demuestra que el porcentaje de mujeres que recurre a la esterilización pasa a ser el $70 \%$, pero después de transcurrido algún tiempo, el porcentaje vuelve a descender a $40 \%$. Por lo tanto, la campaña realizada tuvo resultados positivos pero éstos no duraron. De haber recurrido, en este caso, al empleo de una pre-evaluación y una post-evaluación, se hubiera concluido erróneamente un éxito rotundo de la campaña de información y educación por la mera comparación de las observaciones $\mathrm{O}_{3}$ y $\mathrm{O}_{4}$. El carácter temporal de los resultados no habría sido detectado.

En conclusión, a pesar de la ausencia de un grupo de control y de los efectos de las posibles fuentes de error, como los efectos coyunturales o del instrumento de medición, un diseño de series de tiempo permite un análisis más detallado de los datos y un mejor diagnóstico del impacto del programa, comparado con el diseño que utiliza una pre y post-evaluación, ya que el diseño de series de tiempo porporciona información sobre las tendencias observadas antes y después de la intervención. Este diseño es el más aconsejable cuando se pueden realizar observaciones múltiples antes y después de la intervención.

FIGURA 7.4

Incrementos y decrementos periódicos en una variable antes y después de la intervención de un programa.

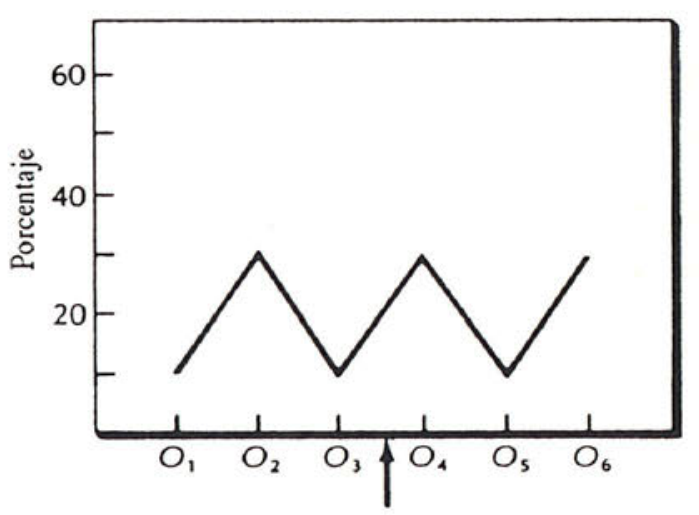

Intervención del programa (X)

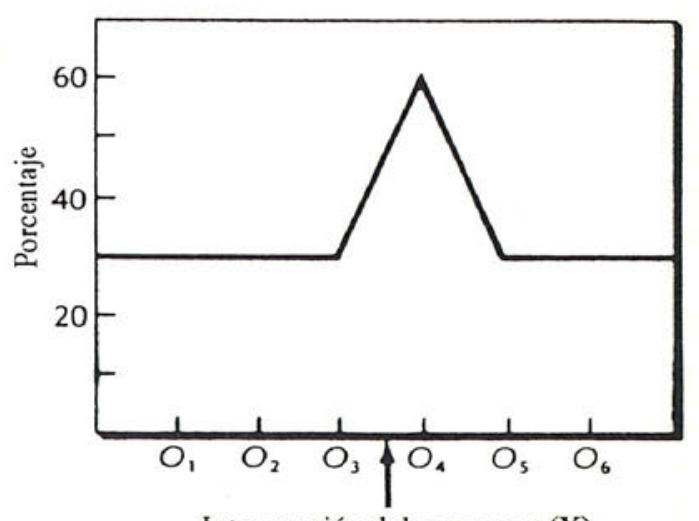

Intervención del programa (X)
FIGURA 7.5

Impacto temporáneo de la intervención de un programa. 


\title{
b Grupo de control no equivalente
}

\author{
Grupo Experimental \\ Grupo de Control no equivalente
}

Tiempo

\begin{tabular}{ccc}
\hline $\mathrm{O}_{1}$ & $\mathrm{X}$ & $\mathrm{O}_{2}$ \\
\hdashline $\mathrm{O}_{3}$ & $\mathrm{O}_{4}$
\end{tabular}

En general, es posible confrontar los datos observados en un grupo experimental con los observados en un grupo de control que presenta ciertas características similares, pero no necesariamente equivalentes. Supóngase, por ejemplo, que se desea evaluar los efectos de un programa de capacitación. Grupos de 20 individuos pueden tomar el programa (X) organizado por el centro de formación con una pre-evaluación $\left(\mathrm{O}_{1}\right)$ y una evaluación final $\left(\mathrm{O}_{2}\right)$. Los datos obtenidos podrían confrontarse con los observados en un grupo que no hubiera tomado el curso de capacitación, pero a quien se le hubiera aplicado la misma preevaluación $\left(\mathrm{O}_{3}\right)$ y la misma post-evaluación $\left(\mathrm{O}_{4}\right)$. La información obtenida en las dos pre-evaluaciones $\left(\mathrm{O}_{1}\right)$ y $\left(\mathrm{O}_{3}\right)$ puede servir, en este caso, para medir la similitud de las características de los dos grupos. En seguida se comparan las dos post-evaluaciones $\left(\mathrm{O}_{2}\right.$ y $\mathrm{O}_{4}$ ) y se espera que $\mathrm{O}_{2}$ sea mayor que $\mathrm{O}_{4}$ debido al efecto del programa de capacitación (X).

Este método se adapta bien a la evaluación de cursos de capacitación o de los efectos de un programa de intervención aplicado en una zona geográfica determinada (un distrito por ejemplo). En este último caso, los datos observados pueden compararse con los datos de una zona limítrofe similar, pero no necesariamente equivalente, que no se hubiera beneficiado del programa. Es primordial, en este método, analizar y comparar adecuadamente los datos proporcionados por las pre-evaluaciones $\left(\mathrm{O}_{1}\right.$ y $\left.\mathrm{O}_{3}\right)$ y detectar los efectos posibles de selección y de las características diferenciales del grupo experimental y del grupo de control no equivalente, a fin de tomarlos en cuenta paraexplicar diferencias (o ausencia de ellas) en las post- evaluaciones $\mathrm{O}_{2}$ y $\mathrm{O}_{4}$.

\section{c Muestras independientes para la pre-evaluación y post-evaluación}

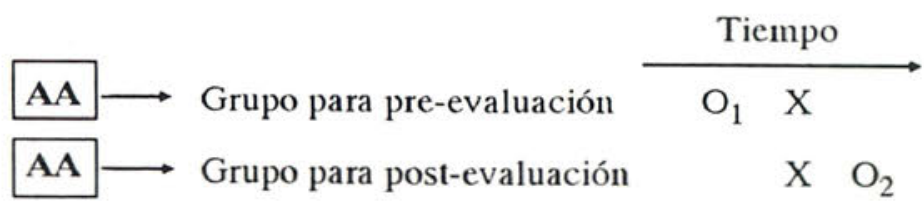

Este procedimiento se emplea frecuentemente en estudios de planificación familiar. Se efectúa una pre-evaluación $\left(\mathrm{O}_{1}\right)$ sobre una muestra aleatoria de la población que se va a beneficiar de un programa. A continuación se introduce la intervención y se efectúa una post-evaluación $\left(\mathrm{O}_{2}\right)$, usando una segunda muestra aleatoria tomada de la misma población. Ese diseño es conveniente para evitar los efectos de repetición, pero no permite controlar otras fuentes de error, como efectos coyunturales, de desaparición, de duración o de modificaciones del instrumento de medición. 


\section{Selección de un diseño de investigación}

Seleccionar un diseño apropiado de investigación operativa puede ser complicado. En este punto del estudio hay que tener presentes algunas consideraciones sobre los aspectos éticos y se debe, al mismo tiempo, equilibrar el manejo de los aspectos técnicos y los prácticos y administrativos.

\section{Aspectos éticos}

La primera cuestión a considerar cuando se selecciona un diseño de investigación es la ética. Si un diseño de investigación conduce a procedimientos faltos de ética, o se violan los derechos y dignidad de las personas, o se niegan servicios que de otra manera estarían disponibles, entonces el diseño debe modificarse o abandonarse, sin importar el efecto que esto tenga sobre la confianza, la validez, el tiempo, los fondos, o la disponibilidad del personal. Si no se puede realizar un estudio dentro de la ética, entonces el estudio no debe hacerse. No puede existir ningún compromiso sobre este punto.

\section{Aspectos prácticos y administrativos}

Todos los investigadores sueñan con tener para sus estudios muchos fondos disponibles, además de tiempo, personal y equipo (la mejor computadora, una impresora láser, quizá un vehículo para transportarse). Desgraciadamente los sueños no siempre se hacen realidad. Es más común que los fondos sean escasos, que el tiempo sea corto, que haya poco personal y que no haya equipo, o que si hay esté obsoleto. Obviamente estas condiciones afectan a la investigación y, en particular al diseño de la investigación operativa. Los fondos, el tiempo y el personal disponibles no permitirán que se diseñen tres grupos experimentales y uno de control. Puede ser que no permitan una encuesta pre-evaluatoria y una de seguimiento a los 24 meses. Puede ser que no permitan hacer la intervención durante 36 meses. Todos estos asuntos prácticos y administrativos afectan irremediablemente la selección de un diseño de investigación.

\section{Aspectos técnicos}

Aunque el objetivo técnico en la selección de un diseño de investigación es minimizar los posibles errores, la dinámica en el campo en la mayoría de los estudios de investigación operativa, presenta generalmente una gran cantidad de problemas para la confiabilidad y validez del estudio. Casi siempre, los estudios experimentales de campo se enfrentan a eventos no previstos como el cierre de un centro de servicios, la transferencia de personai clave, disturbios sociales, una inundación, o acontecimientos de este tipo que afectan el diseño de investigación o que cambian la intervención. Los efectos que estos eventos tienen en la confiabilidad y validez de un estudio son poco claros o, a veces, inclusive se desconocen, pero definitivamente son importantes. En la selección de un diseño de investigación hay algunos asuntos técnicos que deben tomarse en cuenta:

a Cuando sea posible, deben crearse los grupos experimental y de control asignando los casos de manera aleatoria, usando un solo grupo de la población.

b Cuando no sea posible la asignación aleatoria, debe tratarse de encontrar un grupo de comparación que sea casi equivalente al grupo experimental. 
C Cuando no exista un grupo de control asignado aleatoriamente ni un grupo similar de comparación, se puede usar un diseño de series de tiempo que dará información sobre las tendencias antes y después de una intervención (X).

d Si no se puede usar un diseño de series de tiempo, debe tratarse de obtener como mínimo, antes de iniciar el programa, información pre-evaluatoria que podrá ser comparada con información posterior a la intervención del programa (diseño pre y post-evaluatorio).

e Si no se dispone de información pre-evaluatoria, existen limitaciones al tipo de análisis que se puede efectuar. En este caso se puede recurrir a técnicas de análisis multivariado.

f Hay que tener siempre presente el asunto de la validez. ¿Son verdaderas las medidas? ¿Hacen lo que se supone deben hacer? ¿Existen posibles fuentes de error (coyunturales, de selección, de la prueba, de madurez, de desaparición, o de los instrumentos) que expliquen los resultados?

\section{E Lineamientos para seleccionar un "buen" diseño de investigación}

1 Un buen diseño de investigación es ético. Es un diseño que no viola los derechos humanos, ni hieren su dignidad ni les niega la calidad en los servicios.

2 Un buen diseño de investigación es aquel que es capaz de obtener los datos más confiables y válidos dentro de las limitaciones de fondos, tiempo, personal y equipo.

3 Un buen diseño de investigación es aquel que es capaz de medir todo lo que pase en el campo, tanto el impacto de las actividades planeadas como el impacto de las actividades no planeadas y hasta el de los eventos que lo invalidan.

4 Un buen diseño de investigación es aquél que ayuda a un investigador a evitar conclusiones erróneas, como aceptar que una hipótesis es verdadera cuando en realidad es falsa, o por el contrario, a rechazar una hipótesis como falsa cuando es verdadera.

\section{F El principio de las tres múltiples}

Hasta donde sea posible, cuando se está eligiendo un diseño de investigación, es siempre recomendable tener en mente el principio de las tres múltiples. 
1 Buscar múltiples fuentes de datos para obtener información de las mismas variables.

2 Hacer múltiples mediciones de las mismas variables a través del tiempo.

3 Hacer múltiples réplicas del estudio de intervención en diferentes escenarios.

El uso de múltiples fuentes de datos sirve a varios propósitos. Primero, cada fuente puede ser una comprobación de las otras fuentes. Segundo, cada fuente puede dar panoramas distintos sobre un evento o sobre la relación entre los eventos. Tercero, el uso de múltiples fuentes de datos da la oportunidad de obtener información cualitativa del proceso, que puede ser de mucha utilidad para determinar cómo y por qué se obtuvo un efecto y no otro por la intervención.

Múltiples mediciones a través del tiempo de las mismas variables puede dar información de las tendencias antes, durante y después de la intervención. Esta información puede ser muy valiosa para los estudios de campo. Una desviación repentina y radical de las tendencias en el pasado puede ser la primera indicación de que factores extraños al estudio están afectando a un grupo experimental de la población.

Las múltiples réplicas de una intervención, en diferentes escenarios, puede dar información relativa a la extensión en que los efectos de la intervención son únicos para un área y población particular, o pueden generalizarse a otras áreas y poblaciones. Idealmente, las múltiples réplicas significa que uno o más estudios de seguimiento están llevándose a cabo con los mismos objetivos y diseño de investigación, pero que están siendo implementados en otras áreas diferentes. En la práctica, debido a las limitaciones de tiempo y recursos, esto es difícil de llevar a cabo. Una alternativa es introducir la intervención en varios escenarios al mismo tiempo. Este procedimiento no sólo da indicaciones respecto del grado en el que el impacto de la intervención puede generalizarse, sino que da también alguna garantía de que si un área experimental se afecta por las inundaciones, disturbios sociales, retrasos administrativos, huelgas, u otros acontecimientos, el estudio puede continuar en otras áreas.

\section{QUE HACER: Diseño de un estudio}

1 La selección del diseño del estudio es determinada principalmente por los objetivos del estudio. Para delimitar los objetivos se pueden hacer las siguientes preguntas:

a ¿Se desea evaluar un programa? Si la respuesta es afirmativa, considérese el empleo de un diseño experimental o cuasi-experimental.

b ¿Se desea simplemente describir un evento particular? Si se trata de un evento que ya tuvo lugar, se puede emplear el método de post-evaluación $\left(\mathrm{X}_{1}\right)$ y recurrir al análisis multivariado. Si el evento todavía no acontece, es posible utilizar un método con pre y post-evaluación $\left(\mathrm{O}_{1} \mathrm{X}_{2}\right)$, utilizar un diseño de series de tiempo $\left(\mathrm{O}_{1} \mathrm{O}_{2} \mathrm{O}_{3} \mathrm{X} \mathrm{O}_{4} \mathrm{O}_{5} \mathrm{O}_{6}\right)$, o bien recurrir a un grupo de control no equivalente.

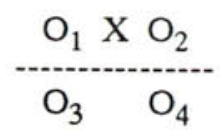

c ¿Se desea evaluar los efectos de un sistema particular de prestación de servicios en planificación familiar? Si éste es el caso, los datos observados en el grupo experimental deberán confrontarse con un grupo de control asignado aleatoriamente, 
o al menos con un grupo que presenta una marcada similitud con el grupo experimental.

2 Establecer, con la ayuda de Os y Xs, el diagrama que corresponda al diseño escogido. No debe olvidarse que los diseños mencionados en este capítulo pueden prestarse a múltiples variaciones.

3 Tomar en cuenta las implicaciones éticas del diseño.

4 Asegurarse que los recursos disponibles son suficientes para poner en marcha el diseno.

5 Revisar la lista de posibles fuentes de error y establecer cuáles son controlables y cuáles no lo son. 


\section{Muestreo}

\section{A selección de área y población}

Los individuos constituyen las unidades estadísticas básicas más utilizadas en la investigación operativa en materia de planificación familiar. Por ejemplo, para estudiar el impacto de la introducción de un nuevo anticonceptivo, podríamos proporcionar éste al grupo A, pero no al B; posteriormente, mediante entrevistas podremos obtener información sobre la práctica anticonceptiva de las mujeres de cada uno de estos grupos. Si los dos grupos fueron asignados de manera aleatoria, podremos verificar la hipótesis de que la disponibilidad del nuevo método afecta la práctica anticonceptiva. En este tipo de estudio, la disponibilidad y uso del nuevo anticonceptivo se consideran como características de las mujeres entrevistadas. Cada mujer es considerada como un sujeto experimental. Puesto que a las mujeres también se les interroga, se les puede llamar encuestadas. De forma más general, podemos también considerarlas como casos, ya que no todos los estudios resultan ser experimentos o encuestas.

Un individuo no necesariamente constituye un caso; las unidades estadísticas también pueden ser conjuntos o grupos de individuos. De esta manera, la relación que se mencionó anteriormente entre la introducción del nuevo anticonceptivo y la de práctica anticonceptiva puede estudiarse a nivel de comunidad. Si los casos objeto de estudio son comunidades enteras (y no individuos), el nuevo anticonceptivo puede considerarse como "disponible" si se ofrece en una clínica situada a una determinada distancia del pueblo; la práctica anticonceptiva podría medirse por tasas de prevalencia del pueblo entero (porcentaje de mujeres casadas en edad reproductiva que utilizan algún método). Los casos también pueden ser organizaciones; por ejemplo, podría realizarse un estudio en clínicas para determinar el efecto de ofrecer un nuevo método anticonceptivo en la mezcla de métodos por parte de nuevas aceptantes.

En general, la unidad estadística básica se determina por la naturaleza del proyecto y por sus objetivos. En el caso de proyectos que tienen como objetivo mejorar el conocimiento y actitud de la pareja en materia de planificaión familiar, la pareja constituirá la unidad estadística básica. En proyectos de capacitación para mejorar los conocimientos y habilidades del personal de campo, éste constituirá tal unidad. En los que tengan como objetivo estudiar el comportamiento de clínicas, éstas serán la unidad de estudio. Algunos estudios pueden contener distintos tipos de unidades. Podría diseñarse un estudio para evaluar los efectos de un nuevo programa de capacitación de personal de campo, que permita constatar sus efectos sobre el personal y sobre las parejas a las que atienden. Un diseño de este tipo requeriría análisis a dos niveles (del personal de campo y de las parejas), lo que exigiría recopilación y procesamiento de datos para cada nivel.

\section{B Métodos de muestreo}

Después de haber seleccionado la unidad estadística básica, se procederá a determinar la manera en que se realizará la selección de las unidades. Para este efecto es útil distinguir la población total de la muestra que será seleccionada de ella. La población está constituída 
por elementos, siendo cada uno de ellos casos potenciales de estudio. En ciertos estudios, la población resulta ser tan pequeña que todos los elementos bien pueden incluirse en la muestra. Por ejemplo, si queremos estudiar el sistema administrativo central de un programa nacional que se compone de 20 o 30 administradores, es deseable que la muestra comprenda el $100 \%$ de la población (o sea, el conjunto total de administradores). De la misma manera, si el programa no comprende más que cinco equipos móviles, el estudio que se refiere a éstos debiera cubrir a todos ellos. Aun cuando la población a estudiar no sea muy pequeña, en ocasiones es preferible optar por una muestra que abarque el $100 \%$ de los casos. Por ejemplo, en un estudio sobre los efectos de un programa en la distribución de usuarios por edad, sería posible analizar datos de todos los usuarios a partir de registros clínicos, especialmente si dichos datos están computarizados. De forma similar, puede tomarse como muestra la población total de clínicas para estudiar el desempeño de las mismas.

Sin embargo, a menudo se trata con casos muy numerosos de personas, regiones o centros de prestación de servicios y, por lo tanto, es necesario recurrir a muestras menores del 100 por ciento para representarlos. Para una encuesta sobre usuarios de planificación familiar en clínicas durante 1982, la población que nos interesa está representada por el total de personas registradas, durante 1982 , como usuarias de anticonceptivos en las distintas clínicas. Si este número es grande, digamos 800000 personas, interrogar a todos sería costoso, muy tardado e innecesario. Lo usual es seleccionar e interrogar a una muestra relativamente pequeña de usuarios de anticonceptivos y considerar los hechos observados como representativos del total de la población. Si la muestra es realmente representativa y comprende varios cientos de casos o más, los resultados serán muy similares a los que se habrían obtenido del total de la población.

Existen dos tipos fundamentales de muestras: 1) muestras probabilísticas y 2) muestras no-probabilísticas.

\section{Muestreo probabilístico}

Una muestra probabilística tiene más posibilidades de ser representativa de la población que la no-probabilística y, por lo tanto, es preferible. La característica esencial de una muestra probabilística es que cada elemento de la población total (cada pareja, cada trabajador de campo, cada clínica) tenga una probabilidad conocida de pertenecer a la muestra (si cada elemento tiene una probabilidad igual de selección, la muestra es calificada de auto-ponderada, y los resultados de la muestra analizada pueden considerarse como representativos del total de la población). Hay varias formas de seleccionar muestras probabilísticas; a continuación se describen las más comunes.

\section{a Muestreo aleatorio simple}

En este procedimiento a cada elemento de la población se le asigna un número único, empleando una tabla de números aleatorios, o alguna otra técnica de sorteo y se seleccionan elementos hasta alcanzar el tamaño de muestra deseado. Este procedimiento suele resultar largo y tedioso cuando la muestra es grande.

\section{b Muestreo sistemático}

Esta es una variante del muestreo aleatorio simple y resulta ser más rápida y fácil de realizar. El total estimado de elementos de la población se divide entre el tamaño de muestra deseado, obteniendo así el intervalo de muestreo (llamémosle n). Para sacar la

muestra se listan arbitrariamente todos los elementos de la población y se selecciona cada n-ésimo elemento, empezando con un número entre 1 y n, seleccionado aleatoriamente. 
A diferencia del muestreo aleatorio simple, que exige que se tenga anticipadamente la lista de todos los elementos que integran la población (denominada marco muestral), el muestreo sistemático permite la obtención simultánea del marco muestral y de la muestra, lo cual disminuye costos. Naturalmente, es preferible disponer anticipadamente del marco muestral, ya que así el muestreo sistemático podrá emplearse para obtener el tamaño preciso deseado de la muestra. Si no se sabe al principio cuál es el total de la población, èl tamaño de la muestra tampoco podrá conocerse. Supóngase, por ejemplo, que se desea sacar una muestra de 20 hogares en una aldea. Para eso se deberá conocer el número de hogares de la aldea, si no se conoce, debe estimarse. Si se estiman 200 hogares, el intervalo de muestreo será de 20; lo que quiere decir que a medida que se elabora la lista de hogares, se interroga un hogar de cada diez. Si la estimación resulta ser muy alta, la muestra será de un tamaño menor al previsto y si es demasiado baja, el tamaño de la muestra será mayor al previsto. Siempre es preferible tener un tamaño de muestra mayor que el que se necesita, en lugar de uno menor. Asimismo, resulta más conveniente tener un presupuesto para una muestra ligeramente mayor que la prevista.

\section{Muestreo estratificado}

Si queremos asegurarnos de la representatividad de la muestra a nivel de ciertos sub-conjuntos de la población estudiada, podemos recurrir a la estratificación tanto con el muestreo aleatorio simple como con el sistemático. Por ejemplo, si deseamos tener en la muestra una estructura por edad idéntica a aquélla de la población estudiada, podemos subdividir la población por grupos de edad -estratificación según la edad- y sacar una muestra por separado de cada estrato o grupo de edad. Si la fracción de muestreo es la misma para todos los estratos de edad, la estructura por edad de la muestra será idéntica a la de la población. Sin embargo, con frecuencia es útil recurrir a fracciones diferentes de muestreo para cada estrato. Por ejemplo, en un estudio sobre aceptantes de la planificación familiar, puede ser deseable llegar a una muestra que comprenda igual número de parejas que empleen la píldora, el condón y la esterilización, aún cuando estos métodos representen proporciones diferentes de usuarios con respecto al total. Esto se podría realizar efectuando una estratificación según el método anticonceptivo utilizado y sacando una muestra de cada estrato, mediante fracciones de muestras diferentes.

\section{d Muestreo de conglomerados}

Podemos simplificar la operación del muestreo seleccionando conglomerados o grupos de elementos (mediante un muestreo aleatorio simple, sistemático o estratificado y proceder a estudiar todos los elementos de los conglomerados muestreados). La mayoría de las veces los conglomerados son áreas geográficas (provincias, distritos, aldeas) o unidades tales como clínicas, clubes o grupos de trabajadores de campo. Por ejemplo, para obtener una muestra de mujeres unidas en edad reproductiva (MUER) en el medio rural, se puede seleccionar primero una muestra de aldeas (conglomerados) y encuestar después a todas las MUER en esos conglomerados. Los inconvenientes principales de esta técnica son: 1) complicaciones adicionales en los cálculos matemáticos de la varianza muestral y por ende, en las pruebas estadísticas y 2) generalmente se requieren tamaños mayores de muestra para obtener resultados estadísticamente significativos a un nivel de confianza determinado.

\section{e Muestreo multi-etápico}

La técnica de selección más comúnmente empleada en poblaciones numerosas y diversificadas es la de muestreo multi-etápico. Primero, la población se divide en conglomerados naturales, de los cuales se selecciona una muestra. A ésta se le denomina la primera etapa de muestreo. La segunda etapa consiste en sacar una muestra de elementos (encuestas, casos) de los conglomerados muestreados. A veces más de dos etapas de 
muestreo son necesarias. Por ejemplo, en la primera etapa se seleccionan provincias, en la segunda etapa se seleccionan distritos dentro de las provincias, en la tercera etapa se seleccionan aldeas dentro de los distritos y finalmente, en la cuarta etapa se seleccionan personas dentro de las aldeas. Se pueden utilizar diferentes técnicas de muestreo en cada etapa, muestreo aleatorio simple, sistemático o estratificado.

\section{f Selección con probabilidades proporcionales al tamaño (PPT)}

Este procedimiento es una variante del muestreo multi-etápico. Consiste en seleccionar cada conglomerado con una probabilidad proporcional a su tamaño y sacar un número igual de elementos dentro de cada conglomerado muestreado. La selección PPT es útil cuando los conglomerados son muy diferentes en tamaño, permitiendo reducir, tanto la varianza muestral, como los costos de la recopilación de datos.

\section{Muestreo No-Probabilístico}

En el muestreo no-probabilístico (también denominado muestreo de conveniencia) se desconocen las probabilidades de selección de cada elemento. Un muestreo no-probabilístico puede ser accidental (tomando los casos que están disponibles) o deliberado (seleccionando explícitamente ciertos tipos de casos). Los procedimientos no-probabilísticos no son válidos para obtener muestras realmente representativas de grandes poblaciones. Estos procedimientos casi siempre tienden a sobre-representar ciertos elementos de la población y a sub-representar a otros. Dada la ausencia de probabilidades conocidas de selección, no hay forma precisa de ajustar tales distorsiones.

A pesar de los inconvenientes señalados el muestreo no-probabilístico constituye, en algunos casos, la única posibilidad de recolectar datos debido a que resultaría difícil y costoso recurrir a un muestreo probabilístico. Veamos el caso, por ejemplo, de un ministro que ha incluído la planificación familiar en las actividades regulares de sus trabajadores de campo y que desea se realice una evaluación. Si el presupuesto para la investigación no permite efectuar los desplazamientos necesarios para cubrir regiones lejanas del país, se podría estudiar únicamente a trabajadores en las regiones más cercanas, aún si su experiencia difiere de la de los trabajadores de campo de las áreas más remotas.

A veces es difícil o muy costoso encontrar, a través de un muestreo probabilístico, suficientes casos de un mismo tipo. Por ejemplo, si el objetivo del estudio fuera analizar el impacto de un programa de radio sobre el conocimiento y actitud de los radioescuchas en materia de planificación familiar, resultaría muy costoso sacar una muestra probabilística de este auditorio. Se requeriría, en efecto, establecer un listado completo del área de transmisión (o de una muestra representativa de sub-áreas) para determinar quién ha escuchado el programa y, entonces, seleccionar una muestra representativa del auditorio. Si los fondos disponibles no permiten llevar esto a cabo, quizás la única alternativa sea entrevistar a los radioescuchas mediante una encuesta de casa en casa hasta llegar al tamaño deseado de muestra. Los resultados de esta muestra deben analizarse cuidadosamente ya que es muy posible que la composición de la muestra se vea afectada por la manera de seleccionar los hogares; así, los oyentes de las zonas rurales o áreas marginales por ejemplo, pueden estar sub-representados por ser relativamente más difíciles de encontrar y entrevistar, que la gente de clase media que vive en la ciudad.

Si resulta necesario llevar a cabo un muestreo no-probabilístico, se deberá tratar de reducir al mínimo los sesgos posibles de la muestra. Si se conocen ciertas características de la población a estudiar, se tratará de incluir en la muestra a todas las categorías de personas, según su proporción en la población. Si se sabe, por ejemplo, que la tercera parte de la población vive en el medio urbano y dos terceras partes en el medio rural, la muestra puede contener las mismas proporciones. Si se conoce la estructura de la población por edades y se piensa que está en relación con el fenómeno a estudiar, se podrá fijar anticipadamente el 
número preciso de personas en la muestra en cada categoría de edad. Este procedimiento se denomina muestreo de cuota ya que la "cuota" de cada sub-grupo se fija por anticipado.

Si el estudio tiene por objeto principalmente obtener la máxima variedad de información cualitativa de un grupo de personas (por ejemplo, tener una visión clara de cómo una determinada estrategia es llevada a cabo, conocer un gran número de problemas a resolver o bien investigar todas las soluciones que se han propuesto a ciertos problemas) el muestreo no probabilístico puede ser la mejor opción. Este permite al investigador seleccionar deliberadamente a aquellas personas que con mayor seguridad responderán clara y fácilmente a preguntas complejas. Es común que los antropólogos obtengan información sobre las comunidades a través de personas claves, escogidas entre los individuos informados, accesibles, pertenecientes a diversos sub-grupos de la comunidad.

\section{Tamaño de la muestra}

El tamaño de la muestra debe fijarse tomando en cuenta dos criterios: 1) los recursos disponibles, que fijan el tamaño máximo de la muestra y 2) las necesidades del plan de análisis, que fija el tamaño mínimo de la muestra. $\mathrm{Si}$, por ejemplo, el número de encuestadores capacitados para realizar una encuesta en un periodo determinado es insuficiente para efectuar más de cierto número de entrevistas, la muestra no podrá rebasar ese número. Por otro lado, el tamaño de la muestra debe ser suficiente 1) para permitir un análisis confiable de tabulaciones cruzadas; 2) para proporcionar el grado de precisión deseado en la estimación de proporciones y 3) para probar si las diferencias entre proporciones son estadísticamente significativas. Si los recursos disponibles para el estudio son insuficientes para obtener una muestra del tamaño adecuado, el investigador deberá buscar financiamiento adicional, o bien modificar el plan de análisis de datos.

Si se trata de analizar tabulaciones cruzadas de las variables, se deben considerar dos aspectos: primero, las frecuencias de cada variable independiente, dentro de cada tabulación cruzada, deberán ser superiores o iguales a 50, ya que los porcentajes calculados con menos de 50 casos, generalmente resultan poco confiables. El tamaño de muestra mínimo requerido, para observar al menos 50 casos en cada categoría de la variable independiente, se obtiene dividiendo 50 entre la proporción $\left(\mathrm{P}_{\mathrm{S}}\right)$ del total de casos esperados dentro de la categoría más pequeña de la variable:

$$
\mathrm{m}=\frac{50}{\mathrm{P}_{\mathrm{s}}}
$$

El segundo criterio a considerar es que el número esperado de observaciones en cada una de las casillas del cuadro llegue a un mínimo de cinco. El tamaño de la muestra se calcula dividiendo cinco entre el producto de las frecuencias relativas más bajas de las dos variables del cuadro.

Podemos ilustrar estos dos criterios con ayuda del Cuadro 8.1 (véase en la siguiente página) en donde aparece una tabulación cruzada para analizar el uso de anticonceptivos, de acuerdo con el nivel de instrucción alcanzado. 
CUADRO 8.1

Tabulación cruzada de prácticas anticonceptivas y nivel de Escolaridad alcanzado

\begin{tabular}{|l|l|l|l|l|}
\hline Práctica anticonceptiva & $\begin{array}{c}\text { Universidad } \\
(\mathbf{5 \% )}\end{array}$ & $\begin{array}{c}\text { Escuela } \\
\text { secundaria } \\
(\mathbf{1 5 \% )}\end{array}$ & $\begin{array}{c}\text { Escuela } \\
\text { primaria } \\
\mathbf{( 4 0 \% )}\end{array}$ & $\begin{array}{c}\text { Sin } \\
\text { escolaridad } \\
\mathbf{( 4 0 \% )}\end{array}$ \\
\hline Actualmente usa (50\%) & & & & \\
\hline Usó anteriormente (20\%) & & & & \\
\hline Nunca usó (30\%) & & & & \\
\hline
\end{tabular}

El nivel de escolaridad constituye en este cuadro la variable independiente (explicativa). Por lo tanto, para obtener una muestra lo suficientemente grande para asegurar que al menos 50 casos caigan en la categoría más pequeña de la variable "nivel de escolaridad" (es decir, en la categoría "universidad" que representa sólo el $5 \%$ del total de casos) se divide 50 entre $5 \%(\mathrm{n}=50 / .05=1000$ casos requeridos $)$. Para calcular el tamaño mínimo de la muestra con el objeto de tener al menos cinco casos en cada casilla, se divide cinco entre el producto de frecuencias relativas más bajas de cada variable ( o sea 0.05 para la categoría "universidad" y 0.20 para la categoría "usó alguna vez anticonceptivos").

$$
\mathrm{n}=\frac{5}{(.05)(.20)}=500 \text { casos requeridos }
$$

Como el tamaño necesario de la muestra debe fijarse teniendo en cuenta los dos criterios (50 para cada categoría de la variable y cinco por cada caso) se escogerá el tamaño superior, o sea $\mathrm{n}=1000$ en lugar de $\mathrm{n}=500$.

Para calcular el tamaño mínimo de la muestra que se necesita para estimar las proporciones con la precisión adecuada, se debe primeramente responder a las siguientes preguntas:

1 ¿Es posible dar por anticipado estimaciones razonables de las proporciones más importantes que van a ser medidas por el estudio? Por ejemplo, si se está estudiando el uso de anticonceptivos, se deberá tratar de proporcionar una pre-estimación de la proporción de usuarios de anticonceptivos. Si esto no es posible, el procedimiento más seguro es suponer que dicha proporción es 0.5 (50\%), lo que aumenta al máximo la varianza esperada y, por lo tanto, asegura una muestra suficientemente grande, cualquiera que sea el valor real de la proporción.

2 ¿Qué grado de precisión se desea? Es decir, ¿qué tanto se permitirá que se desvíen las estimaciones de las proporciones basadas en la muestra de los valores reales de dichas proporciones? Por ejemplo, si con base en la muestra se estima que una proporción tiene el valor de 0.50 , se quiere tener la confianza de que esta estimación no se desvíe más del 1 o 5 por ciento del valor real. Si se desea un alto grado de precisión (por ejemplo 0.01) la muestra deberá ser mayor que cuando el grado de precisión es relativamente menor ( 0.05 , por ejemplo).

3 ¿Cuál es el nivel de confianza deseado? ¿En qué medida podemos estar seguros de los resultados obtenidos? Generalmente se establece un nivel de confianza del $95 \%$. 
4 ¿Cuál es el tamaño de la población de donde se selecciona la muestra? Si es superior a 10000 , el tamaño exacto tiene poca importancia. Por el contrario, si es inferior a 10000 tenderá a disminuir el tamaño de la muestra.

5 Si se busca medir las diferencias entre dos sub-grupos mediante la comparación de sus respectivas proporciones, ¿cuál es la diferencia mínima que puede ser considerada como estadísticamente significativa? Por ejemplo, si se comparan las proporciones de uso de anticonceptivos en un grupo experimental con las de un grupo de control y se encuentra una diferencia de solamente cinco por ciento, ¿esta diferencia tan pequeña podría considerarse estadísticamente significativa? Entre más pequeña es la diferencia que se espera sea estadísticamente significativa, más grande debe ser el tamaño de las muestras en los sub-grupos.

El tamaño de la muestra obtenido, en función de las respuestas a estas cinco preguntas, que permite estimar una proporción con cierto grado de precisión y un determinado nivel de confianza, se calcula para las poblaciones superiores a 10000 , con la fórmula:

$$
\mathrm{n}=\frac{\mathrm{z}^{2} p q}{\mathrm{~d}^{2}}
$$

Donde:

n = tamaño deseado de la muestra (cuando el tamaño de la población es superior a $10000)$.

$\mathrm{z}$ = desviación en relación a una distribución normal standard. Generalmente es fijada en 1.96 (o simplemente en 2.0) que corresponde a un nivel de confianza del $95 \%$.

p = proporción de la población objeto de estudio, que se estima tiene una característica determinada. Si no se dispone de tal estimación úsese 50 por ciento (0.50).

$\mathrm{q}=1.0-\mathrm{p}$.

$\mathrm{d}=$ grado de precisión deseado, en general 0.05 y a veces 0.02 .

Por ejemplo, si se estima que la proporción de la población que tiene una característica determinada es 0.50 , el valor de z igual a 1.96 y el grado de precisión deseado es de 0.05 , el tamaño de la muestra es:

$$
\begin{aligned}
n & =\frac{(1.96)^{2}(.50)(.50)}{(.50)^{2}} \\
& =384
\end{aligned}
$$

Si, para facilitar, se utiliza 2 para el valor de z el tamaño es:

$$
\begin{aligned}
\mathrm{n} & =\frac{(2)^{2}(.50)(.50)}{(.05)^{2}} \\
& =400
\end{aligned}
$$


Nótese que el numerador es 1.0; lo que quiere decir que si la proporción se estima en 0.50 y que el nivel de confianza es del $95 \%$, se puede obtener el tamaño de la muestra con la fórmula:

$$
\mathrm{n}=\frac{1.0}{\mathrm{~d}^{2}}
$$

Si el tamaño de la población estudiada (N) es inferior a 10 000, el tamaño requerido de la muestra es menor y se calcula usando la siguiente fórmula:

$$
\mathrm{n}_{\mathrm{f}}=\frac{\mathrm{n}}{1+\left(\frac{\mathrm{n}}{\mathrm{N}}\right)}
$$

Donde:

$\mathrm{n}_{\mathrm{f}}=$ tamaño deseado de la muestra (cuando el tamaño de la población es inferior a $10000)$.

$\mathrm{n}=$ tamaño deseado de la muestra (cuando el tamaño de la población es superior a $10000)$.

$\mathrm{N}=$ tamaño estimado de la población.

Por ejemplo, si n se calculó en 400 y si el tamaño de la población estudiada es igual a 1000 entonces $n_{f}$ es:

$$
\begin{aligned}
n_{f} & =\frac{400}{1+\left(\frac{400}{1000}\right)} \\
& =\frac{400}{1.4} \\
& =286
\end{aligned}
$$

En el caso en que se desee probar si existe diferencia significativa ( $d^{\prime}$ ) entre las proporciones de dos sub-muestras, suponiendo un número igual de observaciones $\left(n_{1}=n_{2}=n\right)$ en cada sub-muestra, la fórmula para n' es similar a la precedente:

$$
n^{\prime}=\frac{2 z^{2} p q}{\left(d^{\prime}\right)^{2}}
$$


Por ejemplo, supóngase que se desea comparar la proporción de personas que usan anticonceptivos entre un grupo experimental y uno de control. Si se espera que la proporción que usa anticonceptivos (p) sea de .40 y se desea concluir, con un 95 por ciento de confianza, que una diferencia observada de .10 o más es significativa, el tamaño de la muestra podrá entonces calcularse de la siguiente manera:

$$
\mathrm{n}^{\prime}=\frac{2(1.96)^{2}(.40)(.60)}{(.10)^{2}}=184
$$

Por lo tanto, se necesita una muestra de 184 casos en el grupo experimental y de otros 184 en el grupo de control. Al igual que en el ejemplo anterior, la fórmula se simplifica si p se fija en 0.50 y z en 2.0 :

$$
n^{\prime}=\frac{2}{\left(d^{\prime}\right)^{2}}
$$

Si esta fórmula se aplicara al ejemplo anterior, el tamaño de la muestra se calcularía como sigue:

$$
\begin{aligned}
\mathrm{n}^{\prime} & =\frac{2}{(.10)^{2}} \\
& =200
\end{aligned}
$$

Si no pueden suponerse tamaños iguales de sub-muestras, o si las poblaciones de donde se sacan las sub-muestras son muy inferiores a 10000 , el procedimiento para estimar los tamaños de la muestra será más complicado. En estos casos o en otros en donde surjan confusiones, debe consultarse a un estadístico.

\section{QUE HACER: Muestreo}

1 Decidir primero si se desea sacar una muestra y si ésta será probabilística o noprobabilística. Esta decisión debe hacerse tomando en cuenta los objetivos del estudio, el grado de representatividad con respecto al total de población y los recursos disponibles en cuanto a costo, tiempo y personal.

2 Calcular el tamaño de la muestra. Para esto se podrán utilizar las fórmulas presentadas anteriormente; sin embargo, se recomienda, de ser posible, buscar la orientación de un estadístico. Este requerirá una estimación previa de las proporciones a estudiar, del grado de precisión deseado, del nivel de confianza requerido y del tamaño aproximado de la población de la cual será sacada la muestra.

3 Los siguientes principios deberán tenerse en mente:

a Un tamaño de muestra relativamente grande proporcionará resultados más precisos, pero será más costosa que una de menor tamaño.

b Los datos cuantitativos proporcionados por un muestreo probabilístico serán más representativos de una población grande que los proporcionados por un muestreo 
no-probabilístico. Una muestra no-probabilística puede diseñarse de tal manera que aumente al máximo la obtención de información cualitativa relevante usando para ello muestras relativamente pequeñas.

c En los casos en que se requiera analizar ciertos sub-grupos de la muestra, el tamaño de ésta deberá incrementarse adecuadamente. Por ejemplo, para estudiar las características de los usuarios de anticonceptivos en general, puede requerirse una muestra de 400, pero si se desea ampliar el análisis a métodos específicos de anticoncepción, los tamaños de las sub-muestras resultarán muy pequeños para garantizar resultados estadísticamente significativos, por lo que deberá aumentarse el tamaño de la muestra. Aun cuando se considere que la significación estadística no tiene mucha importancia, el número mínimo de observaciones para cada sub-grupo deberá ser de 50 casos, si se desean obtener porcentajes más o menos confiables. 


\section{Recolección de datos}

La recolección de datos puede realizarse de distintas formas. El método seleccionado depende de los objetivos y diseño del estudio, así como de la disponibilidad de personal, tiempo y recursos financieros. Un factor importante que se debe considerar en la selección del método de recolección de datos, es si el estudio pretende producir resultados cuantitativos con cierto grado de precisión o bien datos cualitativos que proporcionen información del tipo descriptivo. Si bien la mayoría de los estudios sobre investigación operativa buscan medir cuantitativamente la operación o impacto de un programa, muchos otros estudios también tienen (o deberían tener) como finalidad obtener información de tipo cualitativo sobre ciertos procesos (por ejemplo, cómo se pone realmente en marcha un proyecto o con qué criterio decide la pareja adoptar un método anticonceptivo determinado sobre otros disponibles); o bien sobre ciertas opiniones y actitudes (por ejemplo, si sabe el usuario cómo se usa el método, o si percibe algún problema en los servicios de un programa). Es frecuente que los objetivos del estudio requieran de información cuantitativa y cualitativa, lo que implica que se debe emplear más de un método de recolección de datos.

\section{A Datos cuantitativos}

Si bien el método más comúnmente utilizado para la recolección de datos cuantitativos es la entrevista estructurada, existen otros métodos que también pueden ser utilizados, tales como cuestionarios autoaplicados (entrevista indirecta), centros de estadísticas vitales y censos, o ciertas fuentes secundarias que puede proveer documentos e información diversos. Si la muestra está constituida por unidades geográficas o por instituciones (como aldeas, distritos, clínicas u hospitales) y no por individuos, los datos cuantitativos generalmente pueden obtenerse de estadísticas de servicios y fuentes secundarias. Si no hay información disponible de estas fuentes, se puede entrevistar a las personas de estas instituciones que estén familiarizadas con ellas.

\section{Entrevistas estructuradas}

Los estudios que obtienen datos mediante entrevistas a personas se denominan encuestas. Si los entrevistados constituyen una muestra representativa de la población, estos estudios se denominan encuestas por muestreo. Si la muestra es suficientemente grande para permitir análisis estadísticos, es común emplear entrevistas estructuradas en lugar de no-estructuradas, ya que las primeras se prestan mejor a análisis cuantitativos y las segundas pueden crear dificultades serias en el procesamiento de datos, particularmente si la muestra es grande. Una entrevista estructurada es la que emplea un cuestionario (o guión de entrevista) con objeto de asegurarse que a todos los encuestados se les hacen las preguntas en el mismo orden. El contenido exacto de cada pregunta se especifica de antemano y el encuestador se concreta a leer cada pregunta al entrevistado. En el diseño del cuestionario y entrenamiento de los encuestadores, deben tomarse en cuenta los siguientes puntos:

a Emplear un lenguaje sencillo que sea fácilmente comprendido por los entrevistados.

b Cuando sea posible, codificar las respuestas para que la información pueda ser fácilmente transferida a programas de computadora o tabuladas en alguna 
forma. Esto hace más difícil el diseño del cuestionario, pero se compensa con el ahorro de tiempo y esfuerzo durante el procesamiento y análisis.

c Tratar de evitar preguntas embarazosas o dolorosas. Si es necesario hacer una pregunta que pueda repercutir emocionalmente en el entrevistado, redactar ésta con mucho tacto y evitar preguntarla al inicio de la entrevista, cuando el entrevistado puede encontrarse más nervioso.

d Limitarse a tratar un asunto por pregunta. Por ejemplo, evitar preguntar: "¿Desean otro hijo usted y su esposo?" Si la entrevistada y el esposo difieren en esta decisión, una respuesta afirmativa o negativa será imposible de interpretar en forma adecuada. Si ella responde "sí" podría interpretarse como "yo quiero otro hijo", "mi esposo quiere otro hijo" o "ambos queremos otro hijo". Por lo tanto es preferible hacer dos preguntas por separado: "¿Desea usted otro hijo?" "¿Desea su esposo otro hijo?"

e Evitar redacciones ambiguas. Por ejemplo, si la planificación familiar ha sido adecuadamente definida, la pregunta: "¿Qué método o métodos emplea usted?" será suficiente. Pero si las encuestadas son mujeres, posiblemente no deba de mencionarse el uso de condones o la vasectomía. Una mejor pregunta será: "¿Qué método o métodos de planificación familiar emplean usted y su esposo?"

f Evitar prolongar el tiempo de la entrevista con asuntos que no son esenciales para el estudio. Tratar de que el cuestionario sea breve, para evitar cansar al entrevistado y simplificar el procesamiento y análisis de los datos.

g Asegurarse de incluir todas las preguntas necesarias para obtener información suficiente sobre las variables que se desean estudiar. Asegurarse también de que los datos necesarios para probar las hipótesis del estudio pueden recolectarse por medio de los instrumentos de recolección de datos. Muchas veces es útil preparar una lista de las variables más importantes del estudio, indicando de dónde se obtendrán los datos para cada variable.

h Comenzar por las preguntas más fáciles, pasando gradualmente a las más difíciles y delicadas, a medida que la tensión del inicio disminuya. Los entrevistados suelen presentar tensión y desconfianza al principio; por lo que el encuestador debe dedicar los primeros minutos a ganarse la confianza del entrevistado. Las preguntas simples y cortas pueden facilitar este proceso.

i Cada pregunta debe hacerse de igual manera a cada uno de los entrevistados. Si la entrevista se realiza en más de un idioma deberá prepararse una traducción completa en cada idioma y los encuestadores deberán usarlas textualmente. No deben permitirse las traducciones libres, salvo cuando se trate de un idioma asociado a un número de encuestados tan reducido que no se justifique el costo de la traducción. Se puede verificar la calidad de cada una de las versiones procediendo a la traducción inversa (volver a traducir al idioma original) por personas que ignoran la versión original. Se puede verificar si las preguntas conservaron el sentido original.

j Efectuar una prueba del cuestionario en una situación real. Los principios básicos que deben considerarse al hacer esto, son los siguientes:

1 En la prueba del cuestionario no es necesario interrogar a un gran número de personas, generalmente entre 30 a 50 son suficientes, si son seleccionadas de forma que reflejen la diversidad esperada de la muestra. Es decir, la prueba deberá incluir a jóvenes y viejos, áreas urbanas y rurales, 
diversos niveles de instrucción, usuarios y no usuarios de anticonceptivos, y otros.

2 Es probable que sea necesario hacer más de una prueba. Si la primera prueba da lugar a un número importante de modificaciones en el cuestionario, es mejor efectuar otra prueba para asegurarse que los cambios introducidos son satisfactorios.

3 La prueba del cuestionario, debe concluirse antes del entrenamiento a los encuestadores. A veces es posible emplear supervisores de campo en la prueba del cuestionario. Esto los ayudará a tener una idea más clara de los objetivos del estudio y serán más útiles en el entrenamiento de los encuestadores.

4 El objetivo principal de la prueba del cuestionario es verificar el grado de comprensión de las preguntas por parte de los interrogados, así como su capacidad de responder acertadamente. De esta manera, la prueba no debe concretarse simplemente a entrevistar a un grupo de personas, sino que debe estar seguida por una discusión sobre las ambigüedades o dificultades presentadas en el transcurso de la entrevista.

k Capacitar ampliamente a todos los encuestadores. El objetivo de la capacitación o entrenamiento es familiarizar a los encuestadores con la intención y significado de las diferentes preguntas. Es útil hacer que ensayen cómo deben hacer las entrevistas; asimismo, es bueno que adquieran experiencia realizando varias entrevistas bajo supervisión.

I Si alguna de las personas encuestadas no se encuentra disponible durante la primera visita, deberá pedirse otra cita. Por lo menos dos intentos deben hacerse antes de abandonar definitivamente la entrevista de una persona.

m Si la muestra es pequeña, será necesario reemplazar a los individuos que no se encontraron. Para esto, el encuestador deberá proceder según las instrucciones que ha recibido previamente, ya sea que busque sustitutos para una muestra aleatoria o que seleccione individuos cuyas características correspondan a las de los seleccionados originalmente. Sin embargo, si la muestra es lo suficientemente grande para permitir la pérdida de algunos casos, lo mejor es no reemplazar los casos perdidos.

n Se tratará por todos los medios de que la entrevista se efectúe a solas con el entrevistado. La presencia de terceras personas puede afectar la calidad de las respuestas. Por ejemplo, la presencia del marido que ignora que su mujer usa anticonceptivos influirá en las respuestas de la entrevistada.

O Verificar los cuestionarios inmediatamente después de las entrevistas para detectar errores, omisiones y posibles contradicciones. Si es necesario, los entrevistados deberán ser visitados una vez más para corregir errores. Una vez que el entrevistador ha revisado y corregido el cuestionario éste debe ser también revisado por el supervisor. Toda esta operación de revisión se denomina verificación de campo.

\section{Estadísticas de servicio}

Todas las organizaciones de planificación familiar generan estadísticas de servicio. Algunas de estas organizaciones tienen establecido un sistema de información gerencial. La calidad de las estadísticas de servicio, sin embargo, puede variar de un país a otro y aún dentro del mismo país, por lo tanto, estas estadísticas deben ser usadas con cautela. Con 
frecuencia las estadísticas de servicio ayudan al investigador a definir los parámetros del problema que desea estudiar. En algunos casos, se pueden usar para comparar los resultados de un estudio en particular con los números de una nación.

\section{Entrevista indirecta}

La encuesta mediante entrevista directa es preferible al procedimiento de entrevista indirecta, siempre y cuando lo permita el presupuesto y haya suficiente personal y tiempo. Dado que generalmente el nivel de educación es bajo en los países en vías de desarrollo, es difícil manejar cuestionarios autoaplicados. Aún cuando se trate de personas instruídas pueden existir otro tipo de dificultades, como la falta de comprensión a ciertas preguntas o instrucciones, por no haber recibido instrucciones del encuestador. Debido a esta situación se dejan en blanco algunas respuestas y por otra parte algunas instrucciones no son claras y pueden crear confusiones (por ejemplo, "si la respuesta a la pregunta 12 es afirmativa, pase a la pregunta 13 , si no, pase a la $\left.18^{\prime \prime}\right)$.

Se pueden usar los cuestionarios autoaplicados cuando los encuestados saben leer y escribir y se les reúne en una sala u oficina en donde puedan sentarse y escribir cómodamente. Este tipo de entrevistas puede resultar particularmente útil para la evaluación de programas de educación en población o para cursos de capacitación.

Algunas veces los cuestionarios son enviados a los encuestados por correo y solicitando sean devueltos por la misma vía. Este sistema tiene la ventaja de ser barato, pero también tiene todos los inconvenientes que se han citado con respecto a cuestionarios autoaplicados, además de que generalmente se dan tasas altas de no-respuesta. El número de respuestas que se reciben por correo es casi siempre de menos de la mitad del total de cuestionarios enviados, aún si se envían uno o dos recordatorios, lo que perjudica la representatividad de la muestra y la confiabilidad de los datos, limitando por tanto la utilidad del cuestionario.

\section{Fuentes secundarias de datos}

Con el objeto de enriquecer el análisis, frecuentemente se incorporan a los datos recolectados información de censos recientes, de registros de estadísticas vitales y aún de otra encuestas. Existe una gran cantidad de datos sobre salud y planificación familiar que han sido recolectados por encuestas mundiales como la Encuesta Mundial de Fecundidad, las Encuestas de Prevalencia de Anticonceptivos y las más recientes Encuestas Demográficas y de Salud.

\section{B Datos cualitativos}

Los estudios que utilizan datos de tipo cualitativo y descriptivo hacen uso de técnicas de recopilación diferentes de las que se utilizan en estudios cuantitativos.

Sería muy recomendable que los estudios de investigación operativa emplearan una combinación de métodos de recolección de datos, tanto cuantitativos como cualitativos, para obtener el panorama más exacto y realista de un programa. Los métodos de recolección de datos cuantitativos de los que se ha hablado anteriormente son importantes para hacer predicciones, cálculos de probabilidades y generalizaciones. 
Los métodos cualitativos que incluyen entrevistas no estructuradas, discusiones con grupos focales, observación directa de las operaciones y análisis de contenido, son importantes para obtener datos sobre los procesos y funcionamiento de un programa, así como para explicar algunos resultados inesperados o no programados.

\section{La entrevista no-estructurada}

El mayor inconveniente de los datos que se obtienen a través de la entrevista estructurada reside en que a veces las respuestas son superficiales. Para contrarrestar este inconveniente y obtener información más completa y profunda, se utilizan preguntas abiertas o semiabiertas. A tales entrevistas se les denomina entrevistas de fondo. En lugar de hacer preguntas tomadas directamente de un cuestionario, el encuestador procede a un interrogatorio partiendo de un guión de tópicos o un conjunto de preguntas generales que le sirven de guía para obtener la información requerida. Las respuestas que no son contestadas adecuadamente en un principio se les hace un seguimiento por medio de una serie de preguntas exploratorias.

El método de la entrevista no-estructurada presenta, no obstante, los siguientes inconvenientes: 1) las respuestas, por no ser uniformes, son difíciles de cuantificar; 2) las entrevistas requieren de encuestadores altamente capacitados y experimentados, y 3) el análisis es muy laborioso. En consideración al limitado número de encuestadores y analistas calificados y al alto costo de realizar y procesar dichas encuestas, por lo regular se emplean muestras pequeñas (algunas veces de 20 a 30 encuestados). Este tipo de entrevista es generalmente utilizado durante la fase exploratoria de los estudios cuantitativos, a fin de esclarecer los conceptos e hipótesis de investigación, que sirvan de base para elaborar cuestionarios para encuestas cuantitativas. Estas entrevistas también sirven de apoyo para obtener los datos complementarios que no han sido obtenidos por la encuesta de mayor escala. Por ejemplo, poco se sabe acerca de las motivaciones de los hombres que desean hacerse una vasectomía. Una entrevista no-estructurada podría ayudar a obtener información introspectiva de la dinámica y determinantes que intervienen en el proceso de tomar una decisión de hacerse la vasectomía.

\section{Discusiones con grupos focales}

Una variante del método de la entrevista de fondo es la reunión de las personas en un grupo para discutir las preguntas (grupo focal). Este método permite obtener información cualitativa detallada, al mismo tiempo que reduce los gastos de personal y tiempo para recolectar y analizar los datos. El encuestador (o monitor de grupo) recurre a las mismas técnicas de las de la entrevista no-estructurada, partiendo de una guía general de discusión y suscitando respuestas más profundas por medio de preguntas exploratorias. Los participantes en general son seleccionados de manera que reflejen la heterogeneidad que exige el estudio. Por ejemplo, para un estudio sobre los métodos anticonceptivos naturales se deben incluir muestras bien seleccionadas de ambos cónyuges, de usuarios actuales de cada uno de los métodos (ritmo, toma de temperatura o moco cervical), de usuarios que hayan interrumpido la práctica de tales métodos y de personas que nunca los hayan empleado.

\section{Observación directa}

La observación directa es una técnica que permite obtener tanto datos cuantitativos como cualitativos, pero que exige períodos de observación considerablemente prolongados y personal y analistas relativamente competentes, lo que incrementa el costo por unidad de observación. Por lo tanto, este método se utiliza principalmente en estudios exploratorios de pequeña escala. Este método es particularmente adecuado para estudiar la respuesta de 
una comunidad a cierto programa. Es el método por excelencia de etnólogos especialistas en estudios de comunidades. Asimismo, esta técnica se adapta muy bien para el estudio del funcionamiento de las clínicas, de las actividades de los trabajadores de campo, o bien de procedimientos administrativos.

\section{Análisis de contenido}

En las investigaciones operativas en planificación familiar, el análisis de contenido de ciertos documentos es utilizado como un método complementario para otras formas de recopilación y análisis de datos. Se puede analizar, por ejemplo, el contenido de los manuales educativos para saber qué conocimientos y aptitudes deben enseñarse durante la capacitación. El análisis de contenido puede ayudar al investigador a diseñar las pruebas de conocimientos y aptitudes para el personal que ha tomado la capacitación. Se puede también analizar el contenido de los materiales de información, educación y comunicación para evaluar los mensajes del programa. También puede analizarse el contenido de los informes de investigaciones que se han efectuado, a fin de establecer el estado actual de los conocimientos sobre un tema determinado y orientar así las investigaciones futuras.

Se pueden estudiar los contenidos de los reportes de la prensa o de los reportes de las declaraciones de los formuladores de políticas para entender las actitudes hacia los temas de planificación familiar y población.

\section{QUE HACER: Recolección de datos}

1 Revisar los objetivos, hipótesis y variables dependientes e independientes del estudio. ¿Qué tipo de información se necesita? ¿Cuáles son las técnicas apropiadas que se pueden usar en este caso para recolectar los datos? ¿Existe alguna fuente de información actualizada sobre este tema?

2 Si se piensa llevar a cabo la recolección de datos mediante una encuesta, deben revisarse los puntos tratados bajo el rubro "Entrevista estructurada". Hay que tener presente durante la elaboración de la propuesta algunos aspectos como la posible necesidad de tener que traducir y/o probar el cuestionario, la capacitación de encuestadores y la elaboración de instrucciones específicas para solucionar problemas en segundas visitas o sustitución de muestras.

3 Hacer una lista de los instrumentos que se piensan usar (calendarios de entrevistas, guías de discusión, guías de observación). En la propuesta se deben dar ejemplos de preguntas que se van a usar, sobre todo las que tienen relación con variables claves de las que dependen las hipótesis. Indicar la forma en que se va a medir cada una de las variables a estudiar. Es útil enumerar todas las variables del estudio y la pregunta o preguntas que les corresponden en el cuestionario. Por ejemplo:

Variable 1: Práctica de la planificación familiar

Pregunta 1: ¿Ha utilizado alguna vez un método de planificación familiar?

Pregunta 2: ¿Utiliza usted actualmente algún método de planificación familiar?

Variable 2: Escolaridad

Pregunta 1: ¿Cuál fue el último grado que usted cursó en la escuela?

4 La propuesta debe describir las técnicas de recolección de datos que se van a utilizar, listándolas junto con los instrumentos. 


\section{Control de calidad de los datos}

Existen diferentes formas de controlar la calidad de los datos de una encuesta:

1 Algunas veces el investigador recurre a dos o más preguntas para obtener el mismo tipo de información. La primera pregunta puede hacerse al principio de la entrevista y la segunda al final. El análisis de las dos preguntas dará una idea de la consistencia de las respuestas. Esta es una manera de verificar la confiabilidad de los datos.

2 Para algunas preguntas difíciles o delicadas, al encuestador se le dan ciertas instrucciones para que se asegure que la respuesta es correcta. Esto es, se hace la misma pregunta de forma diferente o se lee la respuesta al encuestado, verificando si es correcta. Si una mujer, por ejemplo, declara tener dos hijos y tres hijas, el encuestador puede añadir: "Tiene usted cinco hijos en total, dos de sexo masculino y tres de sexo femenino, ¿correcto? ¿No ha olvidado mencionar algún otro hijo?"

3 Los supervisores deberán ayudar a los encuestadores en situaciones delicadas y verificar que estén realizando su trabajo correctamente, ya que se dan casos en que algunos encuestadores llenan los cuestionarios ellos mismos. En algunos estudios se ha usado un supervisor por cada cinco encuestadores.

4 En la mayoría de las encuestas se entrevistan por segunda vez a un porcentaje de los encuestados. La regla general es volver a entrevistar entre el 5 y 10 por ciento de la muestra, dependiendo del tamaño de ésta. Los datos de la primera entrevista se confrontan con los de la segunda para verificar la consistencia de las respuestas, lo que es una manera de verificar la confiabilidad de los datos. Si se encuentran inconsistencias en preguntas importantes como edad, estado civil o paridad, es claro que existe un problema ya sea con el cuestionario, los encuestadores, los métodos de tabulación o con algún otro aspecto de la encuesta.

5 Una vez realizada la recolección y tabulación, ciertos controles estadísticos permiten detectar errores y verificar la consistencia de las respuestas. Por ejemplo, la distribución de frecuencias de la variable paridad puede revelar que varias mujeres declararon tener entre 18 y 19 hijos vivos. Puesto que esto es poco probable, el investigador debe decidir si debe eliminar esos cuestionarios, ignorar la información con respecto a la paridad o bien entrevistar de nuevo a las mujeres que dieron tales respuestas.

\section{QUE HACER: Control de calidad de los datos}

1 Describir los métodos a utilizar para el control de calidad de la información. Considerar los siguientes aspectos:

a Verificar la consistencia de las respuestas mediante varias preguntas en el cuestionario. 
b Recurrir a los supervisores para verificar el trabajo de los encuestadores.

c Entrevistar por segunda vez a un porcentaje de los encuestados con objeto de detectar inconsistencias.

d Recodificar un porcentaje de los cuestionarios para asegurarse de que no hay errores de codificación.

e Examinar la distribución de frecuencias en todas las variables, revisando que no haya valores o códigos extraños, o datos ilógicos.

\section{Confidencialidad de la información}

En relación con este punto, se deberán tener en cuenta varios principios: 1) respetar el carácter confidencial de los datos proporcionados por las personas interrogadas; 2 ) no solicitar información de carácter muy personal, a menos que sea realmente necesaria; 3) siempre que sea posible, usar códigos en lugar de nombres; 4) asegurar a todos los interrogados que se respetará la confidencialidad de los datos; 5) asegurarse de que nadie usará la información para perjudicar a los interrogados; y 6) proteger la confidencialidad de los entrevistados. Por otro lado, si alguna persona se rehúsa a ser entrevistada, deberá respetarse su decisión. Es recomendable usar un folleto en el que se informen los objetivos del estudio y se solicite el consentimiento de los entrevistados a proporcionar informacion.

\section{QUE HACER: Confidencialidad de la información}

1 Describir detalladamente la forma como se va a asegurar la confidencialidad de los datos.

2 Incluir en la propuesta de investigación un ejemplar del folleto de información y consentimiento del encuestado. 


\section{Tabulación y análisis de datos}

Si el único objetivo del estudio fuera la presentación de ciertos resultados de tipo cualitativo o descriptivo, el análisis consistiría simplemente en redactar un informe, incorporando los datos conforme a un determinado formato. Sin embargo, la fase de análisis es más compleja, sobre todo en investigación operativa, pues requiere de cierta manipulación cuantitativa de los datos. Primero, es necesario decidir si la tabulación de datos será realizada manual o mecánicamente. En segundo lugar, se debe decidir cómo deberán ser tratados los datos para permitir un procesamiento eficiente y, en tercer lugar, se deben seleccionar los métodos estadísticos que se van a emplear para el análisis de los datos. Finalmente, es necesario elaborar uno o varios informes con los principales resultados del estudio.

\section{A Tabulación, codificación y verificación de datos}

Actualmente hay microcomputadoras en universidades, institutos de investigación, ministerios de salud y agencias de planificación familiar. Las micros se han convertido en un elemento indispensable para la tabulación y análisis de datos dela investigación operativa. Aún en los pequeños estudios que emplean procedimientos estadísticos relativamente simples, la tabulación de los datos por computadora es muy útil. Las microcomputadoras y las computadoras portátiles facilitanampliamente la producción de tablas y análisis estadísticos, con un margen mínimo de error.

Una vez que se haya decidido cómo se van a generar las tabulaciones, debe también considerarse cómo se van a transformar los datos crudos para su análisis.

Independientemente de que la tabulación se haga manualmente o por computadora, los datos no-numéricos que se vayan a analizar cuantitativamente deben codificarse numéricamente. Además, estos datos deben transferirse de su forma cruda a una forma que permita sutabulación (notas sobre entrevistas o cuestionarios, transcripciones de entrevistas, informes publicados sobre censos,etc.). Para la tabulación manual es útil transferir los datos codificados a tarjetas diseñadas para sortearse a mano. Para entrar a computadora, la información debe ser codificada en hojas y después capturada en cintas, discos duros o discos flexibles.

Se deben preparar las instrucciones para la codificación de datos. Esto permitirá, para todas las variables, convertir cada categoría de respuesta en un solo código numérico. Si el número total de respuestas posibles para una variable determinada es inferior a 10 (incluyendo las respuestas del tipo "no sabe", "no aplicable", "respuesta desconocida", y "otros") el código puede estar compuesto por sólo un dígito. Si el número total de respuestas posibles está comprendido entre 10 y 99 , el código estará compuesto por dos dígitos. Para algunas variables puede ser necesario usar tres, cuatro o aun códigos con un mayor número de dígitos.

Una vez codificados, los datos deberán verificarse. Una parte de la codificación deberá repetirse por otra persona que no haya participado en la codificación original y comparar los resultados. En caso de errores, el supervisor de codificación se encargará de efectuar las correcciones necesarias. Estos errores provienen en general de instrucciones erróneas de codificación o de un adiestramiento deficiente a los codificadores. 
Una vez que la información haya sido codificada, ésta se revisará (aún si los datos crudos ya han sido verificados en elcampo). Los datos codificados pueden revisarse esencialmente para buscar los siguientes tipos de errores:

1 Códigos "inválidos" - códigos que no corresponden a los especificados en las instrucciones de codificación.

2 Omisiones - por ejemplo, un encuestador que no siguió correctamente las instrucciones relativas al llenado del cuestionario.

3 Incoherencias - por ejemplo, si la edad de un entrevistado en el momento de la encuesta resulta ser inferior a la edad en que contrajo matrimonio.

4 Inverosinilitud - por ejemplo, una mujer de 25 años que declare tener 10 hijos vivos.

Una vez que han sido localizados, los errores deben ser confrontados con los datos originales y hacer las correcciones necesarias. La verificación de datos es más fácil cuando se hace por computadora y se conoce como verificación por computadora para diferenciarla de la verificación en el campo. Comúnmente los datos se encuentran almacenados en cintas, discos duros o discos flexibles.

\section{QUE HACER: Codificación y verificación}

1 Decidir si los datos serán codificados y verificados manualmente o por computadora. Tener en cuenta:

a Las facilidades disponibles.

b El tipo de datos (cuantitativos o cualitativos).

c Tipo de análisis a efectuar.

d Personal disponible.

e Costos.

Si se decide recurrir a la computadora, se debe verificar si existen ciertos programas (paquetes), así como asistencia en programación.

2 Decidir qué clase de información debe codificarse. En ocasiones, ciertos datos pueden dejarse sin codificar, ya que determinado tipo de información no lo requiere. Ciertas preguntas abiertas, incluso en los casos de encuestas estructuradas, pueden analizarse mejor en forma descriptiva. En tal caso, precisar qué datos serán tratados en forma cualitativa.

3 Indicar en la propuesta qué provisiones se tomarán para la limpieza y verificación de los datos. 


\section{B Plan para el análisis de datos}

\section{Características de los datos}

El plan de análisis constituye uno de los aspectos más importantes de la propuesta de investigación. El análisis de los datos debe responder a todas las preguntas investigadas en el estudio. El análisis divide a los datos en partes, los agrupa, clasifica y resume. En general, el investigador tratará de encontrar, a través de los datos, una o más de las características siguientes:

\section{a Tendencia central}

Supóngase que el investigador tiene como objetivo conocer la paridad media de un conjunto de mujeres, el método anticonceptivo más utilizado (la moda) o la mediana del nivel de ingreso. La media, la moda y la mediana, constituyen características de tendencia central. La media es simplemente un promedio aritmético obtenido mediante la suma de valores o medidas individuales divididas entre el total de casos. La moda es el valor que ocurrió con más frecuencia de un conjunto de valores. La mediana es el punto medio de un grupo de valores. Estas medidas estadísticas constituyen diferentes maneras de describir la característica típica o tendencia de un grupo.

\section{b Varianza de los datos}

Frecuentemente, el investigador va más allá del análisis de las tendencias promedio de un grupo y busca conocer la varianza en los datos observados dentro del grupo; es decir, cómo los individuos difieren del promedio o tendencia central. Si, por ejemplo, las usuarias de la píldora tienen en promedio 28 años, ¿cuál es el rango de edades en el grupo? ¿Qué edad tienen la usuaria más joven y la mayor? Una medida estadística común de la variación dentro de un grupo es la desviación estándar. Esta medida proporciona la distancia promedio o desviación promedio con respecto a la media del grupo.

\section{c Diferencias entre datos}

Muchas veces el investigador está interesado en saber si los resultados observados no son simplemente producto de la casualidad. Por ejemplo, si el $43 \%$ de un grupo experimental de100 mujeres casadas emplean un método anticonceptivo, comparado con sólo el $21 \%$ de un grupo de control, ¿puede esta diferencia considerarse estadísticamente significativa o ser meramente producto del azar? Posiblemente las pruebas estadísticas más comúnmente utilizadas son la ji-cuadrada $\left(\mathrm{X}^{2}\right)$ y la $t$ para probar diferencias entre medias. El uso de estas pruebas se explica más adelante.

\section{d Relaciones entre datos}

La mayoría de los estudios tratan de determinar si existe relación entre una variable y otra. Por ejemplo, ¿estár elacionado el uso de anticonceptivos con la edad? ¿Está relacionada la capacitación con un mayor rendimiento en el trabajo? ¿Están relacionados los mensajes por 
radio con un mayor conocimiento sobre anticonceptivos? ¿Está relacionado el nivel de educación con el uso de anticonceptivos? Existen diferentes métodos estadísticos para medir estas relaciones, el coeficiente de Pearson o el coeficiente Gama. Estos y otros métodos serán explicados en esta sección.

\section{Procedimientos de análisis}

Es posible que en la propuesta de investigación se describan diferentes métodos analíticos que el investigador planea usar para conocer las tendencias centrales de los datos, varianzas, diferencias y relaciones entre variables. Entre los procedimientos analíticos cuantitativos de uso más común en la investigación operativa en planificación familiar se encuentran:

a Transformación de las variables.

b Análisis univariado.

c Análisis de series de tiempo.

d Comparaciones.

e Análisis bivariado.

f Análisis multivariado.

g Análisis de costo-efectividad.

h Análisis de uso-efectividad.

i Análisis de fecundidad.

En la propuesta de investigación se deben indicar cuáles de estos procedimientos son los más apropiados para alcanzar los objetivos del estudio. La selección del método depende, en primer lugar, de lo apropiado que sea el método para responder alas preguntas del estudio. Otro factor importante que se debe considerar es el grado de conocimiento del método seleccionado por parte del investigador y su capacidad para interpretar los resultados correctamente.

A continuación se enumeran las principales características de los métodos de análisis. Esta enumeración no constituye, en ningún caso, un curso de análisis de datos y su comprensión y manejo suponen un conocimiento previo de métodos estadísticos. Todas las medidas y las pruebas estadísticas que se mencionan enseguida, son muy utilizadas por los investigadores de las ciencias sociales. El lector que desee saber cómo calcularlas e interpretarlas, puede en contrar información y ejemplos en cualquier libro de texto sobre métodos estadísticos elementales.

\section{a Transformación de variables}

El análisis de los datos requiere frecuentemente la transformación de los datos. Por ejemplo, supóngase que en el cuestionario no se registra explícitamente la edad del individuo interrogado, sino únicamente el mes y año de nacimiento. Si la edad es una variable que se va a estudiar, es necesario calcularla diferencia entre la fecha de nacimiento y la fecha de entrevista. Tal operación es más fácil de efectuar durante la fase de análisis que durante la de codificación, especialmente sise dispone de una computadora, lo cual permitirá mayor precisión en los cálculos que el método manual. Esta variable transformada puede requerir otras transformaciones; por ejemplo, si se desea realizar una tabulación cruzada por edades con otras variables, es preferible limitar la distribución de edad a unas cuantas categorías (generalmente se definen categorías cada cinco o diezaños) o aún hasta dicotomizar sólo en dos categorías (por ejemplo, edades entre 15-29 y edades de 
30 o más). Hay varias formas de transformar las variables, entre las más comunes se encuentran las siguientes:

Recodificación. En esta operación se cambian las etiquetas de las categorías. Esta técnica se emplea con objeto de disminuir el número de categorías de una variable. Por ejemplo, cambiar la distribución por años a distribución por grupos etarios de 15-19, 20-24 y 25-29 años.

Conteo. Al interrogar a los encuestadores sobre el uso de 10 métodos anticonceptivos, es útil contar el número de métodos alguna vez usados por cada usuario, generando de esta forma una nueva variable que puede denominarse "Número de Métodos Usados Alguna Vez". El conteo es útil en estudios que abarcan más de una variable.

Escala. En las investigaciones operativas sobre planificaciónfamiliar se utilizan diferentes técnicas de escala, entre las más comunes se puede mencionar a la técnica de Likert, que enocasiones se emplea en el estudio de actitudes. La técnica consiste en presentar al entrevistado una serie de afirmaciones(por ejemplo, la píldora es cancerígena, la píldora es muy eficaz, la píldora es de fácil empleo, la píldora provoca mareos). Posteriormente se pide la opinión del encuestado sobre cada una de ellas, preguntándoles si está total o parcialmente deacuerdo o en desacuerdo. A cada respuesta se le asigna un número del 1 al 5 que indica el grado de aceptabilidad, así el número 1 representa acuerdo total y el 5 desacuerdo total, o viceversa. Los puntajes de todas las respuestas se suman y se dividen entre el número de afirmaciones, produciendo una escala cuyos valoresse encuentran entre 1.0 y 5.0 .

Transformaciones condicionales. Las transformaciones condicionales se utilizan cuando la transformación de una variable depende de otra. Por ejemplo, supóngase que se hacen tres preguntas a los encuestados: 1) ¿Cuántos hijos tiene? 2)¿Desea tener más hijos? 3) ¿Si desea más hijos, cuántos más? Con la información obtenida de estas preguntas puede producirse una nueva variable denominada "Número total deseado de hijos". Esto puede hacerse sumando el número actual de hijos (pregunta 1) al número adicional deseado (pregunta 3). El número de la pregunta 3 se suma al número de la pregunta 1 , solamente si la respuesta a la pregunta 2 es afirmativa.

Otras transformaciones matemáticas. El cálculo de la edad,considerando la fecha de nacimiento y la fecha de entrevista, es un ejemplo de una transformación matemática. Otro ejemplo,relativo al análisis a nivel comunitario, es la prevalencia de uso anticonceptivo obtenido al dividir el número de usuarios en la comunidad entre el número de parejas en estudio.

\section{b Análisis univariado}

Como lo indica su nombre, esta forma de análisis examina cada variable en forma aislada. Muchas veces es importante analizar la distribución de los casos en la muestra con respecto a una sola variable. Por ejemplo, puede examinarse la distribución por edad de la muestra para confirmar que es consistente con la de la población de la cual se extrajo la muestra. El análisis univariado de datos muestrales también puede usarse para conocer la composición de la población conrespecto a las variables más importantes del estudio sobre las cuales no existe información. En ocasiones, se cumplen lamayoría de los objetivos del estudio mediante el análisis univariado. Por ejemplo, un diagnóstico para indicar los puntos fuertes y débiles de un proyecto determinado puede hacerse pormedio de una encuesta a los usuarios, sobre percepciones de y reacciones hacia las diversas operaciones del proyecto. Los aspectos fundamentales del diagnóstico pueden obtenerse mediante el estudio cuidadoso de cada una de las respuestas.

La forma más simple de realizar un análisis a nivel de una sola variable es contando el número de casos en cada categoría, obteniendo la distribución de frecuencia de la variable. Sin embargo, generalmente ésta no es del todo interesante a menos que se efectúen ciertas operaciones estadísticas complementarias. La naturaleza de estas operaciones depende del 
tipo de variable o del tipo de medida que se desea efectuar. Para la investigación operativa en planificación familiar es útil distinguir tres tipos de medidas: nominales, ordinales y de intervalo.

Medidas nominales. En las medidas nominales, las categorías dela variable difieren unas de otras sólo en cuanto al nombre. En otras palabras, una categoría de la variable no es necesariamente mayor ni menor que otra, la única diferencia reside en el nombre. Por ejemplo, la variable sexo tiene dos categorías, masculina y femenina; el investigador puede asignar el número 1 a la categoría masculina y el 2 a la femenina. El único propósito de estos números es distinguir una categoría de la otra. El investigador bien podría asignar el número 2 al sector masculino y el 1 al femenino, o bien el número 1528 podría asignarse al sector masculino y el 83 al femenino; no hay diferencia. Otro ejemplo, sería asignar números a diferentes métodos anticonceptivos: 1 = esterilización femenina; 2 = esterilización masculina; 3 = condón; $4=$ DIU; 5 = orales; $6=$ espermicida. Estos números simplemente distinguen las categorías. El asignar un número grande a una categoría no significa que ésta sea mejor o peor que otra de número menor. Podría usarse cualquier selección de números para clasificar los distintos métodos anticonceptivos, lo importante es ser consistente y emplear siempre el mismo número para la misma categoría.

Las medidas nominales son las más limitadas. Las diferentes categorías de la variable nominal deben ser mutuamente exclusivas y estas categorías difieren en nombre solamente. Los números asignados a las diferentes categorías permiten simplemente agrupar los elementos comunes en la misma categoría (si tienen el mismo número), o en diferentes categorías (si tienen número diferente). Las posibles manipulaciones estadísticas con variables nominales son bastante limitadas. Se puede calcular la moda (la categoría más frecuente), también se puede calcular una distribución porcentual, pero no se pueden calcular medias, ya que no tiene sentido hablar del "sexo medio" o del "método anticonceptivo medio" o de la "religión media". Cada una de éstas es una variable nominal.

Medidas ordinales. Se habla de variables ordinales cuando existe una jerarquía entre las diferentes categorías. En otras palabras, la categoría que tiene el número 1 puede considerarse más elevada que la que tiene el número 2, que puede, a su vez, considerarse mayor que la que tiene el número 3. Por ejemplo, en una investigación operacional sobre planificación familiar que busque conocer la opinión con respecto al uso de anticonceptivos, podría utilizarse la siguiente clasificación:

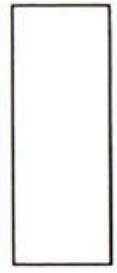

$$
\begin{aligned}
& \mathbf{1}=\text { Aprobación total. } \\
& \mathbf{2}=\text { Aprobación moderada } . \\
& 3=\text { Aprobación escasa. } \\
& 4=\text { Desaprobación total. }
\end{aligned}
$$

Los números asignados a las diferentes categorías no sólo permiten distinguir si los elementos están en una misma categoría o en diferentes (como en el caso de las variables nominales) sino que además indican un orden jerárquico que va del 1, el cual es igual a alto (aprobación total), hasta el 4, que es igual a bajo (desaprobación total). Las variables ordinales se prestan a las mismas operaciones estadísticas que con las nominales (como la moda y los porcentajes); pero además, debido al orden jerárquico de los números, es posible el uso de estadísticas como la mediana, el percentil y varias pruebas no paramétricas que se explicarán posteriormente. Sin embargo, no es posible calcular una media, una desviación estándar o el coeficiente de correlación de Pearson. Por ejemplo, no puede hablarse de la actitud media en relación con la anticoncepción, ya que se desconoce la distancia o intervalo entre cada categoría. En el ejemplo anterior, se desconoce si la distancia entre 1(aprobación total) y 2 (aprobación moderada) sea la misma que en 3 (aprobación limitada) y 4 (desaprobación total). Puede darse el caso de que las respuestas clasificadas en las categorías 1,2 y 3 sean bastante similares unas de otras, mientras que las que caen en la categoría 4 sean muy diferentes. La figura 10.1 ilustra esta situación. Aunque se estableció 
un orden jerárquico en los números asignados a las categorías de las variables, las distancias entre las categorías difieren.

Medidas de intervalo. Una variable de intervalo es aquélla en la que se conoce la distancia (o intervalo) entre las diferentes categorías. Los números asignados a las diferentes categorías de las variables cuantitativas poseen todas las características de las variables nominales u ordinales, con la característica adicional de poseer una unidad constante de medición entre las diferentes categorías que están igualmente espaciadas. La edad y la paridad son variables con intervalos constantes al igual que la duración de uso de anticonceptivos y la fecha de aceptación de un método anticonceptivo. Para cada una de estas variables la distancia entre dos categorías que se siguen es conocida y constante. Una persona de 34 años es cuatro años mayor que una de 30 . Una persona con paridad de seis tiene dos hijos más que una con paridad de cuatro. El tiempo, la temperatura, el dinero y el peso son variables de intervalo debido a que los intervalos entre las categorías son conocidos y constantes; esta situación es representada en la Figura 10.2. Un niño clasificado en la categoría 5 no es solamente distinto (nominal) de un niño situado en la categoría 6 , sino que es también más joven (ordinal) y es un año menor (de intervalo). Todas las operaciones estadísticas que es posible realizar con variables nominales u ordinales también son aplicables a las variables de intervalo, sin ser siempre necesariamente apropiadas para estas últimas. Además de lo anterior, con las variables de intervalo es posible calcular y usar medidas como la media, desviación estándar, coeficiente de correlación de Pearson y muchos otros índices estadísticos.

FIGURA 10.1

Medida ordinal de la actitud hacia el uso de anticonceptivos.

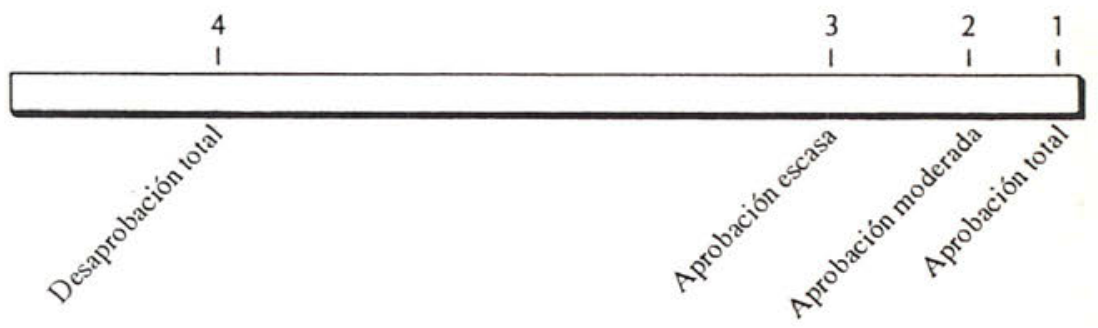

FIGURA 10.2

Medida de intervalo

de la edad.

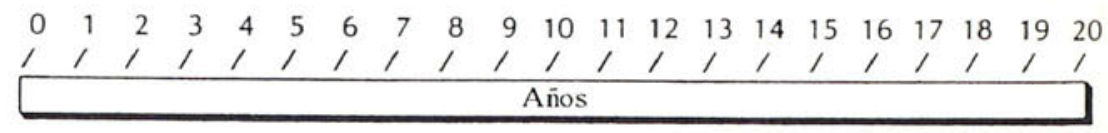




\section{c Análisis de series de tiempo}

El análisis de los datos puede resultar simple y revelador si el estudio se diseña de tal manera que se obtengan datos a través de múltiples observaciones a través de un periodo o series de tiempo. El análisis consiste, en este caso, en observar la evolución en el tiempo de una determinada medida estadística. Esta medida puede tomar diferentes formas, en la mayoría de los casos es una frecuencia (ejemplo: número mensual de usuarios) un porcentaje (ejemplo: una tasa de prevalencia) o una medida de tendencia central (ejemplo: tamaño medio deseado de la familia). Si ocurre una intervención en el transcurso del periodo de observación (ejemplo: $\mathrm{O}_{1} \mathrm{O}_{2} \mathrm{O}_{3} \mathrm{O}_{4} \mathrm{X} \mathrm{O}_{5} \mathrm{O}_{6} \mathrm{O}_{7} \mathrm{O}_{8}$ ) se puede medir el impacto comparando las tendencias antes y después de la intervención.

CUADRO 10.1.

Datos de series de tiempo: número de hombres vasectomizados por mes durante 1991

\begin{tabular}{|c|c|c|}
\hline Mes & Número & \\
\hline Enero & 120 & \multirow{8}{*}{ Promedio enero-abril $=116$} \\
\hline Febrero & 110 & \\
\hline Marzo & 130 & \\
\hline Abril & 105 & \\
\hline Mayo & 1200 & \\
\hline Junio & 30 & \\
\hline Julio & 45 & \\
\hline Agosto & 15 & \\
\hline Septiembre & 30 & \multirow[t]{5}{*}{ Promedio junio-diciembre $=55$} \\
\hline Octubre & 60 & \\
\hline Noviembre & 90 & \\
\hline Diciembre & 115 & \\
\hline Total & 2050 & \\
\hline
\end{tabular}

El Cuadro 10.1 nos permite detectar fácilmente que un acontecimiento extraordinario debió producirse en el transcurso del mes de mayo. Si este resultado se debe a una campaña nacional a favor de la vasectomía, se podría concluir que el impacto fue impresionante. Sin embargo, este cuadro indica también que el número de vasectomías descendió rápidamenbte después de la campaña, pasando de un promedio mensual de 116 antes de la campaña, a un promedio mensual de 55 después de ésta.

Este cuadro puede prestarse a diversas interpretaciones. Una de ellas es que la campaña de mayo "adelantó" casos que iban a suceder en el futuro; es decir, ciertas personas que se hubieran operado en los meses de junio, julio, o agosto, decidieron anticipar su operación en el mes de mayo debido a que la campaña los motivó. Otra interpretación posible consiste en que después de la campaña de mayo, el personal de planificación familiar (médicos, enfermeras y personal de campo) haya disminuido sus esfuerzos para motivar a posibles 
pacientes y simplemente no pudieron reclutar a tantos casos como anteriormente. La tabla de distribución de frecuencias solamente sugiere estas interpretaciones, pero no las comprueba. Estas interpretaciones pueden constituir la base de un estudio para investigar la razón que explique la disminución en el número de esterilizaciones observada después del mes de mayo.

\section{d Comparaciones}

La comparación de variables con frecuencia constituye uno de los objetivos de la investigación. Por ejemplo, en un diseño experimental, los resultados más importantes se desprenden de la comparación del grupo experimental con el grupo de control. Si un estudio experimental se diseña para determinar el efecto de una intervención sobre el uso de anticonceptivos, se podría proceder a comparar la distribución porcentual del grupo experimental con la del grupo de control, en relación al uso de anticonceptivos. Si es posible suponer con bastante certeza que al inicio ambos grupos eran similares y que no tuvieron otras influencias además de la intervención, entonces una diferencia significativa en la proporción de usuarios de anticonceptivos en el grupo experimental comparado con el de control, sería una evidencia de que la intervención fue exitosa.

Para probar diferencias de pares de medias la prueba $t$ es la más común. Esta prueba se usa con muestras pequeñas ( $\mathrm{N}$ igual o inferior a 30 ); y supone que los elementos $\mathrm{u}$ observaciones son extraídos de poblaciones normalmente distribuidas con igual varianza. Para comparar porcentajes la prueba ji-cuadrada $\left(\mathrm{X}^{2}\right)$ es más utilizada. A veces puede ser necesario comparar los porcentajes de respuestas que se han obtenido de la misma muestra en dos momentos distintos; en tales casos la prueba de McNemar para cambios significativos es la más apropiada.

Si el plan de análisis requiere de la comparación simultánea de más de dos medias, la técnica analítica más apropiada es el análisis de varianza (ANVA). Esta técnica emplea la prueba $\mathbf{F}$ para determinar si existen o no diferencias significativas.

\section{e Análisis bivariado}

Los objetivos de la investigación operativa en planificación familiar exigen frecuentemente el estudio de relaciones entre pares de variables, especialmente entre medidas de la operación del programa y los efectos del programa. Las técnicas de análisis indicadas para el estudio de relaciones bivariadas, dependen de la naturaleza de las variables: si son nominales, ordinales o de intervalo.

Relaciones entre variables nominales. El primer paso en el estudio de relaciones entre variables nominales consiste en efectuar la tabulación cruzada de dos variables y en seguida aplicar la prueba ji-cuadrada para determinar si existe una relación significativa. Esta prueba, sin embargo, no mide la importancia de la relación, para esto es necesario una "medida de asociación" y, una de las mejores de tales medidas para variables nominales es la V de Cramer, la cual es derivada del valor de la ji-cuadrada.

Relaciones entre variables ordinales. Existen varios tipos de medidas de asociación para tabulaciones cruzadas de variables ordinales. Una de las más simples de calcular es la estadística gamma; desafortunadamente no existe una prueba simple de significancia para Gamma (la prueba ji-cuadrada puede utilizarse para determinar si la relación entre variables es significativa, pero no hay que olvidar que esta prueba no es sensible a la ordinalidad de los datos y por lo tanto no es realmente una prueba de significación para gamma).

Relaciones entre variables de intervalo. Las relaciones entre las variables de intervalo pueden analizarse con o sin tabulaciones cruzadas. Si se realizan tabulaciones cruzadas con las variables cuantitativas, el tipo de relación es aparente y se pueden calcular los valores de gamma o de V de Cramer. Pero es más usual medir la relación entre variables cuantitativas 
mediante el coeficiente de correlación Pearson $(r)$, sin referirse para ello a ninguna tabulación cruzada. La significación estadística de $(r)$ puede establecerse mediante la prueba $t$.

Si se distingue entre variables dependientes e independientes, se puede emplear el análisis de regresión lineal para examinar la relación. En este caso la medida de asociación es el coeficiente de regresión de orden cero, el cual indica el cambio promedio de la variable dependiente asociada con una unidad de cambio en la variable independiente.

Tanto el coeficiente de correlación como el de regresión miden relaciones de tipo lineal; es decir, el aumento o disminución de una variable se da en proporción directa del aumento o disminución de otra variable. Estos dos coeficientes no son sensitivos a relaciones no-lineales, para las que, por ejemplo, los valores altos de una de las variables pueden estar asociados tanto a los valores elevados como a los bajos de la otra variable (pero no a los valores intermedios).

Todas la medidas de asociación que se discutieron anteriormente, a excepción del coeficiente de regresión y la V de Cramer, toman valores comprendidos entre (-)1.00 (relación perfecta negativa) y (+)1.00 (relación perfecta positiva). Cuando no existe relación alguna entre las variables, el coeficiente es igual a 0.0 .

Nótese que ninguna de las medidas de asociación indica causalidad. El hecho de que las personas que leyeron un documento sobre el DIU sean las que más lo utilicen, no necesariamente significa que la lectura del documento haya causado el uso de éste. Puede ser que las personas que tengan acceso al DIU tengan también acceso a la documentación y que la relación que se observó sea completamente producto de esa coincidencia. También puede ser que una relación sea realmente de tipo causal pero que la dirección de la causalidad sea en sentido contrario. Por ejemplo, puede ser que la documentación sobre DIU tienda a darse a personas que ya son usuarias de DIU con objeto de informarlas más detalladamente de las características de un nuevo dispositivo, o bien ellas mismas pueden solicitar tal documentación despuěs de la colocación del DIU, especialmente si ciertos efectos secundarios comienzan a hacerse sentir. En tal caso, existen al menos tres tipos de relaciones posibles como lo muestra la Figura 10.3.

FIGURA 10.3

Tres posibles relaciones entre la lectura de un folleto y el uso del DIU.
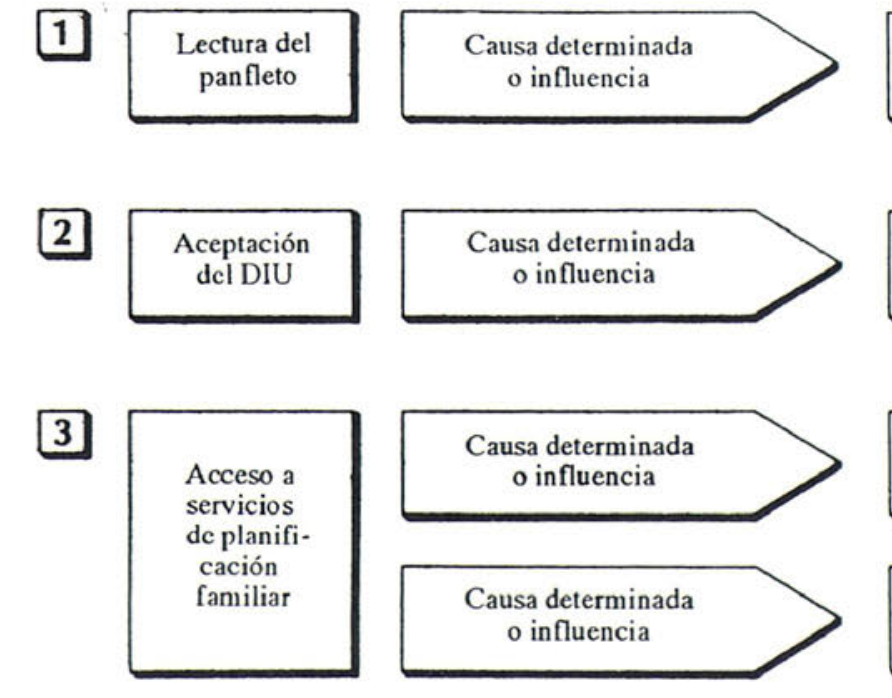

Lectura del panfleto

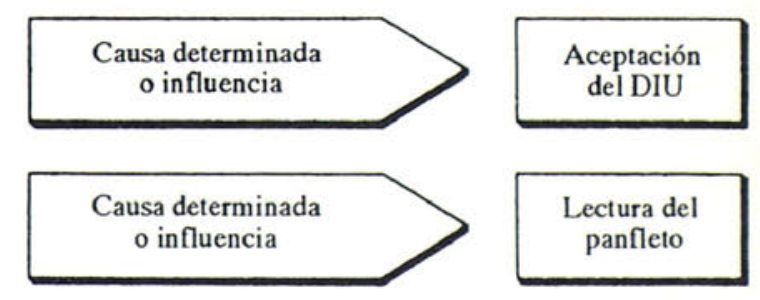


El análisis bivariado en ocasiones suscita preguntas que sólo el análisis multivariado puede resolver. Por ejemplo, si aparentemente existe una relación entre religión y uso de anticonceptivos, se podría suponer $a$ priori que estas diferencias señalan una relación causal directa. Sin embargo, también se puede argüir que las diferencias se deben a otros factores. Por ejemplo, se ha observado desde hace tiempo que el uso de anticonceptivos entre la población indígena en Guatemala es menor que el de la población ladina. Esta relación no es, sin embargo, de tipo causal, ya que los grupos indígenas tienen en general un estatus socio-económico mucho más bajo y viven en regiones en donde los servicios de planificación familiar son escasos. Para verificar si la relación entre raza y práctica anticonceptiva es explicable por las diferencias socio-económicas o por la falta de acceso a los servicios e información sobre la planificación familiar, se deben controlar o mantener constantes las variables ligadas a la situación socio-económica y el acceso a los servicios. Si aún así, la relación se conserva inalterada, se puede concluir que las variables relativas al status socio-económico y al acceso a servicios influyen muy poco o no tienen ninguna influencia en la práctica anticonceptiva. Si por el contrario, la relación desaparece, se puede concluir que se trata de una relación espuria originada por efectos simultáneos, tanto de las variables dependientes como independientes sobre las variables de control.

Las técnicas que permiten al investigador mantener constante o controlar una o varias variables se denominan análisis multivariados, ya que permiten la intervención de varias variables (más de dos). La mayoría de las técnicas multivariadas permiten también medir simultáneamente el grado de asociación entre una variable dependiente y dos (o más) variables independientes. Existen varias técnicas multivariadas y su utilización depende del tipo de variables a estudiar. Para las variables dependientes de intervalo existen tres tipos de análisis multivariados ampliamente usados, cuya selección depende de la naturaleza de las variables independientes, como se explica a continuación.

Todas las variables de intervalo. Cuando todas las variables dependientes $\mathrm{e}$ independientes son de intervalo, la técnica más apropiada es la del análisis de regresión múltiple, que es la más común y más utilizada de las técnicas multivariadas. Esta genera coeficientes de regresión parcial que indican la cantidad de aumento de la variable dependiente asociado a una unidad de aumento en cada una de las variables independientes, manteniendo constantes todas las otras variables independientes. Estos coeficientes con frecuencia se convierten en coeficientes de regresión estandarizados (beta) que indican el grado de variación de la variable dependiente asociado a las variaciones de la variable independiente, en términos de desviación estándar, en lugar de las unidades originales de medición. Esta técnica también genera un coeficiente de regresión múltiple $(R)$, el cual mide las relaciones simultáneas entre la variable dependiente y todas las variables independientes. El cuadrado de coeficiente de regresión múltiple, conocido como el coeficiente de determinación $\left(R^{2}\right)$, mide la proporción de la varianza de la variable dependiente explicada por todo el conjunto de variables independientes.

Variables de intervalo y categóricas. Cuando la variable dependiente es de intervalo y las variables independientes son variables categóricas (nominales u ordinales), la técnica más apropiada es la del análisis de regresión múltiple con variables binarias. Una variable binaria es la que comprende solamente dos categorías. Una variable categórica puede convertirse en varias variables binarias. Por ejemplo, una variable nominal de tres categorías que representa grupos étnicos (indígenas, negros, ladinos) puede generar tres variables binarias. Se puede crear la variable "indígenas" asignando el código para los indígenas y el 0 para todos los demás; también se puede crear la variable "negros", asignando el código 1 a los negros y el 0 a todos los demás. Se puede también crear la variable "ladinos", asignando el código 1 a los ladinos y el 0 a todos los demás. De la misma manera, una variable de cuatro categorías puede transformarse en cuatro variables, una variable de cinco categorías puede transformarse en cinco variables. En el análisis de regresión múltiple, todas las variables binarias obtenidas en esta forma, excepto una, se toman como variables independientes para cada una de las variables categóricas originales. Con variables binarias, los coeficientes de regresión calculados indican la diferencia en la 
variable dependiente entre la categoría considerada por la variable binaria y la categoría omitida del análisis. La interpretación de $R$ y $R^{2}$ es la misma que en un análisis de regresión ordinario.

Todas las variables categóricas. Cuando la variable dependiente es de intervalo y todas las variables independientes son categóricas, la técnica más apropiada es el análisis de clasificación múltiple (ACM). Esta técnica es en realidad una extensión del análisis de regresión múltiple con variables binarias, pero proporciona un valor beta para cada una de las variables categóricas originales, mientras que el análisis de regresión produce valores beta menos útiles para cada variable binaria incluida. El análisis de clasificación múltiple (ACM) produce también los valores $R$ y $R^{2}$.

Si la variable dependiente es categórica, el análisis se limitará a tabulaciones cruzadas multidimensionales (si alguna o todas las variables independientes son de intervalo, podrán ser transformadas fácilmente en variables categóricas para este análisis). En los últimos años ha sido posible perfeccionar ciertas técnicas sofisticadas de análisis multivariado para variables nominales dependientes, pero estas técnicas son dominadas por sólo unos cuantos investigadores y los paquetes para microcomputadoras no se consiguen fácilmente.

Las técnicas de análisis multivariado son poderosos instrumentos de análisis pero deben utilizarse con mesura ya que se apoyan en diversos supuestos, algunos de los cuales no se cumplen; por lo tanto, los resultados no son válidos. El plan de análisis no debe comprender un análisis multivariado, a menos que el investigador domine la técnica o cuente con la asistencia de un asesor calificado.

\section{g Análisis de costo-efectividad}

Todos los programas de planificación familiar requieren recursos financieros para desarrollar sus actividades y obtener los resultados o efectos deseados. En la mayoría de los programas de planificación familiar llevan a cabo actividades que tienen como objetivo tener un efecto que se mide en nuevos usuarios, nacimientos evitados o años-protección-pareja. Una pregunta lógica que se hacen los administradores de un programa es ¿qué actividad es menos costosa y tiene mayores efectos? El análisis de costo-efectividad (ACE) pretende responder a esta pregunta. Este análisis constituye un instrumento para tomar decisiones y es válido si se comparan los costos de dos o más estrategias diferentes, o bien la evolución a través del tiempo de una sola estrategia. Este análisis permite estudiar diferentes alternativas, por lo que se refiere al costo, para llegar al objetivo final.

En el análisis de costo-efectividad se calcula una razón en cuyo numerador aparece el costo del programa y en el denominador los efectos o resultados del mismo. Si bien los cálculos son simples, el ACE presenta ciertas dificultades. En primer lugar, deben determinarse los costos precisos del programa, lo cual no siempre resulta fácil, especialmente si las actividades de planificación familiar están completamente integradas a otras actividades de salud. Por ejemplo, ¿qué proporción del presupuesto de las clínicas donde se efectúan las inserciones del DIU se asigna a la planificación familiar? Igualmente, ¿qué proporción de horas de trabajo y honorarios correspondientes dedican los médicos y las enfermeras a la planificación familiar? ¿Deben tomarse en cuenta ciertos costos generales y otros costos indirectos? ¿Se debe considerar la inflación o el tipo de cambio internacional de una moneda? Estas y otras preguntas surgen de forma ineludible en el análisis de costo-efectividad.

Además de la dificultad ligada a la determinación del costo, surge otro problema al tratar de recolectar información para determinar el efecto del programa. Debe precisarse en qué unidades se va a medir tal efecto. ¿Qué es un usuario de planificación familiar? ¿Qué son años-protección-pareja o nacimientos evitados? Y ¿Cómo se definen estos términos operacionalmente? Existen además otras dificultades; por ejemplo, puesto que los efectos de ciertos programas se van distribuyendo a lo largo del tiempo, los efectos de la esterilización pueden reflejarse a través de varios años. 
En el cálculo de la tasa costo-efectividad deben hacerse supuestos con respecto a la distribución de los efectos sobre el tiempo. En ocasiones ACE involucra tantos supuestos con respecto a costos y efectos que su utilidad como herramienta de decisión se hace cuestionable. Además, puede darse el caso de que el programa más indicado desde el punto de vista costo-efectividad, no sea forzosamente el más indicado desde el punto de vista político o social.

El análisis de costo-efectividad resulta ser más pertinente cuando se trata de comparar programas muy específicos y limitados en el tiempo, con objetivos claramente definidos y costos detallados que pueden ser desagregados. Por ejemplo, supóngase que se define una medición como la aceptación y continuidad en el uso de una nueva píldora durante por lo menos un año. Un ACE puede realizarse para determinar qué es más efectivo: un equipo móvil, personal de campo o clínicas. De manera similar, también puede emplearse ACE para determinar cuál de los diferentes tipos de capacitación es el más idóneo para producir un buen trabajador de campo. ACE también puede servir para comparar el costo de esterilizaciones realizadas en puestos improvisados, en relación con el costo de las realizadas en clínicas o en hospitales.

\section{h Análisis de uso-efectividad}

En la investigación operacional en planificación familiar es importante medir la probabilidad de que una nueva usuaria continúe utilizando mes tras mes un método para no embarazarse. Estas probabilidades pueden estimarse mediante un análisis uso-efectividad con tablas de vida. Los índices más importantes de este tipo de análisis son las tasas de continuidad y las de embarazo. Puede distinguirse entre tasas de continuidad mensuales y acumuladas; entre tasas de continuidad de un solo método y las de continuidad para todos los métodos; entre tasas brutas y netas de embarazo y, finalmente, entre la tasa de fracaso y la tasa global de embarazo.

Una tasa mensual de continuidad mide la probabilidad de que una persona que comienza a usar un método en un mes continúe usándolo hasta el final del mes.

Una tasa acumulada es la probabilidad de que un nuevo usuario continúe usando el método después de cierto número de meses.

Una tasa de continuidad de un solo método mide la probabilidad de continuar el uso de ese método.

Una tasa de continuidad de todos los métodos es la probabilidad de continuar el uso de cualquier método.

Una tasa bruta de embarazo mide la probabilidad de embarazo durante un período determinado, sin tomar en consideración los riesgos de abandono (como la expulsión del DIU, o descontinuación voluntaria debido a efectos secundarios).

Una tasa neta de embarazo mide la misma probabilidad que la tasa bruta de embarazo, pero tomando en cuenta los riesgos de abandono.

La tasa de fracaso mide la probabilidad de embarazarse durante un período específico de tiempo, durante el cual se está usando un método anticonceptivo.

La tasa global de embarazo es la probabilidad de que ocurra un embarazo durante un período específico de tiempo después de aceptado el método, independientemente de que se esté usando o no algún método en ese momento. 


\section{i Análisis de fecundidad}

En virtud de que la mayoría de los programas de planificación familiar están diseñados para provocar o acelerar una reducción en la fecundidad, es frecuente que sea necesario incorporar un análisis de fecundidad en la investigación de operaciones en planificación familiar. Las medidas de fecundidad más usuales para este propósito son:

Tasa bruta de natalidad: número anual de nacimientos por cada 1000 habitantes.

Tasa global de fecundidad: número anual de nacimientos por cada 1000 mujeres en edad reproductiva.

Tasa global de fecundidad marital: número de nacimientos por cada 1000 mujeres casadas o unidas y en edad reproductiva.

Tasas específicas de fecundidad: número de nacimientos por cada 1000 mujeres casadas o unidas, de un grupo de edad determinado.

Tasa total de fecundidad: número promedio de hijos esperados durante el período reproductivo de la mujer, según el patrón de tasas de fecundidad relacionado con la edad específica.

\section{Prototipo de tablas}

La construcción de prototipos de tablas permite visualizar la forma en que los datos pueden ser organizados y resumidos. Una tabla prototipo contiene todos los elementos de una real, excepto que las celdas de las tablas están vacías (Ver Cuadro 10.2) En la propuesta de investigación deben presentarse las relaciones más importantes entre las variables, haciendo uso de tablas artificiales.

Las tablas de tabulaciones cruzadas generalmente presentan frecuencias convertidas a porcentajes basados en el total por renglón o por columna. Cuando una variable dependiente se cruza con una independiente, los porcentajes deben calcularse de manera que sumen el $100 \%$ ara cada categoría de la variable independiente. Por ejemplo, en la siguiente tabla artificial, los porcentajes totales se calculan para cada categoría de la variable independiente (en este caso, "la disponibilidad de personal"). 
CUADRO 10.2

Ejemplo de una tabla artificial: Tasa de prevalencia

en las aldeas y presencia de trabajadoras

de campo. (Distribución porcentual)

Presencia de trabajadoras de campo en la aldea

\begin{tabular}{l|c|c|c}
\hline \multicolumn{1}{c}{ No } & \multicolumn{1}{c}{ Sí } & \multicolumn{1}{c}{ Todas las aldeas } \\
\hline Tasa de prevalencia en aldeas & $(\mathbf{N}=)$ & $(\mathbf{N}=)$ & $(\mathbf{N}=)$ \\
\hline $50+$ por ciento & & & \\
\hline $25-49$ por ciento & & & \\
\hline $0-24$ por ciento & & & \\
\hline Porcentaje total & 100 & 100 & 100 \\
\hline
\end{tabular}

$\mathrm{x}^{2}$ d.f. $\mathrm{p} \leq$ gamma $=$

\section{QUE HACER: Plan de análisis de los datos}

1 Describir detalladamente cada una de las técnicas de análisis, así como las medidas estadísticas a utilizar, indicando cómo cada una de éstas va a contribuir a alcanzar los objetivos del estudio. Qué tipo de variables están involucradas y cuáles fueron las razones que determinaron la elección.

2 Preparar ejemplos de tablas artificiales.

3 El plan de análisis debe presentar claramente cómo serán alcanzados los objetivos del estudio, cómo será utilizada cada variable y finalmente cómo será probada cada hipótesis. 


\section{Difusión de los resultados de la investigación}

No hay razón para llevar a cabo una investigación si los resultados no van a ser comunicados a otros de manera comprensible y útil. Al principio de este manual, se definió a la investigación operativa como un proceso continuo con cinco pasos básicos. Los dos últimos pasos son la difusión y utilización de la información. El proceso de la investigación operativa no está completo si no se presta la misma atención a estos dos pasos, que la que se dio a los tres primeros.

\section{A Estrategias de difusión}

La investigación operativa se hace en principio para obtener información que sea útil y confiable que permita a los administradores de programas y formuladores de políticas mejorar los servicios de planificación familiar. Para que un estudio de investigación operativa tenga un impacto importante, se requiere planear una estrategia de difusión, que responda a estas tres preguntas básicas:

1 ¿Quiénes son los usuarios de los resultados de un estudio de investigación operativa?

2 ¿Qué resultados en particular serán de mayor interés para cada grupo de usuarios potenciales?

3 ¿Cuáles son los mejores canales y medios de comunicación para llegar a cada usuario potencial?

Casi siempre las audiencias o usuarios de los resultados de una investigación operativa son los altos funcionarios y administradores que formulan políticas, académicos, gerentes de nivel medio, trabajadores de campo y prestadores de servicios. Algunos resultados serán de mayor interés para algunos grupos y deberán emplearse canales de comunicación apropiados para llegar a esos grupos. El propósito principal de una estrategia de difusión es identificar los canales más eficaces para llegar a las diferentes audiencias (usuarios de la información) con la información que más necesitan. Una buena estrategia de difusión debe incluir una variedad de medios, repitiendo los mensajes durante un tiempo para lograr llegar a la mayor audiencia posible.

\section{B Elaboración de informes}

Aunque los resultados de la investiga ción deben ser difundidos de distintas maneras, todos los estudios de investigación operativa deben presentarse por lo menos en informes escritos. Los informes deberán elaborarse de acuerdo a las necesidades de cada audiencia particular.

Si la audiencia está compuesta por gerentes de programa, los informes no deben llenarse con datos técnicos sobre muestreo y diseño, obscureciendo los hallazgos importantes, ya que los gerentes no son usualmente investigadores. El material técnico puede agregarse en uno o varios apéndices y no es necesario incluirlo en el cuerpo del informe. 
Algunas veces es difícil que los gerentes vean la importancia de los resultados de una investigación. En estos casos se les debe indicar las implicaciones que los resultados tienen para mejorar el programa, y hacerles recomendaciones de cómo usar los resultados de la investigación.

Una queja común de los gerentes es que los informes de investigación son muy complicados, que tardan mucho en salir y por lo tanto resultan obsoletos. Se debe evitar este problema sacando informes parciales tan pronto como se conoce un resultado importante, haciendo un resumen ejecutivo del informe principal. En el resumen ejecutivo no es necesario hablar sobre el diseño empleado por el estudio, si este fue cuasi-experimental, o si se usó un grupo de control no equivalente para obtener datos que fueron analizados usando múltiples clasificaciones. El informe debe enfocarse en los hallazgos más importantes que tengan implicaciones para mejorar el programa. Deben usarse gráficas fáciles de entender así como un lenguaje simple.

Cuando se escriba un informe para un grupo de académicos, el formato puede ser muy diferente del que se usa para gerentes de programa. En este caso el reporte debe escribirse de manera que el lector pueda juzgar el valor científico del estudio, comprobar si el diseño fue adecuado y, si así lo desea, replicar el estudio en otros lugares con otros sujetos.

\section{QUE HACER: Informe de los resultados de la investigación}

1 Escribir una sección en la propuesta de investigación que describa el plan de difusión de la información. El plan debe indicar:

a Quiénes son los usuarios de la información.

b Qué hallazgos serán de mayor interés para cada grupo de usuarios.

c Qué canales de comunicación son más apropiados para cada grupo de usuarios. 


\section{Utilización de los resultados de la investigación}

La utilización de los resultados es la meta de toda investigación operativa.

Desafortunadamente, en muchas ocasiones no se cumple esta meta. Una razón por la que no se cumple es que las personas que diseñan e implementan los estudios de investigación operativa no son las mismas que usan los resultados. Otra es que algunas veces los investigadores creen que un estudio ha terminado cuando el informe final está escrito y difundido. Este es un error. Como se mencionó en el capítulo anterior, el proceso de la investigación operativa no está completo hasta que los resultados hayan sido difundidos ampliamente y se hayan hecho todos los esfuerzos para que sean utilizados. Esta es una parte muy importante y básica del proceso.

Utilización significa simplemente hacer uso de algo. Para la investigación operativa ese "algo" pueden ser los resultados del estudio o el proceso de este estudio. Existe, por supuesto, una gran variedad de formas de utilizar los resultados o el proceso de un estudio. Por ejemplo, los altos funcionarios del gobierno pueden usar los resultados de la investigación operativa para formular o rediseñar políticas nacionales de salud y planificación familiar. Los directores de agencias de servicios pueden usar los resultados de la investigación operativa para la planeación estratégica. Pueden también usar el proceso de la investigación operativa para identificar las áreas problemáticas y enfocar su atención y recursos a solucionar estos problemas. De la misma manera, los investigadores pueden usar los resultados de la investigación operativa para refinar la teoría de las ciencias sociales y pueden usar el proceso de implementación del estudio para desarrollar nuevas formas de recolección de datos o técnicas de investigación y para capacitar a los jóvenes investigadores. Los supervisores y trabajadores de campo, así como el personal de clínicas, pueden usar los resultados de la investigación operativa para evaluar su propia actividad y para mejorar la calidad de los servicios que prestan.

Es poco común encontrar situaciones donde los resultados de un estudio de investigación operativa son aceptados en su totalidad y adoptados inmediatamente para cambiar un sistema de prestación de servicios. Más bien, los resultados de la investigación operativa se usan combinados con otra información (de tipo político, de experiencias, opiniones de colegas, otros resultados de investigación) para obtener un panorama más completo de una situación. La información nueva puede ser crucial, particularmente si da a los tomadores de decisiones la confianza adicional que requieren para llevar a cabo cambios necesarios en la prestación de servicios. En algunos casos "utilización" no se refiere a los resultados de los estudios, sino al uso de un proceso de investigación operativa para identificar y definir problemas y para estudiar sistemáticamente posibles estrategias para solucionar estos problemas.

Aunque no hay forma de que un investigador garantice que los resultados de un estudio sean usados por los tomadores de decisiones, hay varias formas de aumentar la probabilidad de la utilización. Por ejemplo:

1 En el momento en que se está planeando un estudio, debe formularse una lista específica de tomadores de decisiones que muy probablemente estuvieran interesados en el tema de estudio. Estas personas deben ser contactadas e informadas de los objetivos del estudio.

2 Diseñar un plan para involucrar a los usuarios potenciales de los resultados en todos los aspectos del estudio. Cuanto más activamente se involucran los tomadores de decisiones en la planeación, implementación y análisis de un estudio, más probabilidades hay de que se comprometan a usar los resultados. 
3 Incluir una sección sobre "Implicaciones del Estudio" en los informes parciales y finales de la investigación. Indicar clara y sucintamente las implicaciones del estudio que se crea motivarán cambios mayores.

4 En los seminarios de fin de proyecto, se deberá asignar tiempo suficiente para que los participantes discutan ampliamente los resultados del estudio y para que desarrollen un plan de acción para usarlos. Esto se puede hacer formando pequeños grupos de discusión.

\section{QUE HACER: Utilización de los resultados}

Incluir en la propuesta del estudio una sección sobre utilización de los resultados del proyecto. En esta sección se debe:

1 Identificar a las organizaciones que se crea están más interesadas en el estudio.

2 Discutir la forma de involucrar a estas organizaciones en las distintas fases del estudio: planeación, implementación, análisis y difusión de resultados.

3 Señalar la política o implicación más importante que aportará el estudio al programa. 


\section{Limitaciones del estudio}

\section{A Limitaciones del diseño y del análisis}

Ningún estudio es perfecto y en todo proyecto de investigación pueden surgir dificultades con respecto a la confiabilidad y validez de los datos, el tamaño de la muestra, el diseño del cuestionario o el plan de análisis. Aún cuando el investigador se proponga reducir al mínimo estas limitaciones, algunas subsistirán. En la propuesta del estudio, es mejor reconocer las limitaciones del diseño que tratar de ignorarlas. Por ejemplo, si se hace una selección de una muestra previamente determinada, será inútil pretender que ésta es representativa de una población mucho mayor. $\mathrm{Si}$, a falta de tiempo o de recursos financieros, se hace uso de fuentes de datos que pueden ser cuestionables (tales como expedientes clínicos y estadísticas de servicios) esto deberá tenerse en cuenta y no pretender que los datos son completamente confiables y válidos. No deberá ocultarse el hecho de que el grupo de control no es equivalente al experimental. En todo caso es mejor admitir la existencia de tales limitaciones y tratar de resolverlas, de ser posible, mediante métodos apropiados de análisis, o bien advirtiendo al lector que, debido a ciertas limitaciones en el diseño del estudio, los resultados deben considerarse provisionales.

\section{B Aspectos particulares}

Todo aspecto que pueda influir sobre la calidad del estudio deberá mencionarse en la propuesta. Por ejemplo: 1) dado que en algunos países latinoamericanos es difícil realizar trabajo de campo durante la época de lluvias, se advertirá que no deben llevarse a cabo estudios durante ese periodo; 2) deberá indicarse si se tiene o no acceso a medios informáticos; 3 ) deberá indicarse si es necesario un permiso oficial para llevar a cabo el estudio (éste en ocasiones puede tomar mucho tiempo).

\section{QUE HACER: Limitaciones del estudio}

1 Se debe ser honesto al establecer las limitaciones del estudio y los aspectos específicos que puedan influir sobre la calidad de los datos y resultados del estudio.

2 Explicar las limitaciones y suposiciones del estudio. 


\section{Recursos e infraestructura}

\section{A Recursos}

Generalmente las personas que revisan las propuestas de investigación, desean saber sobre los recursos e infraestructura que se encuentran disponibles para realizar el estudio. Se debe precisar, por ejemplo, si se cuenta con encuestadores y codificadores experimentados, computadoras, fuentes de financiamiento adicionales; ¿cuánto tiempo dedicará el investigador principal a la realización del estudio $(100 \%, 50 \%, 10 \%$ de su tiempo)? Estos y otros aspectos relativos a recursos e infraestructura deben señalarse en la propuesta de investigación.

\section{B Presupuesto}

El presupuesto debe elaborarse en forma realista. En general, las agencias que financian los proyectos de investigación no proporcionan fondos para la adquisición de equipo costoso, ni para la construcción de locales o compra de vehículos. Por lo que respecta al salario del investigador principal, no debe exceder del que haya percibido en otros trabajos. Todas las partidas del presupuesto que sean costosas o poco comunes deben justificarse. Los costos de cada partida deben definirse con precisión en función de los diferentes componentes. Por ejemplo, los sueldos asignados a los encuestadores pueden presentarse de la siguiente manera:

\section{Encuestadores ( 20 a 500 por día x 20 días)}

El presupuesto se puede presentar por categorías de costos (ver Figura 14.1). Si el estudio está programado por más de un año, presentar los costos separados para cada año. También, para los estudios de larga duración, se puede prever una línea presupuestaria que tome en cuenta la inflación.

\section{QUE HACER: Recursos e infraestructura}

1 Describir los recursos e infraestructura disponibles para el estudio, indicando en particular:

a La existencia de fuentes adicionales de financiamiento.

b La disponibilidad de computadoras, encuestadores y codificadores capacitados, apoyo secretarial, vehículos, espacio de oficinas y otros.

2 El presupuesto del estudio deberá presentarse según los siguientes grandes rubros de gastos:

a Salarios y prestaciones. 
b Material, suministros, servicios de procesamiento de datos.

c Viajes.

d Diversos.

3 Todo rubro presupuestal relativamente alto o poco común deberá justificarse.

FIGURA 14.1

Ejemplo de un presupuesto de estudio.

$\begin{array}{lc}\text { Moneda } & \text { Dólares } \\ \text { Local } & \$\end{array}$

\section{A Salarios y prestaciones}

1 Investigador principal,

P 2000/mes x 12 meses

24000

1200

2 Investigador asociado,

P $1700 \times 12$ meses

20400

1020

3 Encuestadores,

20 a $\mathrm{P} 100$ por día $\times 20$ días

$40000 \quad 2000$

4 Codificadores,

20 días-persona a P 150/día

$3000 \quad 150$

5 Servicios secretariales (sin cargo)

Subtotal:

87400

4370

B Materiales, provisiones, servicios de cómputo

1 Impresión del cuestionario

2 Materiales administrativos

$7600 \quad 380$

3 Captura y verificación de datos

$4000 \quad 200$

4 Programación de computadora

$5000 \quad 250$

5 Tiempo de computadora

15000

750

6 Impresión del informe y envío por correo (200 copias)

Subtotal:

$\frac{25000}{\mathbf{5 9 6 0 0}} \quad \frac{1250}{\mathbf{2 9 8 0}}$

\section{Viajes}

1 Prueba del cuestionario

2 Transportación local para encuestadores (P 2000 por día)

Subtotal:

$10000 \quad 500$

D Seminario de Difusión del Proyecto

$\frac{40000}{50000} \quad \frac{2000}{2500}$

E Gastos diversos

$10000 \quad 500$

Total de costos directos:

2000

100

209000

10450

Total de costos del Proyecto:

209000

10450

Tasa de cambio: Pesos $20.00=$ U.S. $\$ 1.00$ 


\section{Apéndices}

Cualquier información complementaria que pueda ser de utilidad, deberá figurar en los apéndices de la propuesta de investigación. Esta información puede incluir el curriculum vitae del investigador principal, un ejemplar del cuestionario, si está listo, y el Formulario de Consentimiento Informado. Asimismo, pueden incluirse los documentos de la institución que llevará a cabo la investigación (folletos informativos, informe anual de actividades y otros). Finalmente, deberán mencionarse las fuentes de las referencias bibliográficas que se citen en la propuesta de investigación. 


\section{Portada y abstracto}

Aunque ambos aparecen en la primera sección de la propuesta de investigación, la portada y el abstracto son los últimos en escribirse. La portada (Figura 16.1) presenta la información esencial de la propuesta. El abstracto (Figura 16.2) debe resumir la información básica contenida en todas las demás secciones, no debe llenarse con datos innecesarios y será lo más breve y preciso posible (una o dos páginas). El abstracto debe dar información sobre los siguientes puntos:

1 El problema a estudiar.

2 Los objetivos principales del estudio.

3 Las implicaciones principales que se esperan.

4 Quién - el investigador principal.

5 Cuándo - la fecha de iniciación y terminación del estudio.

6 Dónde - el lugar del estudio.

7 La metodología de la investigación.

8 Los recursos que se requieren.

\section{QUE HACER: Portada y abstracto}

1 Resumir en una o dos frases lo esencial de cada sección de la propuesta.

2 Redactar un abstracto a partir de estos resúmenes.

3 Preparar una portada para la propuesta de investigación. 
FIGURA 16.1

Ejemplo de Portada.

Propuesta de Investigación Operativa en Planificación Familiar

1 Título: Estudio experimental de investigación operativa para incrementar el nivel de aceptación de planificación familiar por medio de usuarios satisfechos.

2 Lugar:

Oaxaca, Oax., México.

3 Institución

Instituto de Desarrollo Rural, Social y

Patrocinadora:

Económico (IDRSE).

4 Investigador

Dra. Guadalupe López, Directora, IDRSE

Principal:

Oaxaca, Oax., México.

5 Fechade

Iniciación:

Febrero, 1991.

6 Fecha de

Terminación:

Julio, 1994.

7 Costo Total: US $\$ 10,450$.

Firma

Fecha 
FIGURA 16.2

Ejemplo de un abstracto.

En México, las tasas de prevalencia de uso de (Problema) anticonceptivos varían mucho de una población a otra. Aún cuando, en teoría, todas las regiones reciben el mismo nivel de prestación de servicios de salud y planificación familar, las tasas entre mujeres casadas varían entre el 6 y el $80 \%$.

Los objetivos (Objetivos) inmediatos del estudio consisten en analizar los factores económicos, sociales y sanitarios asociados con las variaciones regionales de las tasas de prevalencia de uso de anticonceptivos. Otro objetivo, de más largo alcance, consiste en proporcionar a los responsables del programa los elementos que expliquen las razones por las cuales el programa nacional de planificación familiar tiene éxito en unas áreas y en otras no.

(Implicaciones) Esta información puede ser usada para desarrollar estrategias educacionales y modificar los enfoques en materia de prestación de servicios, a fin de lograr tasas de prácticas anticonceptivas uniformemente más altas en todas las áreas del país.

(Quién) El estudio será auspiciado por el Instituto de Investigación Demográfica de México, (Cuándo) de enero a diciembre de 1991. Todas las poblaciones comprendidas (Dónde) en estos dos distritos serán clasificadas en función de sus tasas de prevalencia de uso de anticonceptivos.

(Metodología) Posteriormente, se procederá a seleccionar aleatoriamente a 25 poblaciones de los estratos formados según niveles de prevalencia alta, media y baja. En cada una de las poblaciones se interrogará a todas las mujeres casadas entre $15 \mathrm{y}$ 44 años de edad. También se recolectará información sobre aspectos económicos, sociales y sanitarios de las poblaciones.

(Recursos) Se formará un equipo de encuestadores y supervisores para que se hagan cargo de las actividades de campo. La codificación, verificación y procesamiento de datos se harán en la computadora de la Universidad Autónoma de Oaxaca. Se prevé concluir el informe final de investigación para diciembre de 1991. El presupuesto estimado para el pago de salarios de personal, viáticos, elaboración de cuestionarios, tiempo de computación y un seminario de difusión asciende a US\$10,450. 


\section{Bibliografía}

Andrews, Frank M., Laura Klem, Terrence N. Davidson, Patrick M. O'Malley, and Willard L. Rodgers. A Guide for Selecting Statistical Techniques for Analyzing Social Science Data. Ann Arbor: Institute for Social Research, 1974.

Andrews, Frank M., James N. Morgan, John A. Sonquist, and Laura Klem. Multiple Classification Analysis (2nd ed.). Ann Arbor: Institute for Social Research, 1975.

Barclay, George Watson. Techniques of Population Analysis. New York: Wiley, 1958.

Berelson, Bernard. Content Analysis in Communication Research. New York: Hafner, 1971.

Blalock, Hubert M., Jr. An Introduction to Social Research. Englewood Cliffs, New Jersey: Prentice-Hall General Sociology Series, 1970.

Blalock, Hubert M., Jr. Causal Models in the Social Sciences. Chicago: Aldine-Atherton, 1971.

Blalock, Hubert M., Jr. Social Statistics (2nd ed.). New York: McGraw-Hill, 1972.

Blalock, Hubert M., Jr., and Ann B. Blalock. Methodology in Social Research, New York: McGraw-Hill, 1968.

Bogue, Donald J. Cost-Effectiveness Analysis of Family Planning Programs. Manual \# 11. Chicago: Community and Family Study Center, 1973.

Bourke, G. J., and J. McGiluray. Interpretation and Uses of Medical Statistics. Oxford and Edinburgh: Blackwell Scientific Publications, 1969.

Campbell, Donald T., and Julian C. Stanley. Experimental and Quasi-Experimental Designs for Research. Chicago: Rand McNally, 1963.

Caro, Francis G. (ed.). Readings in Evaluation Research. New York: Russell Sage Foundation, 1971.

Chandrasekaran, C., and Albert I. Hermalin (eds.). Measuring the Effect of Family Planning Programs on Fertility. Dolhain: Ordina Editions, 1976.

Cochran, W. G., and G. M. Cox. Experimental Designs (2nd ed.). New York: Wiley, 1957.

Cook, Thomas D., and Donald T. Campbell. Quasi-Experimentation: Design and Analysis Issues for Field Settings. Chicago: Rand McNally College \& Publishing Co., 1979.

Cuca, Roberto, and Catherine S. Pierce. Experiments in Family Planning: Lessons from the Developing World. Baltimore: The Johns Hopkins University Press for the World Bank, 1977.

Davis, James A. Elementary Survey Analysis. Englewood Cliffs, New Jersey: Prentice-Hall, 1971.

Dixon, Wilfred J., and Frank J. Mossey, Jr. Introduction to Statistical Analysis (3rd ed.). New York: McGraw-Hill, 1969.

Dunn, Olive Jean. Basic Statistics: A Primer for the Biomedical Sciences. New York: Wiley, 1964.

Fink, Allene, and Jacqueline Kosecoff. An Evaluation Primer. Beverly Hills: Sage Publications, 1978. 
Fitz-Gibbon, Carol Taylor, and Lynn Lyons Morris. How to Calculate Statistics. Beverly Hills: Sage Publications, 1978.

Fitz-Gibbon, Carol Taylor, and Lynn Lyons Morris. How to Design a Program Evaluation, Beverly Hills: Sage Publications, 1978.

Freund, John E. Modern Elementary Statistics (2nd ed.). Englewood Cliffs, New Jersey: Prentice-Hall, 1960.

Green, Lawrence W. Marshall W. Kreuter, Sigrid G. Deeds, and Kay B. Partridge. Health Education Planning: A Diagnostic Approach. Palo Alto: Mayfield Publishing Co., 1980.

Grundy, F., and W. A. Reinke. Health Practice Research and Formalized Managerial Methods. Geneva: World Health Organization,1973.

Guilford, J. P. Psychometric Methods. New York: McGraw-Hill, 1954.

Guttentag, Marcia, and Elmer L. Struening (eds.). Handbook of Evaluation Research (Vols. I and II) Beverly Hills: Sage Publications, 1975.

Hansen, Morris H., William N. Hurwitz, and William G. Madow. Sample Survey Methods and Theory. New York: John Wiley \& Sons, 1953.

Haupt, Arthur, and Thomas T. Kane. Population Handbook. Washington, D.C.: The Population Reference Bureau, 1980.

Henerson, Marlene E., Lymn Lyons Morris, and Carol Taylor Fitz-Gibbon. How to Measure Attitudes. Beverly Hills: Sage Publications, 1978.

Hermalin, Albert I., and Barbara Entwisle (eds.). The Role of Surveys in the Analysis of Family Planning Programs. Liege: Ordina Editions, 1980.

Hilton, Elizabeth T., and Arthur A. Lumsdaine. Field Trial Designs in Gauging the Impact of Fertility Planning Programs. In Carl A. Bennett and Arthur A. Lumsdaine (eds.). Evaluation and Experiment: Some Critical Issues in Assessing Social Programs.

New York: Academic Press, 1975.

Hyman, Herbert. Survey Design and Analysis. Glencoe: The Free Press, 1955.

Katz, F. M., and R. Snow. Assessing Health Workers' Performance: A Manual for Training and Supervision. Geneva: World Health Organization, 1980.

Katzer, Jeffrey, Kenneth H. Cook, and Wayne W. Crouch. Evaluating Information: A Guide for Users of Social Science Research. Reading, Massachusetts: Addison-Wesley Publishing Company, 1978.

Kerlinger, Fred N. Foundations of Behavioral Research. New York: Holt, Rinehart and Winston, 1964.

Kish, Leslie. Survey Sampling. New York: Wiley, 1965.

Knox, E. G. (ed.) Epidemiology in Health Care Planning: A Guide to the Uses of a Scientific Method. Oxford: Oxford University Press, 1979.

Laing, John. Demographic Evaluation of Family Planning Programs. Canberra: The Australian National University, 1982.

Lewis-Beck, Michael S.: Applied Regression: An Introduction. Beverly Hills: Sage Publications, 1980.

Lilienfeld, Abraham, and David E. Lilienfeld. Foundations of Epidemiology. New York: Oxford University Press, 1980. 
Miller, Delbert C. Handbook of Research Design and Social Measurement. New York: Longman, 1964.

Morris, Lynn Lyons, and Carol Taylor Fitz-Gibbon. Evaluator's Handbook. Beverly Hills: Sage Publications, 1978.

Morris, Lynn Lyons, and Carol Taylor Fitz-Gibbon. How to Present an Evaluation Report . Beverly Hills: Sage Publications, 1978.

Morton, Richard F., and J. Richard Hebel. A study Guide to Epidemiology and Biostatistics. Baltimore: University Park Press, 1979.

Nie, Norman H., C. Hadlai Hull, Jean G. Jenkins, Karen Steinbrenner, and Dale H. Bent. SPSS: Statistical Package for the Social Sciences (2nd ed.). New York: McGraw-Hill, 1975.

Payne, Stanley L. The Art of Asking Questions. Princeton, New Jersey: Princeton University Press, 1951.

Polansky, Norman A. (ed.). Social Work Research. Chicago: University of Chicago Press, 1970.

Popham, W. James. Educational Evaluation. Englewood Cliffs, New Jersey: Prentice-Hall, 1975.

Population Council. A Manual for Surveys of Fertility and Family Planning: Knowledge, Attitudes, and Practice. New York: The Population Council, 1970.

Pressat, Roland. Demographic Analysis. Chicago: Aldine Atherton, 1972.

Reynolds, Jack. A Framework for the Selection of Family Planning Program Evaluation Topics. Manual \# 1 (rev. ed.). New York: International Institute for the Study of Human Reproduction, 1973.

Reynolds, Jack. Operational Evaluation of Family Planning Program Through Process Analysis. Manual \# 4 (rev. ed.). New York: International Institute for the Stuy of Human Reproduction, 1973.

Roberto, Eduardo L. Strategic Decision-Making in a Social Program: The Case of Family Planning Diffusion. Lexington, Mass.: Lexington Books, 1975.

Robinson, Warren C. Cost Benefit and Cost-Effectiveness Analysis in Family Planning Programs. In Financial Management of Population/Family Planning Programs. Kuala Lumpur: Inter-Governmental Coordinating Committee, 1976, pp. 82-91.

Rosenberg, Morris. The Logic of Survey Analysis. New York: Basic Books, 1968.

Rossi, Peter H., and Howard E. Freeman. Evaluation: A Systematic Approach. Beverly Hills: Sage Publications, 1982.

Rossi, Peter H., and W. Williams. Evaluating Social Programs: Theory, Practice and Politics. New York: Seminar Press, 1972.

Rutman, Leonard. Planning Useful Evaluations: Evaluability Assessment. Beverly Hills: Sage Publications, 1980.

Rutman, Leonard (ed.). Evaluation Research Methods: A Basic Guide. Beverly Hills: Sage Publications, 1977.

Selltiz, Claire, Marie Jahoda, Morton Deutsch, and Stuart W. Cook. Research Methods in Social Relations (rev.1-volume ed.). New York: Holt, Rinehart and Winston, 1959.

Shryock, Henry S., and Jacob S. Siegel and Associates. The Methods and Materials of Demography. New York: Academic Press, 1976. 
Siegel, Sidney. Nonparametric Statistics for the Behavioral Sciences. New York: McGraw-Hill, 1956.

Simon, Julian L. Basic Research Methods in Social Science. New York: Random House, 1969.

Sinquefield, Jeanne E. Single and Multiple Decrement Life Table Procedures for Analysis of the Use-Effectiveness of Contraception. Manual 8. Chicago: Community and Family Study Center, 1973.

Snedecor, George W., and William G. Cochran. Statistical Methods. Ames: Iowa State University Press, 1972.

Studies in Family Planning. Special Issue: Focus Group Research. Vol. 12, no. 12, Part 1.

Suchman, Edward A. Evaluative Research: Principles and Practices in Public Services and Social Action Programs. New York: Russell Sage Foundation, 1967.

Sudman, Seymour. Applied Sampling. New York: Academic Press, 1976.

Summers, Gene F. (ed.). Attitude Measurement. Chicago: Rand McNally \& Co., 1970.

Tanur, Judith M. (ed.). Statistics: A Guide to the Unknown. San Francisco: Holden-Day, 1972.

Taylor, Howard C., Jr., and Robert J. Lapham. General Guidelines for an MCH-Based Family Planning Project. New York: The Population Council, 1974.

Torgerson, Warren S. Theory and Methods of Scaling. New York: Wiley, 1958.

United Nations. The Methodology of Measuring the Impact of Family Planning

Programmes on Fertility. Manual IX. New York: United Nations, 1979.

United Nations. Statistical Office. A Short Manual on Sampling. Studies in Methods, Series F. No. 9. New York: United Nations, 1960.

Warwick, Donald P., and Charles A. Lininger. The Sample Survey: Theory and Practice. New York: McGraw-Hill, 1975.

Webb, Eugene J., Donald T. Campbell, Richard D. Schwartz, and Lee Sechrest. Unobtrusive Measures: Non Respective Research in the Social Sciences. Chicago: Rand McNally, 1966.

Weiss, Carol H. (ed.). Evaluating Action Programs: Readings in Social Action and Education. Boston: Allyn and Bacon, 1972.

Weiss, Carol H. Evaluation Research: Methods for Assessing Program Effectiveness. Englewood Cliffs, New Jersey: Prentice-Hall, 1972.

Wishik, Samuel M., and Kwan-Hwa Chen. Couple Years of Protection. Manual 7. New York: International Institute for the Study of Human Reproduction, 1973.

World Fertility Survey. Basic Documentation Series. Nos. 1-10, Core Questionnaire and related manuals and documentation. The Hague-Voorburg: International Statistical Institute, 1975-1977.

World Health Organization. Statistical Indices of Family Health. Geneva: World Health Organization, Technical Report Series, No. 587, 1976.

World Health Organization. Health Programme Evaluation. Geneva:World Health Organization, 1981. 




